\title{
Taxes, Informality and Income Shifting: Evidence from a Recent Pakistani Tax Reform*
}

\author{
Mazhar Waseem ${ }^{\dagger}$
}

November 2013

\begin{abstract}
This paper analyzes the effects of personal income taxation on earnings, formality and business organization choices of agents. I use a tax reform introduced in Pakistan in 2009, which increased taxation of partnership firms substantially relative to other unincorporated firms, as a natural policy experiment to identify behavioral responses to taxation that include movement into informality, under-reporting taxable earnings, and income shifting to tax-favored business forms. Relying on administrative tax records that comprise the universe of income tax returns filed in 2006-11, I find that the tax rate rise caused the exit of a large number of treated firms: the number of such firms reporting positive taxable earnings declined by $41 \%$ in 2009, by another $27 \%$ in 2010, and by an additional $15 \%$ in 2011 . By tracking personal income tax returns of owners of the exited firms, I find that around $45 \%$ of the owners moved into informality, the rest switched their business organization. For the treated firms that did not exit, I document almost $50 \%$ reduction in reported earnings compared to untreated firms. Combining these estimates of behavioral responses with a simple conceptual framework, I compute that $133 \%$ of the projected increase in tax revenue was lost through the behavioral responses, implying that the new tax rate on partnership earnings was on the wrong side of the Laffer curve and would not have been optimal under any social preferences. The excess burden created by the reform increases by nearly $17 \%$ if negative spillovers on VAT base are also taken into account.
\end{abstract}

Keywords: Efficiency, Income Tax, VAT, Organizational form, Informality

JEL-Classification: H21, H240, H250, H320, O17

*I thank Michael Best, Robin Burgess, Michael Devereux, Anders Jensen, Henrik Kleven, Camille Landais, Matthew Skellern, Johannes Spinnewijn and seminar participants for helpful comments and suggestions. Financial support from the International Growth Centre (IGC), Pakistan Programme is gratefully acknowledged.

${ }^{\dagger}$ STICERD and Department of Economics, London School of Economics (m.waseem@lse.ac.uk) 


\section{Introduction}

The presence of large informal sector - estimated on average to be around one-third of the official economy $^{1}$ - constrains taxation capacity of developing countries in two important ways. First, there is a direct effect as taxation is limited to a narrow set of formal taxpayers. Second and more subtle is the indirect effect: the governments tend to keep tax rates low owing to the fear that increased taxation might unravel the formal sector. ${ }^{2}$ Though there is a large body of literature that estimates the sensitivity of tax base to marginal tax rates in rich countries, ${ }^{3}$ the corresponding evidence for developing countries is extremely limited. In fact, there is no micro-based study that considers the effects of taxation on informality choices of agents, which arguably is a more important margin of response to taxation in a limited tax capacity setting. This paper fills the gap by presenting evidence on the responsiveness of earnings, formality and business organization choices of agents to personal income taxation in Pakistan.

To consider these effects, I use an income tax reform introduced in Pakistan in $2009^{4}$ (hereafter "the reform"), which creates a large tax rate variation between very similar taxpayers, as a natural policy experiment. Before the reform, unincorporated businesses (sole proprietorships and partnerships), which constitute more than $50 \%$ of the personal income tax filers in Pakistan, were treated symmetrically for the purposes of taxation. Their earnings were taxed through a graduated tax schedule comprising 14 brackets with tax rates varying progressively from $0 \%$ to $25 \%$. The reform replaced this scheme with two different tax systems for partnership and sole proprietorship firms. For partnerships, a flat-tax scheme, carrying a tax rate of $25 \%$ with no exemption threshold, was introduced. For sole proprietorships, the graduated tax scheme was continued, but the number of brackets was reduced (from 14 to 6 ) and the bracket thresholds were moved such that a majority of sole proprietors experienced tax reduction. The purpose of the reform was to promote incorporation of partnership firms by bringing their taxation on a par with small corporate firms. ${ }^{5}$ Unintentionally, however, it created a large tax rate variation across very similar firms in the unincorporated sector, especially at the bottom of the income distributions where some of the partnership firms experienced a greater than 50-fold increase in tax rates. This compelling variation has been used in this paper to estimate behavioral responses to taxation including movement into informality, under-reporting taxable earnings, and income shifting to other business forms.

The reform was announced on 06-06-2010 and officially took effect from 01-07-2010. It was, however, retroactively applied to partnership earnings from 01-07-2009. By the time the tax changes were announced, most of the real earning activity corresponding to tax year 2009 had already taken

\footnotetext{
${ }^{1}$ See Fuest \& Riedel (2009) for a recent survey of literature on tax evasion and avoidance in developing countries.

${ }^{2}$ For example, starting income tax rate in Pakistan, India and Bangladesh was $7.5 \%, 10 \%$ and $10 \%$ respectively in 2011, which is low compared to similar rate in developed countries.

${ }^{3}$ See Saez et al. (2012) for a recent survey.

${ }^{4}$ Pakistani tax year runs from July 1 to June 30; year $t$ in this paper refers to the tax year from July $t$ to June $t+1$.

${ }^{5}$ Pakistan's tax administration, the Federal Board of Revenue (FBR), explained the motivation for the reform in the following words: "In order to strengthen the drive for documentation, a uniform tax rate for small companies as well as AOPs is proposed @ 25\% of their taxable income"(FBR 2010).
} 
place. This implies that any systematic differences in filing or reported earnings in 2009 across the firms affected and not affected by the reform could only be because of tax evasion. Detecting tax evasion and understanding its relationship to tax rates has traditionally been difficult because those engaging in it tend to keep such behavior concealed. In general, theoretical predictions on the effect of tax rates on evasion are highly sensitive to modeling assumptions (Slemrod \& Yitzhaki 2002), and the sign and magnitude of the effect are open empirical questions. A unique advantage of the context, however, is that it allows clean identification of tax evasion enabling qualitative and quantitative determination of its sensitivity to marginal tax rates.

For the empirical analysis, I use administrative data from the Federal Board of Revenue (FBR) comprising the population of income tax returns filed in 2006-11 and a rich set of firm characteristics reported at the time of registration and updated from time to time. My main results are the following. The tax rate rise on partnership earnings led to the exit or break up of a multitude of partnership firms: the number of such firms reporting positive taxable earnings decreased by $41 \%$ in 2009 , by another $27 \%$ in 2010, and by an additional $15 \%$ in 2011 . Thus, within three years of the reform the number of tax paying partnerships in Pakistan declined to $36 \%$ of the pre-reform level. The firms that did not exit reported lower earnings. Compared to sole proprietorships, which did not experience tax rate changes in 2009 (control group), reported earnings of partnership firms decreased by more than 50\% (intensive margin elasticity of about 2.4). Because of the reasons mentioned earlier, this response mostly identifies tax evasion demonstrating that every percentagepoint decrease in the net-of-tax rate resulted in a $2.4 \%$ increase in under-reporting of taxable earnings.

Partnership and sole proprietorship business forms are close substitutes. Therefore, a natural response to expect is that following the increase in taxation of partnership income individual owners of the treated firms shift their earnings to tax-favored sole-proprietorship base. Exploiting the longitudinal nature of the data, I track owners of the partnership firms that exit and find that $55 \%$ of such individuals report positive sole proprietorship earnings after the reform. This indicates that following the tax changes nearly half of the owners of partnership firms switched their business organization to sole proprietorships, the rest disappeared into informality. ${ }^{6}$ For the partnership firms that do not exit and respond only along the intensive margin, I separately estimate the responses of different components of taxable earnings reported by their owners and find that around $10 \%$ of the reduced earnings of such firms are caused by income shifting by their owners to sole proprietorship base.

The purpose of the reform, however, was to cause income shifting of another kind. It was hoped that eliminating preferential tax treatment of partnership firms would lead to the expansion of corporate sector in Pakistan either through the incorporation of partnership firms or the growth of

\footnotetext{
${ }^{6}$ Throughout this paper I treat all extensive response to the reform as exit into informality, whereas some proportion of the response could be because of a real loss of work. In developing economies, however, boundaries between real non-participation and informal participation are quite blurred. In the absence of state-provided social security, outof-work individuals fall back on private - family or community based - social networks for consumption. In return, the individuals may be required to work in domestic production. In such settings, any distinction between real and informality choices would largely be artificial.
} 
existing corporations at the expense of other business forms. To see if the policy had the intended effect, I examine the entry and reported earnings of corporate firms in Pakistan in 2006-11. I find that though the registration of new partnership firms declined by almost $50 \%$ in the post-reform periods, there was no discernible increase in the entry of corporate firms. Furthermore, there was no significant change in the taxable income reported by corporate firms in the post-reform years. This indicates that income shifting to corporate tax base did not take place as intended and that the reform did not meet its objectives, at least in the short-run.

I combine the estimates of behavioral responses presented above with a simple conceptual framework to compute the excess burden created by the tax rise. I find that almost $133 \%$ of the projected increase in tax revenue was lost through the behavioral responses, implying that the new flat tax rate of $25 \%$ imposed on partnership earnings was clearly on the wrong side of the Laffer curve and would not have been optimal under any social preferences. Around $25 \%$ of the treated firms were also registered to remit VAT on their sales. ${ }^{7}$ Reform-driven changes in their behavior would also reduce government revenue from the VAT base as well. ${ }^{8}$ The excess burden created by the reform increases by nearly $17 \%$ if these negative spillover effects are also taken into account.

This paper contributes to three different strands of literature. First, it adds to a large number of studies that estimate the elasticity of tax base with respect to marginal tax rates using administrative tax return data (see Saez et al. 2012 for a recent survey). Most of the existing work in this literature, however, is based on the OECD countries and concerns itself mainly with the estimation of taxable income responsiveness at the top of the income distribution. Kleven \& Waseem (2013) was the first study that extended the literature to a developing country setting, but their methodology was not suited to uncover extensive margin responses. This paper, therefore, represents the first effort at comprehensively analyzing all tax-driven responses in a developing country context.

Second, a vast literature estimates tax evasion and investigates its determinants (see Andreoni et al. 1998 and Slemrod \& Yitzhaki 2002 for surveys). Historically, the literature has used macroeconomic indicators such as money supply and aggregate electricity demand to estimate the extent of under-reporting in the economy (see Slemrod 2007, Fuest \& Riedel 2009 and Slemrod \& Weber 2012 for surveys). Methodological limitations with this approach, however, imply that the precision and usefulness of these estimates are limited. Recently, a few studies (Marion \& Muehlegger 2008; Kleven et al. 2011; Best et al. 2013) have exploited experimental or quasi-experimental variation to uncover tax evasion and examine its causes. This paper adds to this literature by presenting a well-identified measure of tax evasion and by estimating its responsiveness to the tax rates.

Finally, this paper is related to a sizable literature that examines the influence of taxes on business organization choice of agents. The literature finds that tax distortions can lead agents either to change business organization or to shift earnings to a lower-taxed form (see Gordon \& Slemrod 2000; Kleven \& Waseem 2013 for evidence on income shifting and Gordon \& MacKieMason 1994, 1997; Goolsbee 1998, 2004; Egger et al. 2009; De Mooij \& Nicodème 2008; Liu 2012;

\footnotetext{
${ }^{7}$ Manufacturing and retail firms with annual sales up to Rs. 5 million are not required to register for VAT.

${ }^{8}$ For example, firms that report lower earnings will remit lower VAT owing to the reduction in the taxable base; firms that exit the formal sector will be lost to VAT entirely.
} 
Edmark \& Gordon 2013 on the sensitivity of business organization choice to tax rates). I contribute to this literature by presenting evidence on income shifting within the unincorporated sector and by investigating the effects of taxation on incorporation choice of firms.

The rest of this paper is organized as follows. Section 2 develops conceptual framework, section 3 provides an overview of the context and data, section 4 presents evidence on behavioral responses generated by the reform, section 5 explores heterogeneity in response, section 6 computes excess burden created by the tax change and, and section 7 concludes.

\section{Conceptual Framework}

The focus of this paper is the tax behavior of unincorporated firms - sole proprietorships and partnerships. These are worker-owned firms with no separate legal existence of their own. ${ }^{9}$ The profits of these firms are their owners' earnings and are taxed through the personal income tax system. This implies that the standard utility maximization framework underlying the new tax responsiveness literature (see Saez et al. 2012 for a recent survey of this literature) can be applied to investigate the responses induced by the reform. In this section, I propose two extensions to the standard model to make it compatible with the Pakistani setting.

The standard model considers an individual's utility maximization problem broadly as a choice between consumption $c$ and multiple dimensions of labor supply captured by taxable income $z$. These dimensions may include hours, effort, training, career choices and tax evasion. Individuals are assumed to maximize utility $u(c, z)$ subject to a budget constraint $c=z-T(z)=(1-\tau) \cdot z+E$, where $T($.$) is tax liability, \tau \equiv T^{\prime}($.$) is marginal tax rate, and E \equiv \tau . z-T(z)$ is the virtual income generated by the tax system $T($.$) . Such maximization produces a taxable income supply function$ $z=z(1-\tau, E)$, where optimal $z$ depends on net-of-tax rate $1-\tau$ and virtual income $E$. Assuming weak separability between consumption $c$ and activities underlying $z$, Feldstein (1999) showed that the responsiveness of taxable income to net-of-tax rate, the elasticity of taxable income (ETI) $\varepsilon \equiv \frac{1-\tau}{z} \cdot \frac{\partial z}{\partial(1-\tau)}$, is a sufficient statistic summarizing the deadweight loss arising from all margins of response including tax evasion. ${ }^{10}$

The first extension to the standard model assumes that taxable income $z$ could be of two types: the income earned as a sole proprietor $z^{s}$ and the income earned as a partner in a partnership firm $z^{p}$. Utility now takes the form $u\left(c, z^{s}, z^{p}\right)$ with budget constraint $c=z^{s}+z^{p}-T\left(z^{s}, z^{p}\right)$, where $T\left(z^{s}, z^{p}\right)$ is a non-linear income tax system through which $z^{s}$ and $z^{p}$ are taxed, $\tau^{j} \equiv \frac{\partial T}{\partial z^{j}}$ is marginal tax rate on income of type $j$, and $E \equiv \sum_{j \in\{s, p\}} \tau^{j} . z^{j}-T\left(z^{s}, z^{p}\right)$ is the generalized virtual income. Utility maximization now generates two distinct income supply functions $z^{j}=$ $z^{j}\left(1-\tau^{s}, 1-\tau^{p}, E\right) ; j \in\{s, p\}$, where the optimal choice of income $z^{j}$ depends on the two netof-tax prices and virtual income. To keep the empirical specification simple, however, I ignore the

\footnotetext{
${ }^{9}$ Pakistani law does not allow creating limited liability partnerships. Accordingly, the partnership firms I study here have no legal personality and the owners are liable for all obligations of the firm.

${ }^{10}$ This, however, is subject to the caveat pointed out by Chetty (2009) that with tax evasion ETI is a sufficient statistic only if the costs of evasion are pure resource costs rather than transfers to other agents in the economy (for example fines imposed on evaders).
} 
income effects so that the optimal earnings choices are a function of the two prices only. ${ }^{11}$ This extension allows the use of empirical specification to separately estimate two distinct responses to changes in $\tau^{p}$ : the own-price effect captured by the taxable income elasticity $\varepsilon^{p} \equiv \frac{1-\tau^{p}}{z^{p}} \cdot \frac{\partial z^{p}}{\partial\left(1-\tau^{p}\right)}$ and the cross-price effect captured by the income shifting elasticity $\varepsilon^{s} \equiv \frac{1-\tau^{p}}{z^{s}} \cdot \frac{\partial z^{s}}{\partial\left(1-\tau^{p}\right)}$.

In addition to the two earnings responses, discrete changes in tax liability created by the tax reform may give rise to extensive margin responses. Increased tax burden could push agents on the margin of participation either to drop out of labor force or to move into informal sector. To consider such behavior, I incorporate a discrete participation choice into the model. Utility maximization now takes place over two stages. In the first stage, agents make optimal earning choices conditional on participation and in the second stage they decide whether to participate or not. The participation in the formal sector, however, entails fixed utility gains $q$ arising, for example, from warm glow or the productivity gains from the ability to use financial sector or better production technologies. An agent participates only if the utility from participation $u\left(z^{s}+z^{p}-T\left(z^{s}, z^{p}\right), z^{s}, z^{p}\right)+q$ exceeds the utility from non-participation assumed to be $u_{0}$, that is iff $q \geq u_{0}-u\left(z^{s}+z^{p}-T\left(z^{s}, z^{p}\right), z^{s}, z^{p}\right) \equiv \bar{q}$. Given a smooth distribution of $q$ in the population represented by distribution function $F(q)$ a fraction $\theta\left(\tau^{s}, \tau^{p}\right) \equiv 1-F(\bar{q})$ of all agents participate. Therefore, any movement into and out of the formal sector triggered by changes in $\tau^{p}$ can be captured by the participation elasticity $\eta^{p} \equiv \frac{\left(1-t^{P}\right)}{\theta\left(\tau^{s}, \tau^{p}\right)} \cdot \frac{\partial \theta\left(\tau^{s}, \tau^{p}\right)}{\partial\left(1-t^{P}\right)}$, where $t^{P}$ denotes average tax rate on participation.

To see the implications of a tax change in this setting, consider a small tax reform that raises marginal tax rate on partnership earnings by $d \tau^{p}$. Summing individual earnings supply functions $z^{p}\left(1-\tau^{s}, 1-\tau^{p}\right)$ and $z^{s}\left(1-\tau^{s}, 1-\tau^{p}\right)$, I obtain aggregate earnings $Z^{p}\left(1-\tau^{s}, 1-\tau^{p}\right)$ and $Z^{s}(1-$ $\left.\tau^{s}, 1-\tau^{p}\right)$ such that government revenue $R$ is given by $\tau^{p} . Z^{p}\left(1-\tau^{s}, 1-\tau^{p}\right)+\tau^{s} . Z^{s}\left(1-\tau^{s}, 1-\tau^{p}\right)$. Here, I consider linear taxation only because it is closer to the Pakistani context. The small change $d \tau^{p}$ produces the following change in government revenue

$$
d R=Z^{p} d \tau^{p}+\tau^{p} d Z^{p}+\tau^{s} d Z^{s}
$$

The first term in (1) reflects the projected increase in government revenue in the absence of any behavioral response - the mechanical effect $(d M)$ of the tax change. The other two terms capture the change in tax revenue caused by the own-price substitution effect and the cross-price income shifting effect respectively - the behavioral effect $(d B)$ generated by the tax change. Defining $e^{p} \equiv \frac{1-\tau^{p}}{Z^{p}} \cdot \frac{\partial Z^{p}}{\partial\left(1-\tau^{p}\right)}$ and $e^{s} \equiv \frac{1-\tau^{p}}{Z^{s}} \cdot \frac{\partial Z^{s}}{\partial\left(1-\tau^{p}\right)}$ as the aggregate taxable income and income shifting elasticities with respect to the net-of-tax rate on partnership earnings, ${ }^{12}$ the behavioral effect can be rewritten as

\footnotetext{
${ }^{11}$ Most of the existing evidence in the ETI literature suggests that the income effects produced by tax rate changes are not significant. Gruber \& Saez (2002) estimate these effects in the context of personal income taxation in the US and find them to be small and insignificant. Kleven \& Schultz (2013) analyze the behavioral responses of Danish income taxpayers over a period of 25 years and find statistically insignificant income effects for the self-employed. Bastani \& Selin (2012) use Monte Carlo simulations to show that even income effects produced by large tax rate changes are insignificant.

${ }^{12}$ For a linear tax system with no demogrant and homogeneous elasticities, the aggregate elasticity equals the sum of the intensive and extensive margin elasticities defined above $e^{p}=\varepsilon^{p}+\eta^{p}$.
} 


$$
\begin{aligned}
d B & =-\frac{\tau^{p}}{1-\tau^{p}}\left[e^{p}+\psi e^{s}\right] Z^{p} d \tau^{p} \\
& =-\frac{\tau^{p}}{1-\tau^{p}}\left[e^{p}+\psi e^{s}\right] d M,
\end{aligned}
$$

where $\psi \equiv \frac{\tau^{s} Z^{s}}{\tau^{p} Z^{p}}$ stands for the fraction of government revenue from sole-proprietorships compared to that from partnerships. Because $Z^{s}$ and $Z^{p}$ reflect optimal choices of agents, the envelope theorem implies that the behavioral effect creates no first-order welfare loss and can be ignored. Consequently, the change in welfare caused by the tax rise equals $d M$ and $-d B$, the additional welfare loss over and above the tax revenue collected $d R$, represents the marginal excess burden of taxation. Thus, for every rupee collected the reform imposes an extra cost of

$$
-\frac{d B}{d R}=\frac{\tau^{p}\left(e^{p}+\psi e^{s}\right)}{1-\tau^{p}-\tau^{p}\left(e^{p}+\psi e^{s}\right)}
$$

on the treated taxpayers.

We get two key insights from formula (2). First, the elasticity of taxable income is not a sufficient statistic in this setting and we need to estimate three parameters $\left(e^{p}, e^{s}\right.$ and $\left.\psi\right)$ to compute the marginal deadweight loss created by the tax rise. Second, if $e^{p}$ and $e^{s}$ are of opposite signs (which is expected), income shifting mitigates the loss of tax revenue from the behavioral effect. The extent of compensation, however, depends on the magnitude of the parameter $\psi \equiv \frac{\tau^{s} Z^{s}}{\tau^{p} Z^{p}}$. Intuitively, the smaller is the revenue from sole-proprietorship base as a fraction of that from partnership base, the less effect income shifting - as captured by $e^{s}$ - has in offsetting the lost revenue. Because $\psi$ is fairly close to zero in the Pakistani setting $\left(\tau^{s} \ll \tau^{p}\right.$ and $Z^{s} \ll Z^{p}$ for the treated taxpayers), (2) implies that even a large amount of income shifting would not reduce the efficiency cost of the reform significantly.

In the above framework, individuals differ in terms of their skills to produce income of each type and the utility gains from operating in the formal sector $q$ they draw from the distribution $F(q)$. This heterogeneity will be reflected in the earnings and participation choices made by them. Partnerships are formed mainly to exploit production complementarities, to overcome credit market constraints, or to reduce agency costs of monitoring employees. The individuals choosing $z^{p}>0$ will, therefore, search for and match with the entrepreneurs with whom they could exploit such gains. In this way, the individual choices of $z^{p}$ will be mapped at the aggregate level in the number of and the taxable earnings reported by partnership firms. ${ }^{13}$ The behavioral responses to the change in partnership income taxation, therefore, can be studied by examining the firm or individual-level outcomes. Accordingly, in empirical section of the paper I estimate the responses both at the firm and individual level.

\footnotetext{
${ }^{13}$ Note that I deliberately abstract from describing a fully specified model of partnership formation in the economy. My purpose here is to focus only on the features that highlight the fundamental econometric issues in the empirical application.
} 


\section{Institutional Background and Data}

As noted earlier, partnerships and sole proprietorship firms constitute more than $50 \%$ of all personal income tax filers in Pakistan. This section describes the taxation regime of these firms and the administrative tax data I use for the empirical analysis.

\subsection{The Tax Reform}

Figure I plots the tax schedules applicable to these firms in 2006-11. The pre-reform schedule, common to both types of firms, is illustrated by the solid blue curve in the figure. It consists of 14 tax brackets with fixed average tax rate, varying from $0 \%$ at the bottom to $25 \%$ at the top, applied to each bracket. In 2009, the schedule was replaced with two different tax systems. The dashed red curve in the figure depicts the flat-tax scheme, comprising a tax rate of $25 \%$ and no exemption threshold, introduced for partnership firms with retroactive effect from the beginning of 2009. The short-dashed gray curve in the figure shows the new tax system for sole proprietorship firms, which became operative from the beginning of 2010. It reduced the number of brackets from 14 to 6 and raised bracket cutoffs, while ensuring that the new average tax rates were never greater than the ones in the old regime. The movement of the bracket cutoffs, however, meant that sole proprietorships in certain areas of the income distribution experienced tax reduction. The most salient of such reductions was at the bottom of the income distribution where the exemption threshold was increased from Rs. $100,000^{14}$ to Rs. 300,000 in 2010 and further to Rs. 350,000 in 2011. Overall, these changes led to a huge tax rate differential between the two group of firms, especially at the lower levels of income.

For at least two reasons, the reform generates almost ideal conditions for studying the effects of taxation on earnings, business organization and compliance choices of agents. First, it creates compelling quasi-experimental variation between very similar taxpayers. Both set of firms have identical initial earnings and tax rates but experience drastically different tax changes. The prereform earnings trends are parallel for the two groups and diverge sharply for the treatment group exactly at the time of the reform. In addition, the tax changes introduced by the reform are large, particularly at the bottom of the earnings distribution where some partnership firms (earnings $\leq$ Rs. 110,000) experience a greater than 50-fold increase in tax rates. Large and salient tax rate changes are useful in eliciting responses as past work has shown that optimization frictions prevent taxpayers from reacting to small tax changes (Chetty et al. 2009; Chetty 2012; Chetty et al. 2011). Second, the assignment to higher tax rates is based on business form and is not correlated with reported earnings. This implies that the identification will not be confounded by the issues such as mean reversion created specifically by the income based control groups (see Saez et al. 2012; Saez 2004; Slemrod 1998; Kopczuk 2012 for a detailed exposition of the identification issues in the new tax responsiveness literature).

\footnotetext{
${ }^{14} \mathrm{PKR}$-USD exchange rate is about 105 as of October 2013.
} 


\subsection{Partnership Tax Penalty}

Partnership firms, in most of the tax jurisdictions, are treated as pass-through entities. Under this arrangement, the firm does not pay tax on its income. Instead, the owners pay tax on their distributive share in the firm's profits with their personal income tax returns. In Pakistan, however, partnership earnings are taxed at the firm level. This implies that the tax code is not neutral between the two forms of earnings studied in this paper, and reporting a certain sum as partnership income, even for the common pre-reform tax schedule, attracts a higher or lower tax liability compared to if the sum were reported as sole proprietorship earnings. ${ }^{15}$ To see this, consider a partnership firm $j$ with taxable income $Z_{j}$ and $N_{j}$ number of partners such that $Z_{j}=\sum_{i=1}^{N_{j}} z_{i}^{p}$, where $z_{i}^{p}$ is partner $i$ 's distributive share in the firm's profits. This firm, for a tax system $T(z)$, incurs a tax liability of $t\left(Z_{j}\right) \cdot Z_{j}$, where $t(z) \equiv \frac{T(z)}{z}$ denotes the average tax rate applicable to earnings level $z$. The partners, however, face no further taxation on partnership income, which they report in their personal income tax returns. In case they have earnings from other sources, their additional tax liability is calculated through the averaging method. For aggregate taxable income $z_{i}=z_{i}^{p}+z_{i}^{s}$ partner $i$ pays an additional liability of $t\left(z_{i}\right) \cdot\left(z_{i}-z_{i}^{p}\right)$, where $t\left(z_{i}\right)$ is average tax rate applicable to $z_{i}$. Thus, a sum $x$ attracts a tax liability of $t\left(Z_{j}\right) \cdot x$ if reported as earnings from firm $j$ and $t\left(z_{i}\right) \cdot x$ if reported as sole proprietorship income. For a non-linear tax system $t\left(Z_{j}\right)$ and $t\left(z_{i}\right)$ are generally not equal, and partner $i$ experience a partnership tax penalty of $x .\left[t\left(Z_{j}\right)-t\left(z_{i}\right)\right]$, which for a progressive tax schedule may even be negative if $z_{i}>Z_{j}$.

To explore the importance and dynamics of the penalty, I plot in Figure II the year-wise histograms of the penalty weighted by taxable income $\left(z_{i}^{p}\left[t\left(Z_{j}\right)-t\left(z_{i}\right)\right] / z_{i}\right) .{ }^{16}$ Table I reports in column (2) the year-wise mean values of the level of the penalty $\left(z_{i}^{p}\left[t\left(Z_{j}\right)-t\left(z_{i}\right)\right]\right)$ in PKRs and in column (3) the year-wise mean values of the penalty weighted by taxable income. Together, the evidence illustrates the following two points. First, prior to the reform a vast majority of taxpayers reporting $z_{i}^{p}>0$ experience partnership tax penalty (about 91\%) rather than subsidy. After the reform, tax rate on partnership income is never lower than the tax rate on sole proprietorship income, and as a consequence everyone with positive partnership earnings experiences higher taxation. Second, though there is considerable variance, the partnership tax penalty is quite large and increases substantially after the reform. Average penalty is about 4 percentage points before the reform and increases by more than three times to 15 percentage points after the reform. Furthermore, in the post-reform period the penalty is as high as 25 percentage points for a large number of taxpayer (42\%). This happens because the reform increases tax rate on partnership income to a flat $25 \%$ but makes sole proprietorship income up to 300,000 (350,000 in 2011) exempt from tax.

Partnerships are much more common in developing countries as compared to developed countries

\footnotetext{
${ }^{15}$ This is conceptually similar to the joint taxation of married couples in the US, which, given the progressive income taxation, gives rise to the "marriage penalty" or "marriage subsidy". See, for example, Eissa \& Hoynes (2000) for details.

${ }^{16}$ While setting up the expression of partnership tax penalty, I ignored the possibility that individuals could be partners in more than one firm. In my empirical application, about $6 \%$ of the individuals reporting $z_{i}^{p}>0$ are partners in multiple firms. I drop these individuals from the sample for Figure II and Table I, because I observe only $z_{i}^{p}$ and not its breakdown by firms.
} 
where they are restricted mostly to human capital intensive industries like accounting and law. Production complementarities, imperfect capital markets and agency problems arising from costly monitoring of employees are believed to be the main reasons for this ubiquity. The distribution and size of the partnership tax penalty reflects the importance of these factors in the Pakistani setting. More importantly, however, the evidence also shows that incentives to misreport partnership income as sole proprietorship income exist and are strong even before the reform. The reform only enhances these incentives. This implies that the partnerships we observe prior to the reform comprise the individuals for whom the productivity gains from making the co-labor arrangement formal are large enough to overcome the tax disincentives. The substantial increase in the size of the penalty may lead to break up of such firms. This may be a real change in business form or a mere misreporting of the income source. The prevalence and size of the penalty, however, show that in either case the owners of such firms will suffer significant welfare loss.

\subsection{Data}

For this study, I use two administrative datasets from the FBR in Pakistan. To investigate behavioral responses to the reform, I use tax return data comprising the universe of income tax returns filed by corporations, unincorporated firms, self-employed individuals and wage earners in 20062011. The dataset has more than 5 million year-observations and contains variables corresponding to line items reported on the tax return form. To study the major policy and firm observables that influence tax compliance, I use registration data that includes a host of individual and firm characteristics reported at the time of registration and updated from time to time. Since July 2009, electronic return filing is mandatory for all partnership firms and for sole proprietorship firms only if they are registered for VAT or need to claim tax refund. ${ }^{17}$ More than $57 \%$ of the partnership returns and around $12 \%$ of the sole proprietorship returns used in this study have been filed electronically. The rest of the returns were filed at designated bank branches and were fed into the computers by an IT firm distinct from the FBR. Throughout the period covered by this study, the FBR has been using the data for the automated processing and payment of VAT and income tax refunds, which has ensured that the data is updated and is free of errors.

\section{Behavioral Responses to the Reform}

In this section, I present empirical evidence on the behavioral responses and fiscal externalities generated by the tax rate changes.

\subsection{Effects of the Reform on Partnership Firms}

The reform made changes to the taxation regime of both sole proprietorship and partnership firms. In my empirical analysis, however, I focus only on partnerships and the individuals who own these

\footnotetext{
${ }^{17}$ Because tax returns for year $t$ are filed in year $t+1$, this provision is applicable to all returns for the years $2008-2011$.
} 
firms. It is because $(i)$ they experience the larger and broader of the tax variation and $(i i)$ very effective control groups are available for these taxpayers.

\subsubsection{Overall Response}

This section presents graphical evidence on the changes in the number of and the taxable income reported by partnership firms. Later on, the response is decomposed to investigate intensive and extensive margin behavior separately. Figure III plots the yearly taxable income distributions of partnership firms in 2006-11. ${ }^{18}$ Panel A, which contains the pre-reform distributions only, shows that the number of partnership firms filing for tax was growing before the reform: the number grew by $9 \%$ in 2007 and by a further $28 \%$ in 2008 . Two other features of the distributions are salient: there is strong bunching of firms at the notches ${ }^{19}$ in the pre-reform tax schedule and the yearly distributions are remarkably similar to each other - though the number of firms increases from year to year, the addition only expands the distribution vertically without any discernible change in shape. Together, the features demonstrate that earnings and reporting choices are strongly shaped and influenced by tax incentives and that for a given tax system they remain stable.

To see the effects of the tax rate increase, I contrast the post-reform distributions with the 2008 distribution. Panel $\mathrm{B}$ of the figure makes such a comparison and illustrates the enormous response generated by the tax rate changes. In contrast to the increasing pre-reform trend, the number of tax paying partnerships started decreasing sharply after the reform: the number decreased by $41 \%$ in 2009 , by another $27 \%$ in 2010 and by a further $15 \%$ in 2011 . Thus, within three years of the reform the number of partnership firms reporting positive taxable earnings declined to $36 \%$ of the pre-reform level. In addition to the large extensive response, the distributions also feature the evidence of depressed reported earnings: the post-reform densities are higher at the lower levels of income (earnings $\in(0$ 100,000]) capturing a clear leftwards shift of the earnings distribution.

The responses depicted in Panel B of the figure are concentrated in the earnings range where the firms experience the largest tax increases. This suggests that the responses are driven by the tax changes. Before drawing causal inference, however, we need to rule out other non-tax contemporaneous influences by examining the behavior of similar firms not affected by the tax changes. As noted earlier, the reform creates a very natural control group - sole proprietorships firms for which the tax system did not change in 2009. The earnings of sole-proprietorships, however, are reported by their owners in their personal income tax returns. Some of these individuals are also partners in partnership firms and consequently face an incentive to shift earnings to tax-favored soleproprietorships in the post-reform periods. To ensure that no one in the control group is affected by the tax changes, I include only those individuals in the group who drive their earnings exclusively from sole proprietorship firms in all the years considered in this study. Such individuals constitute

\footnotetext{
${ }^{18}$ Throughout the empirical analysis, I focus only on taxpayers with earnings $\in(0650,000]$, which constitute more than $90 \%$ of the sample. I do not consider taxpayers in the rest of the income distribution because they experience the least of the tax variation and the density of tax filers there is too thin to estimate responses credibly.

${ }^{19}$ Notches refer to the points in the tax schedule where tax liability changes discontinuously. See Kleven \& Waseem (2013) for the analysis of behavioral responses to these notches in the income tax schedule of Pakistan.
} 
a majority (more than 90\%) of the self-employed in the sample.

Figure IV shows the yearly taxable income distribution of the control group in 2006-11. The comparison of the pre-reform densities (Panels A of Figure IV) with those of the treated firms (Panel A of Figure III) illustrates the similarity of the treatment and control groups. Both group of firms bunch at the notches in the pre-reform tax system in an identical manner indicating their comparable behavioral responses to tax incentives. Also, the pre-reform distributions of the control group, like their counterparts for the treatment group, exhibit little change from year to year demonstrating the stability of filing and earnings trends for a given tax system. The examination of the post-reform densities of the control group (Panel B of Figure IV) reveals that the reporting behavior of this group of firms did not change in 2009: both the number of tax filers and taxable income evolved strictly in accordance with the 2006-08 trend. Predictably, however, the 2010-11 distributions of the control group are different from the ones in the pre-reform years, as they feature strong response to the tax rate changes that become applicable to this set of firms from 2010 . The evidence, hence, confirms that the changes in the behavior of partnership firms depicted in Figure III are caused by the tax changes enacted by the reform.

\subsubsection{Intensive Margin}

The leftwards shift of the earnings distribution (Panel B of Figure III) provides strong evidence that the treated firms reported lower earnings after the tax rate increase. In this section, I use the differences-in-differences (DD) methodology to estimate the elasticity underlying the response. The control group for the analysis, as defined in the previous section, comprises the individuals who drive their earnings exclusively from sole proprietorship firms in all the years (2006-11). Since the group itself experiences tax changes in 2010, I restrict the period of estimation to 2006-09. The intensive-margin is defined to include the responses of firms that do not exit the formal sector but may report lower earnings after the reform. Due to retroactive applicability of the tax rate increase, the response identified here comprises under-reporting of taxable earnings ${ }^{20}$ so that the elasticity estimates reflect the responsiveness of tax evasion to marginal tax rates.

In the new tax responsiveness literature, the DD research design has been implemented using both repeated cross-section and panel approaches. While repeated cross-section method is considered more robust to mean reversion, panel approach is argued to be the right method if the composition of sample changes over time (see Saez et al. 2012; Saez 2004; Kopczuk 2012 for a detailed discussion on identification with these approaches). As mean reversion is not likely to be a problem in the current context, ${ }^{21}$ and the composition of sample does change owing to the large-

\footnotetext{
${ }^{20}$ As noted earlier, the tax increase on partnership firms was given retroactive effect. The reform was announced on 06-06-2010 but was made applicable to partnership earnings from 01-07-2009. By the time the reform was announced, most of the real earning activity corresponding to the tax year 2009 had already taken place. This implies that the reduction in reported earnings identified here could only be a consequence of tax evasion rather than any other margin of behavior. Some of the reduced earnings are also a result of misreporting partnership earnings as sole proprietorship earnings. Such income shifting, however, is also in the nature of tax evasion as no real change of business form is involved.

${ }^{21}$ Generally, the taxpayers with above-mean (below-mean) income one year are expected to have lower (higher) earnings next year owing to the fluctuations of transitory component of earnings from year to year. This seriously
} 
scale extensive response, applying DD to a panel of firms is the most appropriate specification for identifying intensive margin response in the current setting. Accordingly, I estimate the following baseline model

$$
\Delta \ln \left(z_{i t}\right)=\varepsilon \cdot \Delta \ln \left(1-\tau_{i t}\right)+\alpha_{0} \cdot 1(i \in \text { Partnership })+\alpha_{1} \cdot 1(t \in \text { After })+\nu_{i t},
$$

where $z_{i t}$ is taxable income reported by firm $i$ in period $t$, Partnership is an indicator for partnership firm, After is a dummy for the post-reform period and $\ln \left(1-\tau_{i t}\right)$ is instrumented by the interaction term $1(i \in$ Partnership $) .1(t \in$ After $) .{ }^{22}$ The DD estimate of $\varepsilon$ in (3) consistently identifies the elasticity if it can be shown that the parallel trends assumption holds - in the absence of tax changes, reported earnings would have evolved identically in both the treatment and control groups.

To see if the assumption is satisfied and also to provide non-parametric evidence on underreporting, Figure V plots the earnings growth path of the two group of firms. To explore heterogeneity in response across the earnings distribution, I present the plots in three income ranges $(0$ 250K], (0 450K] and $(0650 \mathrm{~K}]$ for both balanced and unbalanced panel samples. ${ }^{23}$ The evidence in Panels A-F of the figure clearly demonstrates that the identifying assumption is satisfied for all the samples considered. The earnings trends are parallel prior to the reform but separate sharply at the time of the reform. In addition, the plots also depict the sharp decline of reported earnings in the treatment group ranging from 0.48 to 0.83 log points across different samples with the low-income samples experiencing the highest fall.

Table II reports the elasticities estimated from the DD regressions. Column (1) of the table shows the income group, columns (2)-(4) the estimates from unbalanced panel regressions, and columns (5)-(7) the estimates from balanced panel samples. Consistent with the graphical evidence (Figures III and V), the results reflect substantial behavioral response to the reform: the elasticities for all the samples are large with point estimates ranging between 2.3 and 2.9. Two other features of the results in Table II are important: the elasticities decline gradually when higher income firms are added to the sample and the balanced panel estimates are slightly larger in comparison to the unbalanced panel estimates. The declining responsiveness along the income distributions captures the widely discussed correlation in literature between the size and tax compliance of firms (see, for example, Kleven et al. 2009; Gordon \& Li 2009; Kopczuk \& Slemrod 2006). Because high-income firms are also the larger firms, they have lesser ability to manipulate their earnings and consequently respond less to the tax rate changes. There are two potential explanations on why balanced panel estimates are larger than the unbalanced estimates. First, the firms in the balance panel regressions

obfuscates behavioral responses to taxation, especially if variation in tax rates between high and low income taxpayers is used as a source of identification. In the present context, however, there is no reason to expect that transitory income fluctuations are correlated with the business organization of taxpayers and, therefore, vary systematically across the treatment and control groups.

${ }^{22}$ Since for a non-linear tax system $\tau_{i t}$ changes endogenously with $z_{i t}$, we need to instrument $\tau_{i t}$ to ensure the consistency of the estimated parameters.

${ }^{23}$ The balanced panel sample consists of the firms that file in all the four years (2006-09) and report taxable income in the range indicated in each panel's heading. The unbalanced panel sample, on the other hand, contains for year $t$ the firms that file in both year $t$ and $t+1$ and report taxable earnings in the range indicated in the figure. 
are different from the population in the sense that they have been filing tax returns regularly for at least three years prior to the reform and in the process may have acquired greater awareness of tax laws or the ability to manipulate the system. Their larger responses echo a similar result in Kleven \& Waseem (2013), who find that regular tax filers are more likely to bunch at tax notches and are less likely to make strictly dominated choices, signaling their superior tax literacy. Second, the unbalanced panel estimates are smaller because they are affected by the change in the composition of the sample in 2009. Lower elasticity estimates from these regressions show that the firms that exit in 2009 on average had lower earnings growth prior to the reform. Nevertheless, the fact that the balanced and unbalanced panel estimates are quite close to each other shows that these effects are not of primary importance. Furthermore, over time all firms are expected to attain a good degree of tax awareness, the balanced panel estimates, therefore, reflect the long-term responsiveness in the population and, accordingly, are the preferred estimates.

Another salient feature of the results is that the elasticities presented in Table II are large compared to similar elasticities reported in the past literature, especially Kleven \& Waseem (2013) who find a maximum friction-adjusted elasticity of 1.021 for the self-employed in Pakistan. This, however, should not be surprising, for it is widely known in literature that the ETI is not a structural parameter depending solely on the underlying preferences and technology. It, rather, is a function of tax system and, therefore, may vary from reform to reform. ${ }^{24}$ Specifically, large tax reforms, being salient and costly to ignore, induce larger responses (Chetty 2012; Chetty et al. 2011, 2009). Similarly, reforms targeted to narrow tax bases, by creating opportunities of income shifting, produce stronger responses. The tax rate changes instituted by the reform are both large and not very broadbased. Hence, they generate stronger behavioral responses.

Because the control group itself experienced tax rate changes in 2010, the above analysis was restricted to 2006-09. To explore medium-term response to the reform, which is of more interest for policy-making, Figure A1 in the appendix plots the earning growth path of partnership firms in 2006-11. The two panels of the figure are constructed analogously to Panels E and F of Figure V and show that though reported earnings growth is on average lower in all the post-reform years, the major decline occurs only in 2009. It illustrates that the intensive margin response to the tax rate rise was immediate and permanent so that the medium-term responsiveness is nearly equal to the short-term responsiveness estimated above - if we relate the changes in reported earnings between 2008 and 2011 to the changes in marginal tax rates between the same pair of years, it will yield elasticities comparable to those estimated above.

\subsubsection{Extensive Margin}

The graphical evidence presented in section 4.1.1 demonstrates that the reform triggered the exit of a large number of partnership firms. In this section, I use a three-step strategy, illustrated in panels A-L of Figure VI, to identify the elasticity governing the response.

\footnotetext{
${ }^{24}$ In fact, Slemrod \& Kopczuk (2002) have argued that the policy makers can optimally choose the ETI by appropriately designing the tax base. For example, broadly defined tax bases create less opportunities for income shifting and hence will give rise to lower elasticity.
} 
The first step in the strategy is to estimate the number of partnership firms that would have reported positive taxable income in the post-reform periods had there been no tax change (the counterfactual). Panel A of the figure compares the evolution of tax filing in the treatment and control groups, and shows that the filing in the control group was on a weakly-declining linear trend prior to the reform and continued to evolve on the trend after the reform. In contrast, the filing in the treatment group was increasing before the reform, but started declining sharply after the reform. The comparison of the two series suggests that one approach to estimate the counterfactual could be to use the conventional difference-in-difference specification augmented with separate linear time trends for the treatment and control groups to account for the non-parallel pre-reform trends. Given, however, that data on filing is available only for three pre-reform years, it is difficult to justify the linear time trend convincingly. A more conservative alternative to estimate the counterfactual is to assume that the number of partnership firms in the post-reform years would have stayed at the pre-reform level if there were no tax change. The evidence that this approach provides a lower bound on the response is presented in Panels B-D of the figure.

The Pakistani tax code contains provisions that mandate registered taxpayers to file tax returns even when there is no real earning activity or taxable income from the activity falls below the exemption threshold. This implies that every year a number of taxpayers with zero earnings file tax returns (nil filers). In Panel B of the figure, I plot two filing series for the treatment group: the dark blue curve illustrates the firms that report taxable earnings $\in$ (0 650k] (positive filers), while the light blue curve depicts the firms with earnings $\in[0650 \mathrm{k}]$ (aggregate filers). The comparison of the two series shows that the aggregate filing in the treatment group stops increasing in 2009 and becomes almost flat at the pre-reform level. Panel C, which plots the corresponding two series for the control group, demonstrates that both types of filing in the control group evolve smoothly on the pre-reform trend. Panel D, which depicts month-wise registration of partnership firms, illustrates that the entry of new partnerships falls by almost $50 \%$ at the time of the reform. ${ }^{25}$ Together, the evidence confirms that in the absence of the tax reform the number of partnership firms reporting positive earnings would have stayed at least at the pre-reform level. This can be seen as follows. Both filing series in Panel B are affected by the reform: that the positive filers series is depressed is obvious; the aggregate filing series, however, is also depressed because it carries the effects of reduced entry and non-filing response (some of the firms following the tax reform stop filing returns altogether $\left.{ }^{26}\right)$. In the absence of these two responses, the series would have been at a much higher level in the post-reform periods, especially because the entry response is demonstrably quite large. The fact that even this series stays nearly at the pre-reform level supports the assertion that tax paying partnership firms would not have decreased if there were no tax change.

Panels $\mathrm{E}$ and $\mathrm{F}$ show the counterfactual filing series from the two alternative approaches. The

\footnotetext{
${ }^{25}$ Note that I cannot compare the entry of partnerships with that of sole-proprietorships, because the latter firms are not registered separately from their owners. In Panel A of Figure X, however, I compare the entry of partnerships with that of corporate firms to show that the entry of latter firms has no structural break at the time of the reform.

${ }^{26}$ The enforcement of mandatory filing provisions is far from perfect - only about 1 million of the 3.5 million registered taxpayers file returns. The data shows that some of the firms that should have filed after the reform do not file suggesting non-filing to be as important a margin of extensive response as nil-filing.
} 
counterfactual in Panel E is obtained by running a difference-in-difference regression on the two series in Panel A with separate linear time trend for the treatment and control groups. The counterfactual in Panel $\mathrm{F}$ is the lower bound as discussed above. The comparison of the observed and counterfactual series demonstrates that by 2011 the reform had caused the exit of at least $64 \%$ of the partnership firms in the economy. This corresponds roughly to an extensive margin elasticity of 3 , as these firms experience an average change in net-of-participation-tax rate of around $21 \%$. The overall elasticity, however, masks considerable heterogeneity because the graphical evidence (Figure III) illustrates that the response is not uniform throughout the earnings distribution.

To explore such heterogeneity, the second step in the strategy is to estimate the counterfactual distribution of partnership firms in the post-reform periods. For the lower bound exercise, the 2008 distribution is the counterfactual distribution for all the post-reform periods. To estimate counterfactual distributions for the linear trend approach, I use one important feature of the prereform distributions noted earlier: for an unchanged tax system, the distribution changes very little from year to year. Increase in the number of taxpayers only expands the distribution vertically without any discernible shift sideways. Accordingly, I find counterfactual distributions for the linear trend approach by shifting the 2008 distribution upwards proportionally to have the same mass as predicted by the DD counterfactual. These counterfactual distributions for the post-reform years are shown in Panels G, I and $\mathrm{K}$ of the figure.

The observed and counterfactual distributions, however, are still not comparable, as the observed distributions feature large intensive margin responses. Because the earnings distribution shifts leftwards in 2009, the comparison of the post-reform empirical distributions with the counterfactual distributions may lead to the underestimation of response at lower levels of income and overestimation at higher levels. To make the two distributions comparable, the final step in the strategy is to strip the observed distributions of intensive responses. Using the earning responses estimated in section 4.1.2, I impute to the firms observed in the post-reform periods the earnings they would have reported had they not responded on the intensive margin. Panels $\mathrm{H}, \mathrm{J}$ and $\mathrm{L}$ of the figure show these distributions along with the counterfactual distributions. The counterfactual distributions illustrate the number of firms that would have reported positive earnings had there been no tax-driven response at all; the observed distributions stripped of intensive response show the number of such firms had there been no response at the intensive margin. By comparing the two, extensive margin response can be estimated throughout the income distribution.

These estimates are presented in Table III. Column (1) of the table shows the income group, column (2) the number of firms in the observed distribution stripped of intensive response, column (3) the number of firms in the counterfactual distribution, and column (4) the extensive margin elasticities. The estimates in columns (2)-(4) relate to 2009; columns (5)-(10) contain the corresponding estimates for 2010 and 2011. The results in Panels A and B are based on the two alternative approaches to estimate the counterfactual. Overall, the estimates reflect the significant heterogeneity in extensive margin behavior across income groups and over time depicted in Figure VI: the elasticities decrease with earnings and increase over time. The dynamics of the response 
is also heterogeneous across income groups: low-income firms respond almost immediately, while high-income firms respond only over a longer horizon.

The decreasing responsiveness along the income distribution reflects heterogeneous returns from formality. Low-income firms have little productivity gains from operating in the formal sector and are always on the margins of participation and non-participation. The reform was a big shock for such firms, and caused the exit of a large majority of them. Increasing response over time reflects, on the one hand, the fact that the tax differential between partnership and sole proprietorship earnings grows over time. On the other hand, long-term responses are also larger because adjusting to a tax change takes time. The individuals affected by the reform need to find alternative occupations or business forms and may wait for periods with low adjustment costs to make such a change. This influence is particularly evident from the fact that high-income firms $(z>400 \mathrm{k})$, which do not experience the increasing tax differential over time, respond over a longer horizon only (their short-term responses are not significant).

\subsection{Effects of the Reform on Partners}

The conceptual framework (section 2) indicates that the firm-level outcomes mirror the choices made at the individual level. A partnership firm's intensive or extensive margin response reflect the decisions of its owners to under-report activity, shift earnings to other sources, or to leave the formal sector. By investigating these individual-level outcomes, the firm-level response can be decomposed into its underlying components. In this section, I investigate these responses.

\subsubsection{Overall Response}

Figure VII plots the density distributions of various components of earnings reported by owners of partnership firms. Panels A and B of the figure show the before and after densities of partnership income $\left(z^{p}\right)$ reported by these individuals. Expectedly, the distributions are qualitatively and quantitatively similar to the corresponding distributions of partnership firms and display comparable effects produced by the tax rise. Panels $\mathrm{C}$ and $\mathrm{D}$ of the figure, which illustrate the density distributions of sole proprietorship income $\left(z^{s}\right)$, provide the clear evidence of income shifting from partnership to tax-favored sole-proprietorship base. After a very stable pre-reform trend, the number of partnership owners reporting positive sole proprietorship earnings started increasing sharply and the distributions shift rightwards after the reform demonstrating income shifting along the intensive margin. To see the extent to which such income shifting compensates the loss of partnership earnings, in Panels $\mathrm{E}$ and $\mathrm{F}$ of the figure, I plot the densities of aggregate taxable income $z=z^{p}+z^{s}$ reported by these individuals. The two plots suggest that less than $50 \%$ of the fall in partnership earnings could be explained by such income shifting. In the next two sections, I decompose the overall response depicted in Figure VII into its constituent intensive and extensive margin components to get the precise decomposition of the firm-level response. 


\subsubsection{Intensive Margin}

Figure VIII depicts intensive margin response of owners of the treated firms. Panels A-C illustrate respectively the evolution of partnership income $\left(z^{p}\right)$, sole proprietorship income $\left(z^{s}\right)$, and aggregate taxable income $\left(z=z^{p}+z^{s}\right)$ reported by individuals in their personal income tax returns. Consistent with the earlier analysis, the intensive-margin is defined to include the taxpayers that do not exit the formal sector but may report lower earnings after the reform. The treatment group for the analysis consists of the individuals who report $z^{p}>0$ in each of the three pre-reform periods (200608), and the control group comprises the individuals who report $z^{p}=0$ in all the years. Since the control group itself experiences tax changes in 2010, the period of estimation is restricted to 2006-09. Here, I focus on a balanced panel of taxpayers only because income shifting response can cleanly be identified by tracking the same individuals over time. The three panels of the figure also report the corresponding elasticities from the following regressions

$$
\Delta \ln \left(z_{i t}^{k}\right)=\varepsilon^{k} . \Delta \ln \left(1-\tau_{i t}^{p}\right)+\alpha_{0} \cdot 1(i \in \text { Partner })+\alpha_{1} \cdot 1(t \in \text { After })+\nu_{i t},
$$

where $z_{i t}^{k}$ is the income of type $k$ reported by individual $i$ in period $t, \varepsilon^{k}$ is the elasticity of income type $k$ with respect to $1-\tau^{p}$, Partner is an indicator for treatment, After is a dummy for the post-reform year, and as earlier $\ln \left(1-\tau_{i t}^{p}\right)$ is instrumented by the interaction term $1(i \in$ Partner $) .1(t \in$ After $)$.

Partnership earnings elasticity (point estimate 0.91), ${ }^{27}$ shown in Panel A of the figure, though quite large is less than half of the corresponding firm-level elasticity (nearly 2.4). The individuallevel elasticity is smaller because of the following reason. As partnership earnings in Pakistan are taxed at the firm-level, it is conceivable that some of the owners - especially those who drive their earnings solely from partnerships - may not file their personal tax returns. Although the tax code requires all registered taxpayers to file personal tax returns, filing for such individuals is only a formality as no tax is payable with the return. If this happens, partnership earnings reported at the individual level would not correspond to those reported at the firm level. Indeed, the data shows that prior to the reform only around $60 \%$ of the aggregate partnership profits were reported at the individual level; the ratio increases to $82 \%$ after the reform. Since a much larger proportion of partnership earnings was not reported at the individual level before the reform, the elasticity identified from the owners' personal income tax returns would underestimate the response.

Panel $\mathrm{B}$ of the figure explores income shifting ${ }^{28}$ and illustrates that relative to the control group the sole proprietorship earnings reported by the treated individuals grow significantly in 2009 (cross-price elasticity of -0.58). But this income shifting has little influence in compensating the under-reporting of partnership earnings, as aggregate taxable income response (Panel C) is nearly the same as partnership earnings response (Panel A): aggregate elasticity, which is a weighted sum

\footnotetext{
${ }^{27}$ The pre-reform earnings trends are not completely parallel for partnership earnings. To control for this, the DD specification to estimate this elasticity also includes separate linear time trends for the treatment and control groups.

${ }^{28}$ Only a few of the treated individuals (less than 20) shift earnings to wage or capital income. I drop these individuals from the analysis in this section to focus only on income shifting between $z^{p}$ and $z^{s}$, which is the predominant margin of response.
} 
of the two constituent elasticities, ${ }^{29}$ is nearly $95 \%$ of the partnership earnings elasticity. The analysis shows that only a small proportion of the under-reporting of partnership earnings (results in Table II) was achieved through income shifting. Also, as the tax rates at which the shifted earnings are taxed are only a fraction of the one on partnership earnings (25\%), such income shifting has even less impact in offsetting the revenue leakage from the erosion of partnership tax base. In section 6 of the paper, I use formula (2) to estimate the exact excess burden imposed by the tax rise.

\subsubsection{Extensive Margin}

As seen in section 4.1.3, the reform caused the exit of a large number of partnership firms. When a partnership firm leaves, its owners leave as well or change business organization. In this section, I decompose the firm-level extensive response into its two underlying components - the informality response and the change in business organization (switching) response. The informality response is defined to include the treated taxpayers who stop filing tax returns (non-filers) or file but report zero earnings after the reform (nil-filers). The switching response, on the other hand, comprises the treated taxpayers who report zero partnership earnings but positive aggregate taxable earnings after the reform. ${ }^{30}$ To identify switching, it is important that a constant set of taxpayers is observed over time to see how the composition of reported income responds to the tax rate changes. This suggests the use of a balanced panel of individuals who file in all the years in the sample (2006-11). With balanced panel, however, the informality response cannot cover non-filers. Given, however, that the decomposition of the firm-level extensive response is the main aim of this section, I use the balanced panel analysis with the tradeoff that the informality response identified here comprises nil-filing margin only.

Panels A and B of Figure IX show the difference-in-difference setup to estimate the informality response. The definitions of the treatment and control groups are the same as in the last section (4.2.2). Panel A illustrates the log number of filers in the treatment and control groups who report positive taxable earnings in 2006-11. For the control group, the series evolves smoothly and shows no signs of break at the time of reform. For the treatment group, however, the number of such taxpayers drops significantly at the time of reform. In Panel B of the figure, I plot the filing series for the treatment group along with a counterfactual obtained from running the difference-in-difference regression on the two series in Panel A. To account for the fact that filing in the control group is also affected by the tax rate changes that become applicable in 2010, I estimate the DD for the period 2006-09 only and extrapolate the counterfactual to 2010-11. The counterfactual estimates the number of treated taxpayers who would have reported positive taxable earnings had there been no tax change. The comparison of the observed and the counterfactual series demonstrates that by 2011 the reform had driven around $28 \%$ of the treated taxpayers into informality. As the treated

\footnotetext{
${ }^{29}$ In a simplified framework with linear taxation and homogeneous responsiveness, the weights depend on the composition of aggregate taxable earnings. $d Z=d Z^{p}+d Z^{s} \Longrightarrow e=(1-\gamma) e^{p}+\gamma e^{s}$; where $\gamma=\frac{Z^{s}}{Z} \approx 0.25$ in the Pakistani setting.

${ }^{30}$ In this section, I consider switching to sole proprietorship business form only. The next section explores switching to corporate business form.
} 
individuals experience a net-of-participation-tax rate change of roughly $20 \%$, this corresponds to an elasticity larger than one on account of nil-filing margin only.

To explore switching, I repeat the above steps but regard the treated taxpayers who report zero partnership earnings but positive aggregate earnings in the post-reform periods (the switchers) as nil-filers. Panels $\mathrm{C}$ and D of the figure show the difference-in-difference setting for this analysis. Expectedly, the filing in the treatment group (the blue curve in Panel C) now shows much larger effects of the reform. Compared to the DD counterfactual (Panel D), which in this setting represents the number of treated taxpayers who would have reported positive partnership earnings if there were no tax reform, the observed tax filers are fewer by 43\%, 54\% and $63 \%$ in 2009, 2010 and 2011 respectively. The reduction represents the aggregate extensive response to the reform comprising both the informality and the switching response.

Overall, the above analysis demonstrates that the tax rise on partnership earnings forced around $63 \%$ of the individuals who were partners for at least three consecutive years in partnership firms to leave the firms: about $45 \%$ of them disappeared into informality, the rest switched business organization to sole proprietorships. For at least two reasons, however, this represents a conservative estimate of the extensive response in the population. First, for this analysis I focus on a balanced panel of taxpayers who file consistently in all the six years in the sample and report positive partnership earnings in each of the three pre-reform periods. Arguably, the costs of leaving the firms or the formal sector are the highest for this set of taxpayers. Second, the informality response identified here captures only one margin of response. Potentially, the non-filing margin is as important as nil-filing and omitting it also results in under-estimation of the overall response.

\subsection{Income Shifting to Corporate Tax Base}

As noted earlier, the purpose of the reform was to promote incorporation of partnership firms by bringing their taxation on a par with small corporate firms. In this section, I investigate if the policy was able to achieve its objective. Theoretically, a firm's decision to incorporate is influenced by a variety of factors. Incorporation offers limited liability, ${ }^{31}$ legal continuity and perpetual existence. Corporations, however, are costly to create and maintain: they need to keep audited accounts, face higher regulations, experience double taxation, and have more onerous registration requirements. While making organizational form choice, entrepreneurs tradeoff these costs and benefits, and the degree to which tax incentives influence the choice is not clear, particularly in the context of a developing country. Past empirical literature on the subject has found moderate to large effects (see Gordon \& MacKie-Mason 1994, 1997; Goolsbee 1998, 2004; Liu 2012 for evidence in the US and De Mooij \& Nicodème 2008; Egger et al. 2009; Da Rin et al. 2011; Edmark \& Gordon 2013 for evidence in Europe).

To evaluate if the reform had a significant impact on the incorporation choice of firms, I examine in Figure X the entry and taxable income distribution of corporate firms in Pakistan. Potentially,

\footnotetext{
${ }^{31}$ Because limited liability partnerships are not allowed in Pakistan, corporate business organization is the only form that offers this benefit.
} 
the reform can spur the entry of new corporations through two different channels. Some of the existing partnership firms may incorporate after the tax changes if the adjustment costs of doing so do not exceed the returns. Also, some new firms that in the absence of the tax changes would have entered as partnerships might enter as corporations. Panel A of the figure shows the month-wise registration of new firms with the FBR in 2006-12. The series for corporate firms shows no sign of structural break at the time of the announcement of the reform. ${ }^{32}$ Though there are considerable fluctuations, the number of new registrations settles to an almost constant level six months prior to the reform and continues to evolve on the trend after the reform. Contrary to this, the series for partnership firms shows clear signs of tax-driven response: the entry of new firms declines by almost $50 \%$ in the post-reform periods.

This evidence of weak or no effect is further strengthened by examining the taxable income reported by corporate firms. Panels $\mathrm{B}$ of the figure plots the taxable income distributions of such firms in 2006-11. The yearly histograms show no discernible change across the years, and the postreform empirical distributions (2010-2011) are almost identical to the pre-reform distributions. In sharp contrast to this, the corresponding distributions of partnership firms (Figure III) exhibit large effects of the tax rate changes.

The evidence, therefore, suggests that the reform had no significant short-term effects on the incorporation choice of firms and did not cause income shifting from non-corporate to corporate tax base. The result, however, needs to be careful interpreted. Incorporation is a costly process needing non-trivial adjustments. The appropriate time frame for evaluating the response is, hence, long-term when all firms are expected to have adjusted to the new incentives.

\subsection{Spillover Effects on VAT Base}

Around $25 \%$ of the partnership firms that reported positive taxable earnings in 2008 were also registered to remit VAT on their sales. ${ }^{33}$ Reform-driven changes in their behavior will also impact government revenue in the VAT base. Specifically, firms that report lower earnings will remit lower VAT owing to the reduction in the taxable base. ${ }^{34}$ Firms that exit the formal sector will be lost to VAT entirely. Similarly, VAT paid by partnerships that break up into smaller sole proprietorships will also be lost if the new smaller firms fall below the VAT exemption threshold. In this section, I investigate these spillover effects generated by the reform.

In Figure XI, I plot taxable income distributions of firms stratified by their VAT registration status. The sample for the analysis and the definitions of the treatment and control groups are the same as in section 4.1. The 2006-07 distributions are not shown for space considerations but changes in the number of firms in these years are indicated in the respective plots. The examination of the treated density distributions (Panels A and B) demonstrates that the VAT registered partnerships

\footnotetext{
${ }^{32}$ If a new corporation is created by the incorporation of an existing partnership firm, it will also show up as a new registrant in this series as corporations are required to register separately.

${ }^{33}$ Manufacturing and retail firms with annual sales up to Rs. 5 million are not required to register for VAT.

${ }^{34}$ Value-added tax is applied to a base that, under certain conditions, equals the sum of the profits of and the wages paid by the firm
} 
report lower earnings and the number of such firms goes down after the reform, though these responses are considerably smaller relative to the treated firms not registered for VAT. To rule out any non-tax contemporaneous influences driving these responses, the corresponding distributions for the control group are shown in Panels $\mathrm{C}$ and $\mathrm{D}$ of the figure .

To quantify the effects, I use the methodology presented in sections 4.1.2 and 4.1.3 and decompose the overall response into its intensive and extensive margin components. Figure XII compares the intensive margin responses of VAT-registered partnerships with the rest of the partnerships, and Table IV reports the corresponding elasticities estimated from the difference-in-difference specification (3) using a balanced panel approach. Figure XIII shows the breakdown of the aggregate extensive response presented in subsection 4.1 .3 by VAT registration status of firms. Together, the evidence demonstrates that the VAT-registered firms report significantly lower earnings after the tax changes: the intensive margin elasticities are more than one for all the sub-samples. Moreover, a number of such firms break down or leave the formal sector so that by 2011 partnership firms remitting VAT on their sales in Pakistan were down to $56 \%$ of their pre-reform level. ${ }^{35}$ These sizable spillovers imply that the cost of the tax rate hike on partnership earnings are far greater than the one given by formula (2). In section 6 of the paper, I take into account the VAT revenue loss to quantify the exact excess burden of the tax reform.

\section{Which Firms Respond to the Reform?}

Firms remit more than $80 \%$ of the tax collected in advanced countries (Christensen et al. 2001; Shaw et al. 2010). In developing countries this percentage could be even higher though no reliable estimates are available. It is, hence, not surprising that investigating the determinants of firm compliance has been an area of great importance, particularly in countries with limited tax capacity. I have argued earlier (section 4.1.2) that, owing to the retroactive applicability, short-term response to the reform mostly identify non-compliance. In this section I use the firm characteristics data to explore heterogeneity in this response and thus to uncover the major determinants of firm compliance.

\subsection{Intensive Margin}

To probe heterogeneity in intensive margin behavior, I run 2SLS regressions of the form (3) with the modification that in the second stage interactions of various firm characteristics with fitted values of log-change in net-of-tax rate are also included. The coefficient on the interaction term $\left(1 \hat{-} \tau_{i t}\right) \cdot 1\left(i \in\right.$ Characteristic $\left._{j}\right)$, accordingly, captures the differential responsiveness of firms with the particular characteristic $j$, and thus reflect the influence of the firm observable in determining compliance. The details of the firm characteristics used in the regressions are provided in Appendix

\footnotetext{
${ }^{35}$ For two reasons, the exit of partnership firms will have little short-run effect on overall VAT collection in the country. First, partnership firms constitute only a small fraction (about 4\%) of the total VAT base. Second, the VAT distribution is very skewed as more than $90 \%$ of the tax is remitted by top 300 firms that are either corporations or firms not affected by the reform having earnings greater than Rs. 1.3 million.
} 
A to this paper. The results, presented in Table V, demonstrate that while sophisticated firms proxied by the variable Electronic Return Filer - respond more to the tax rate changes, the firms that $(i)$ are large, $(i i)$ are more experienced, $(i i i)$ have greater proportion of their tax withheld at source, $(i v)$ are registered for VAT, or $(v)$ withhold taxes of other agents respond less.

These results are consistent with the recent literature on tax enforcement, which emphasizes the importance of third-party reporting in deterring evasion. Third party reporting provides independent information on the taxable base to the government, and thus reduces a firm's ability to under-report earnings (Kleven et al. 2011, 2009). There are a variety of ways in which such information is generated in the economy such as arm-length business transactions, formal access to credit, and wage payments to workers. The results highlight the importance of these mechanisms in determining firm compliance. The elasticity for large firms, which are expected to have higher financial exposure and larger number of employees, is smaller by $56 \%$ in comparison with the elasticity for other firms. Similarly, VAT-registered firms, which are linked to their buyers and suppliers through the invoice-credit mechanism, have $40 \%$ lower elasticity. The variables Tax Withholding and Withholding Agent capture the extent to which third-party information is available on the sales and purchases of the firm respectively. Large coefficients on these variables reflect the relevance of such information in deterring evasion: firms with a higher degree of withholding evade substantially less (around 50\%) as compared with the others.

\subsection{Extensive Margin}

To investigate the major characteristics of firms that respond on the extensive margin, I report in Table VI results from the following regressions

$$
\text { Exit }_{i t}=\beta_{0}+\beta_{1} \cdot X_{i}+\beta_{2} \cdot \Omega_{i}+\nu_{i t} .
$$

Here Exit it $_{\text {is }}$ an indicator that firm $i$ reported positive earnings in 2008 but did not in year $t$, $X_{i}$ are the firm observables of interest, and $\Omega_{i}$ are a rich set of controls comprising $(i)$ tax office fixed effects (15 categories capturing the location and type of tax office ${ }^{36}$ ); (ii) industry fixed effects (six-digit industry code the firm belongs to); and (iii) age fixed effects (10 categories). All variables are introduced into the specification non-parametrically so that there are a total of 339 dummy variables in equation (5). The results in columns (2)-(5) illustrate that the firms that $(i)$ are large, (ii) are sophisticated, (iii) have greater proportion of their tax withheld at source, $(i v)$ are registered for VAT, or $(v)$ withhold taxes of other agents are less likely to exit as compared to other firms in the same industry, tax office and age decile. Broadly, the results echo those in the last section and highlight the importance of information for tax enforcement.

Two points about the above analysis need further explanation. First, one disadvantage of using so many controls is that I lose observations where data is missing on any of the variables in the regression equation (results in Table VI are based only on around $50 \%$ of the potential sample).

\footnotetext{
${ }^{36}$ Pakistan has two types of tax offices: Large Taxpayer Units (LTUs), located in Karachi, Lahore and Islamabad, cater to top tax contributors; Regional Tax Offices (RTOs), located in twelve cities, administer the rest of firms.
} 
Consequently, the results may not be representative of the population, if the missing observations are systematically different from the ones included in the sample. However, columns (1)-(3) of the table show that exit probability for the included firms is 45\%,63\% and 68\% in 2009, 2010 and 2011 respectively, which is not different from such probabilities for the population (Figure VI, Panel F). This shows that the missing observations are at least not different in terms of the dependent variable. To further allay the concern, I rerun the regressions after dropping the controls with the most missing data (industry code and annual sales). Such specifications produce results (not shown) similar to those reported in the table. Second, another worry with the results is that the regression specification treats every firm that leaves after 2008 as a tax-driven response. Some of the firms that exit would have done so regardless of the tax rate changes. To allay this concern, I re-estimate (5) with a sample that comprises only the firms that report positive taxable income in all the three pre-reform years. These are regular filers the exit of which is more likely to have been driven by the tax rate changes only. These regressions also produce qualitatively similar results, demonstrating that the correlations reported in Table VI are quite robust.

\section{Welfare Analysis}

In this section, I combine the evidence presented in the previous sections to estimate the marginal excess burden created by the tax rise. Formula (2) shows that for every rupee raised the tax rate increase imposes an extra cost of

$$
-\frac{d B}{d R}=\frac{\tau^{p}\left(e^{p}+\psi e^{s}\right)}{1-\tau^{p}-\tau^{p}\left(e^{p}+\psi e^{s}\right)}
$$

on the treated taxpayers. Using the data I estimate a value of 0.023 for $\psi \equiv \frac{\tau^{s} Z^{s}}{\tau^{p} Z^{p}}$, which implies that income shifting has negligible influence in mitigating the efficiency cost of the tax rise and can be ignored. ${ }^{37}$ With this simplification, formula (2) reduces to the standard formula used in the literature (Saez et al. 2012) for computing the deadweight loss of a flat tax

$$
-\frac{d B}{d R} \approx \frac{\tau^{p} e^{p}}{1-\tau^{p}-\tau^{p} e^{p}}
$$

Using the most conservative of the elasticity estimates presented in sections 4.1.2 and 4.1.3, $\varepsilon^{p}=$ $2, \eta^{p}=2 \Longrightarrow e^{p} \approx 4$, I calculate a value of -4 for $\left(-\frac{d B}{d R}\right)$ in $2009 .^{38}$ The negative sign here

\footnotetext{
${ }^{37}$ For two reasons, income shifting has very little bite in the current setting. First, most of the shifted earnings are in the range where tax rates on sole proprietorship earnings are only a small fraction of the one on partnership earnings $\left(\tau^{s} \ll \tau^{p}\right)$. Second, aggregate sole proprietorship earnings reported by the treated taxpayers is only around $25 \%$ of the aggregate partnership earnings $\left(Z^{s} \approx 0.25 Z^{p}\right)$.

${ }^{38}$ In arriving at the number, I make two simplifying assumptions. First, I assume homogeneous responsiveness in the population, which for a linear tax rate implies that the aggregate elasticity equals the sum of intensive and extensive margin components. To make sure that the assumption does not result in overestimation of the inefficiency, I use the most conservative estimate of the intensive and extensive margin elasticities in the population. Second, to estimate $\psi$ I assume that the tax rate is flat on both sole proprietorship and partnership earnings, whereas it is flat only for the latter type of earnings. Both these assumptions, however, can easily be relaxed resulting in a more complicated excess burden formula without any significant change in the result.
} 
demonstrates that the tax rise on partnership earnings reduced instead of increasing the government revenue. An alternative way of looking at the cost of the tax rise is that about $133 \%\left(-\frac{d B}{d M}=1.3\right)$ of the projected increase in revenue was lost through the behavioral response. The new tax rate of $25 \%$ was, accordingly, on the wrong side of the Laffer curve and would not have been optimal under any social preferences. In fact, formula (6) can be rearranged to show that the $25 \%$ rate generates additional revenue only if $e^{p}<3$, whereas the evidence in sections 4.1.2 and 4.1.3 illustrates that the elasticity was larger than this cutoff in 2009 and increased steadily over time. Moreover, with $e^{p} \approx 4$ and $\psi=0.023$ we need an aggregate income shifting elasticity $\left(e^{s}\right)$ in excess of 43 for the new tax rate to be below the Laffer bound.

The above analysis assumes that the reform creates no fiscal externality other than income shifting to sole-proprietorship base. We, however, have seen that the reform was meant to cause income shifting to corporate tax base and that it reduced government revenue from the VAT base. Following Saez et al. (2012), these spillovers can be incorporated into the efficiency calculations using the formula

$$
-\frac{d B}{d R} \approx \frac{e^{p}\left(\tau^{p}-\sigma^{c} \tau^{c}+\sigma^{v} \tau^{v}\right)}{1-\tau^{p}-e^{p}\left(\tau^{p}-\sigma^{c} \tau^{c}+\sigma^{v} \tau^{v}\right)}
$$

where $\sigma^{i}$ represents the share of partnership earnings taxed in base $i$ at the rate $\tau^{i}$ and $i \in\{c, v\}$ indexes the corporate and VAT bases respectively. The evidence in section 4.3 shows that almost no income shifting to corporate base took place so that its effects can be ignored. The spillover effects on VAT base, however, are considerable and need to be taken into account. Using the fact that around $25 \%$ of the treated firms were required to remit VAT so that $\sigma^{v}=0.25$ and applying the

prevalent VAT rate of $\tau^{v}=0.17$ raises the value of $\left(-\frac{d B}{d M}\right)$ to 1.56 . This implies that the deadweight loss of the reform increases by $17 \%$ if the negative spillover on VAT base are also taken into account.

\section{Conclusions}

This paper has examined the effects of personal income taxation on earnings, formality and business organization choices of agents in the context of a developing country. The tax rate rise on partnership earnings resulted in large-scale exit, breakup, or reduced earnings of the affected firms. That the earnings and formality choices are considerably elastic to marginal tax rates, especially at the bottom of the earnings distribution, has three important lessons for the tax policy in developing countries. First, the tax systems should actively seek to lessen the costs of operating in the formal sector by instituting progressively increasing taxation. Low-income firms are particularly sensitive on the participation margin and steep tax rates at the bottom could lead them to informality. The declining intensive margin responsiveness along the income distribution further strengthens the case for progressive taxation. Second, large tax rate changes are known to produce large behavioral responses and need to be avoided to protect already thin tax bases and to limit the efficiency costs of raising taxes. Third, tax rate increases on narrowly defined tax bases produce large incentives and opportunities for income shifting. Such reforms are less likely to produce additional revenue 
but impose significant welfare costs. Tax rate changes, hence, need to be as broad-based as possible.

The retroactive applicability of the reform creates additional variation across firms that has been exploited to uncover non-compliance. The estimates of short-run responses to the reform provide perhaps the cleanest evidence in literature on the responsiveness of tax evasion to marginal tax rates and on how such responsiveness varies with the firm observables. The findings that the firms that are large, are registered for VAT, or have greater proportion of their tax withheld at source are more tax compliant highlight the importance of third-party information as an enforcement device. This calls for policies to expand third-party reporting on transactions besides wage payments to which it is mostly restricted now. The use of tax withholding on business transaction as a means to elicit thirdparty information, however, is questionable, as such withholding could potentially lead to different effective tax rates across firms and can give rise to production inefficiency losses. Future work, hence, may undertake the design of optimal mechanisms through which the availability of thirdparty information can be enhanced in an economy without creating distortions and inefficiencies.

\section{References}

Andreoni, James, Erard, Brian, \& Feinstein, Jonathan. 1998. Tax complicance. Journal of Economic Literature, 36, 818-860.

Bastani, Spencer, \& Selin, Hakan. 2012. Bunching and non-bunching at kink points of the Swedish tax schedule. Working Paper, CESifo.

Best, Michael, Brockmeyer, Anne, Kleven, Henrik, Spinnewijn, Johannes, \& Waseem, Mazhar. 2013. Production vs Revenue Efficiency with Limited Tax Capacity: Theory and Evidence from Pakistan. London School of Economics Working Paper.

Chetty, Raj. 2009. Is the Taxable Income Elasticity Sufficient to Calculate Deadweight Loss? The Implications of Evasion and Avoidance. American Economic Journal: Economic Policy, 1(2), $31-52$.

Chetty, RaJ. 2012. Bounds on Elasticities With Optimization Frictions: A Synthesis of Micro and Macro Evidence on Labor Supply. Econometrica, 80(3), 969-1018.

Chetty, Raj, Looney, Adam, \& Kroft, Kory. 2009. Salience and Taxation: Theory and Evidence. American Economic Review, 99(4), 1145-77.

Chetty, Raj, Friedman, John, Olsen, Tore, \& Pistaferri, Luigi. 2011. Adjustment Costs, Firm Responses, and Micro vs. Macro Labor Supply Elasticities: Evidence from Danish Tax Records. Quarterly Journal of Economics, 126, 749-804.

Christensen, Kevin, Cline, Robert, \& Neubig, Tom. 2001. Total Corporate Taxation:" Hidden," Above-the-Line, Non-Income Taxes. National Tax Journal, 54(3), 495-506. 
Da Rin, Marco, Di Giacomo, Marina, \& Sembenelli, Alessandro. 2011. Entrepreneurship, firm entry, and the taxation of corporate income: Evidence from Europe. Journal of Public Economics, 95(9), 1048-1066.

De Mooij, Ruud A, \& Nicodème, Gaëtan. 2008. Corporate tax policy and incorporation in the EU. International Tax and Public Finance, 15(4), 478-498.

Edmark, Karin, \& Gordon, Roger H. 2013. The choice of organizational form by closelyheld firms in Sweden: tax versus non-tax determinants. Industrial and corporate Change, 22(1), 219-243.

Egger, Peter, Keuschnigg, Christian, \& Winner, Hannes. 2009. Incorporation and taxation: Theory and firm-level evidence. University of St. Gallen, Economics Discussion Paper.

Eissa, Nada, \& Hoynes, Hillary. 2000. Tax and transfer policy, and family formation: Marriage and cohabitation. University of California Davis Working Paper.

FBR. 2010. Salient Features For The Budget 2010-11. http://www.geo.tv/important_events/ 2010/budget2010/SalientFeatures/SALIENTFEATURES (IncomeTax) .pdf.

Feldstein, Martin. 1999. Tax Avoidance And The Deadweight Loss Of The Income Tax. The Review of Economics and Statistics, 81(4), 674-680.

Fuest, Clemens, \& Riedel, Nadine. 2009. Tax evasion, tax avoidance and tax expenditures in developing countries: A review of the literature. Report prepared for the UK Department for International Development (DFID).

Goolsbee, Austan. 1998. Taxes, organizational form, and the deadweight loss of the corporate income tax. Journal of Public Economics, 69(1), 143 - 152.

Goolsbee, Austan. 2004. The impact of the corporate income tax: evidence from state organizational form data. Journal of Public Economics, 88, 2283 - 2299.

Gordon, Roger, \& Li, Wei. 2009. Tax structures in developing countries: Many puzzles and a possible explanation. Journal of Public Economics, 93(7-8), 855-866.

Gordon, Roger, \& Slemrod, Joel. 2000. Are 'Real' Responses to Taxes Simply Income Shifting Between corporate and Personal Tax Bases? In: Slemrod, Joel (ed), Does Atlas Shrug? The Economics Consequences of Taxing the Rich.

Gordon, Roger H., \& MacKie-Mason, Jeffrey K. 1994. Tax distortions to the choice of organizational form. Journal of Public Economics, 55(2), 279 - 306.

Gordon, Roger H., \& MacKie-Mason, Jeffrey K. 1997. How Much Do Taxes Discourage Incorporation? Journal of Finance, 52(2), 477-505. 
Gruber, Jon, \& Saez, Emmanuel. 2002. The elasticity of taxable income: evidence and implications. Journal of Public Economics, 84(1), 1 - 32.

Kleven, Henrik J., \& Waseem, Mazhar. 2013. Using Notches to Uncover Optimization Frictions and Structural Elasticities: Theory and Evidence from Pakistan. Quarterly Journal of Economics, 128, 669-723.

Kleven, Henrik Jacobsen, \& Schultz, Esben Anton. 2013. Estimating Taxable Income Responses Using Danish Tax Reforms. London School of Economics Working Paper.

Kleven, Henrik Jacobsen, Kreiner, Claus Thustrup, \& Saez, Emmanuel. 2009. Why Can Modern Governments Tax So Much? An Agency Model of Firms as Fiscal Intermediaries. NBER Working paper 15218.

Kleven, Henrik Jacobsen, Knudsen, Martin B., Kreiner, Claus Thustrup, Pedersen, Søren, \& Saez, Emmanuel. 2011. Unwilling or Unable to Cheat? Evidence From a Tax Audit Experiment in Denmark. Econometrica, 79(3), 651-692.

Kopczuk, Wojciech. 2012. The Polish business "flat" tax and its effect on reported incomes: a Pareto improving tax reform? Columbia University Working Paper.

Kopczuk, Wojciech, \& Slemrod, Joel. 2006. Putting Firms into Optimal Tax Theory. American Economic Review Papers and Proceedings, 96(2), 130-134.

LiU, LI. 2012. Income Taxation and Business Incorporation: Evidence from the Early Twentieth Century. Oxford University Centre for Business Taxation Working Paper 1205.

Marion, Justin, \& Muehlegger, Erich. 2008. Measuring Illegal Activity and the Effects of Regulatory Innovation: Tax Evasion and the Dyeing of Untaxed Diesel. Journal of Political Economy, 116(4), 633-666.

Saez, Emmanuel. 2004. Reported Incomes and Marginal Tax Rates, 1960-2000: Evidence and Policy Implications. In: Tax Policy and the Economy, Volume 18. National Bureau of Economic Research.

Saez, Emmanuel, Slemrod, Joel, \& Giertz, Seth. 2012. The Elasticity of Taxable Income with Respect to Marginal Tax Rates: A Critical Review. Journal of Economic Literature, 50, $3-50$.

Shaw, Jonathan, Slemrod, Joel, \& Whiting, John. 2010. Administration and compliance. Dimensions of Tax Design: the Mirrlees Review, J. Mirrlees, S. Adam, T. Besley, R. Blundell, S. Bond, R. Chote, M. Gammie, P. Johnson, G. Myles and J. Poterba (eds), Oxford University Press.

Slemrod, Joel. 1998. Methodological Issues in Measuring and Interpreting Taxable Income Elasticities. National Tax Journal, 51(4), 773-788. 
Slemrod, Joel. 2007. Cheating Ourselves: The Economics of Tax Evasion. Journal of Economic Perspectives, 21, 25-48.

Slemrod, Joel, \& Kopczuk, Wojciech. 2002. The optimal elasticity of taxable income. Journal of Public Economics, 84(1), 91-112.

Slemrod, Joel, \& Weber, Caroline. 2012. Evidence of the invisible: toward a credibility revolution in the empirical analysis of tax evasion and the informal economy. International Tax and Public Finance, 19(1), 25-53.

Slemrod, Joel, \& Yitzhaki, Shlomo. 2002. Tax avoidance, evasion, and administration. In: Auerbach, A. J., \& Feldstein, M. (eds), Handbook of Public Economics, vol. 3. 
The Tax Reform

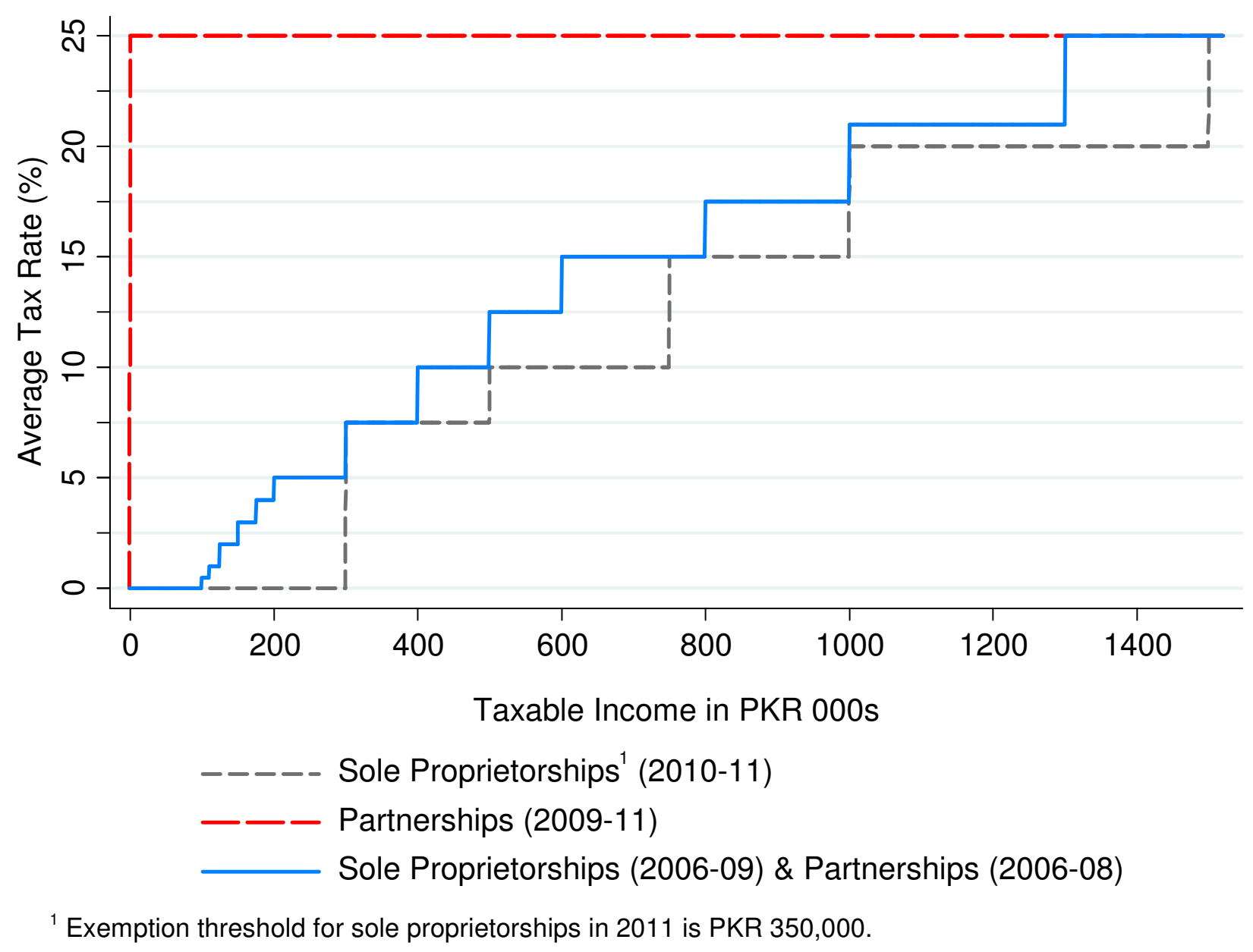

Notes: the figure displays the changes made to the personal income tax regime of unincorporated businesses by the reform. The solid blue curve depicts the pre-reform tax schedule applicable to both sole proprietorship and partnership firms in 2006-08. The reform, announced on 14-06-2010, replaced this scheme with dichotomous taxation of sole proprietorship and partnerships. The post-reform schedule for partnership earnings, applicable retroactively from 01-07-2009, is shown by the dashed red curve. The dashed grey curve denotes the post-reform schedule for sole-proprietorship earnings, which was applicable prospectively from 01-07-2010. The exemption threshold for sole-proprietorship earnings was increased from PKR 300,000 to PKR 350,000 in 2011. All schedules show variations in average tax rates as a function of annual taxable income. Bracket boundaries, where tax rate changes, are included in the lower tax brackets. Taxable income is shown in thousands of Pakistani Rupees (PKR), and the PKR-USD exchange rate is about 105 as of October 2013. 


\section{Size and Dynamics of Partnership Tax Penalty}

A: 2006

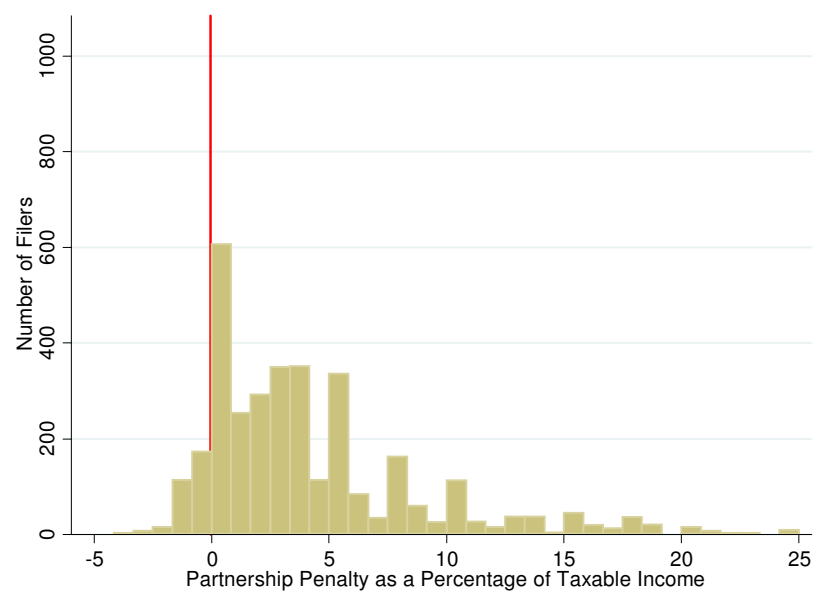

C: 2008

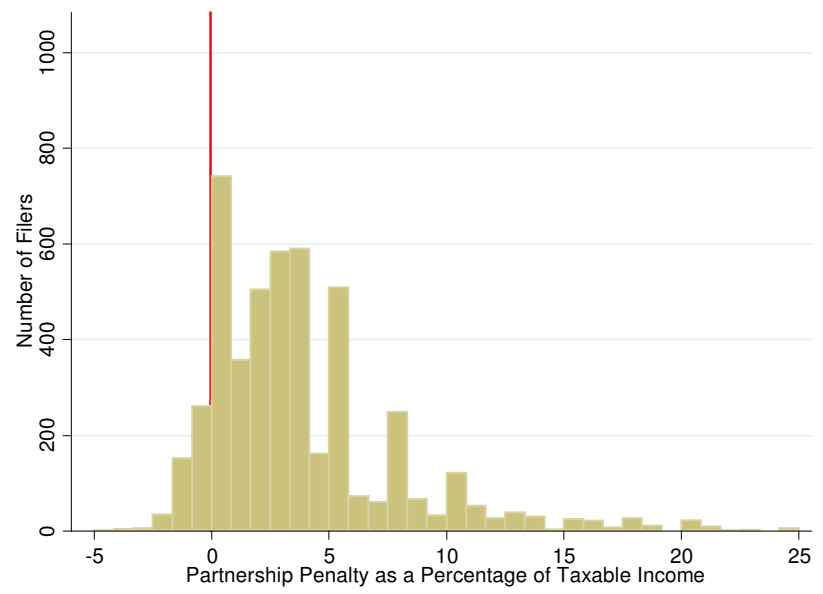

E: 2010

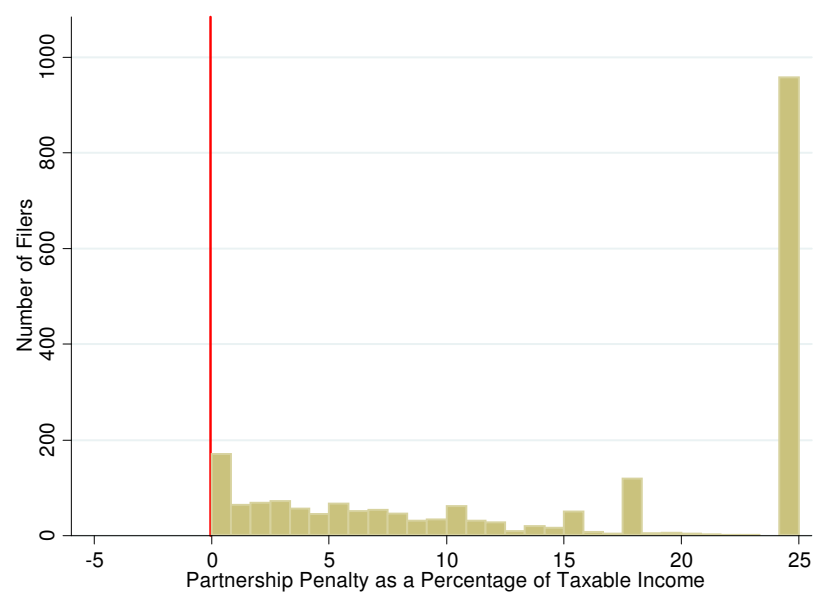

B: 2007

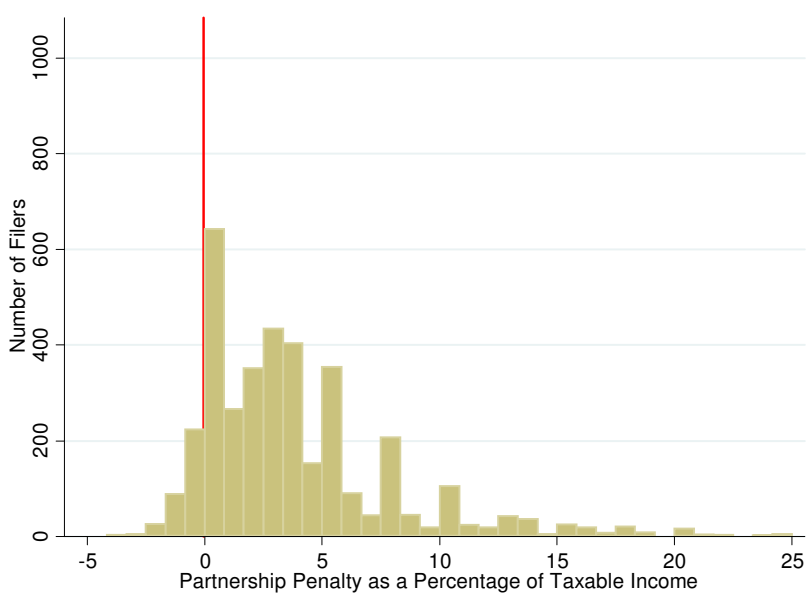

D: 2009

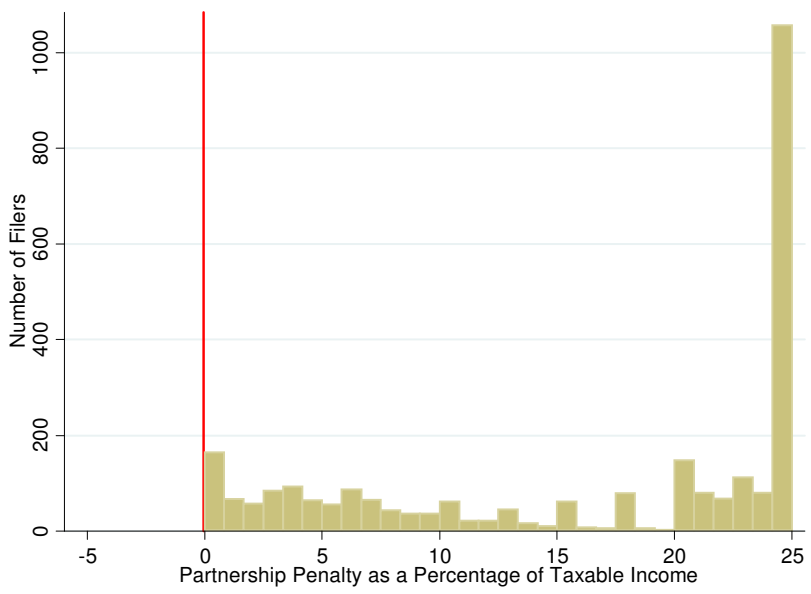

F: 2011

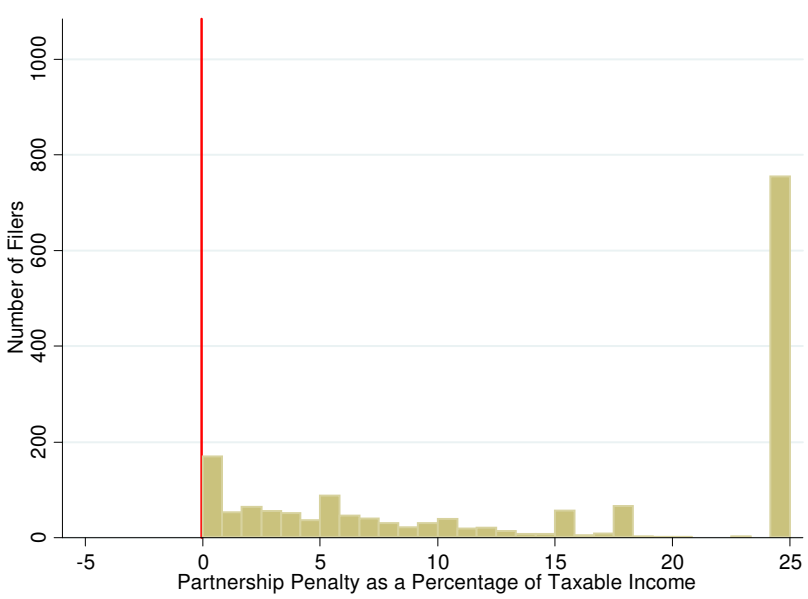

Notes: the figure shows the size and dynamics of the partnership tax penalty. For a taxpayer $i$ who reports a sum $x$ as partnership earnings, the penalty represents the additional tax liability that $i$ experiences in reporting $x$ as partnership earnings rather than sole proprietorship earnings. Panels A-F illustrate the yearly density distribution of the penalty as a percentage of taxable income. The distributions are shown in bins of size 0.83 , where each bin includes the upper bound of the interval. The red vertical line demarcates the boundary below which taxpayers experience tax subsidy rather than penalty. 


\section{Taxable Income Distribution of Partnership Firms}

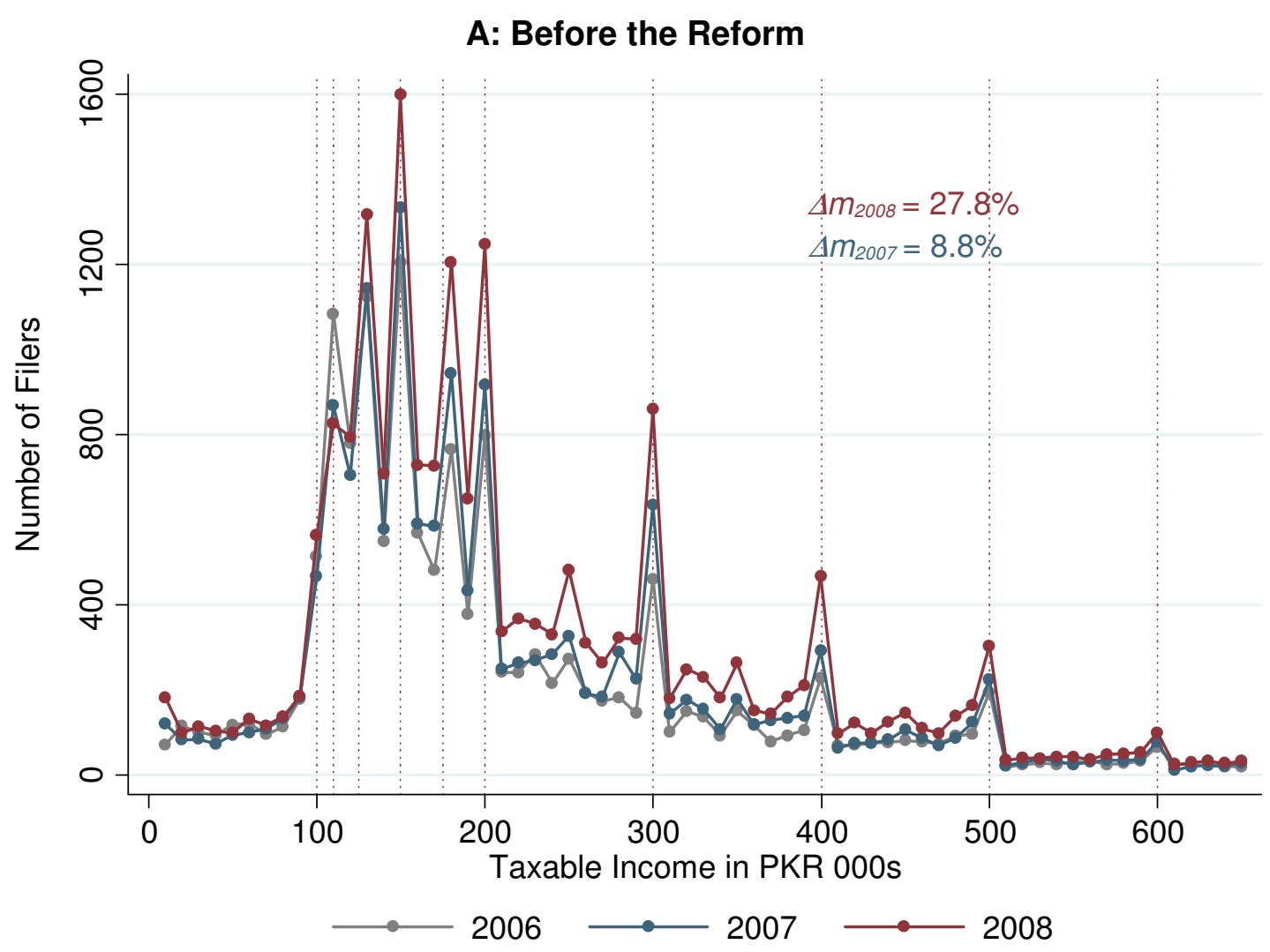

\section{B: After the Reform}

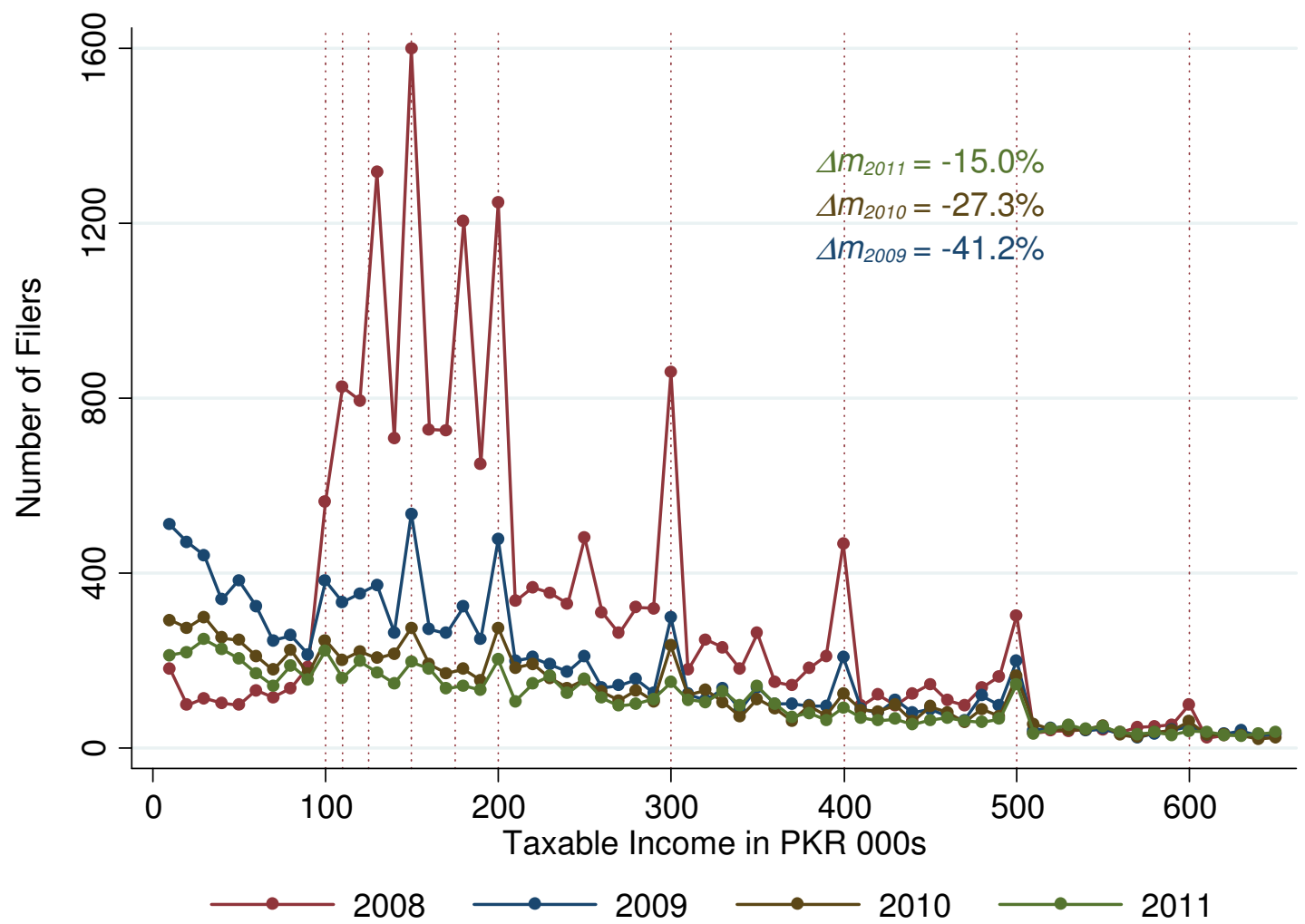

Notes: the figure shows the behavioral responses of partnership firms to the tax rate increase in 2009. Panels A and $B$ illustrate the empirical taxable income distributions of partnership firms before and after the reform. Each dot in the plots represents the upper bound of a PKR 10,000 bin and denotes the number of firms reporting earnings within that bin. The notches in the 2006-08 schedule are shown by the vertical dotted red lines. In Panel B, the 2008 distribution is plotted again for comparison purposes. Yearly changes in tax filing are shown by $\Delta m_{t}$, which is calculated as the change in the number of filers between years $t$ and $t+1$ as a percentage of filers in year $t$. 
Taxable Income Distribution of Sole Proprietorship Firms

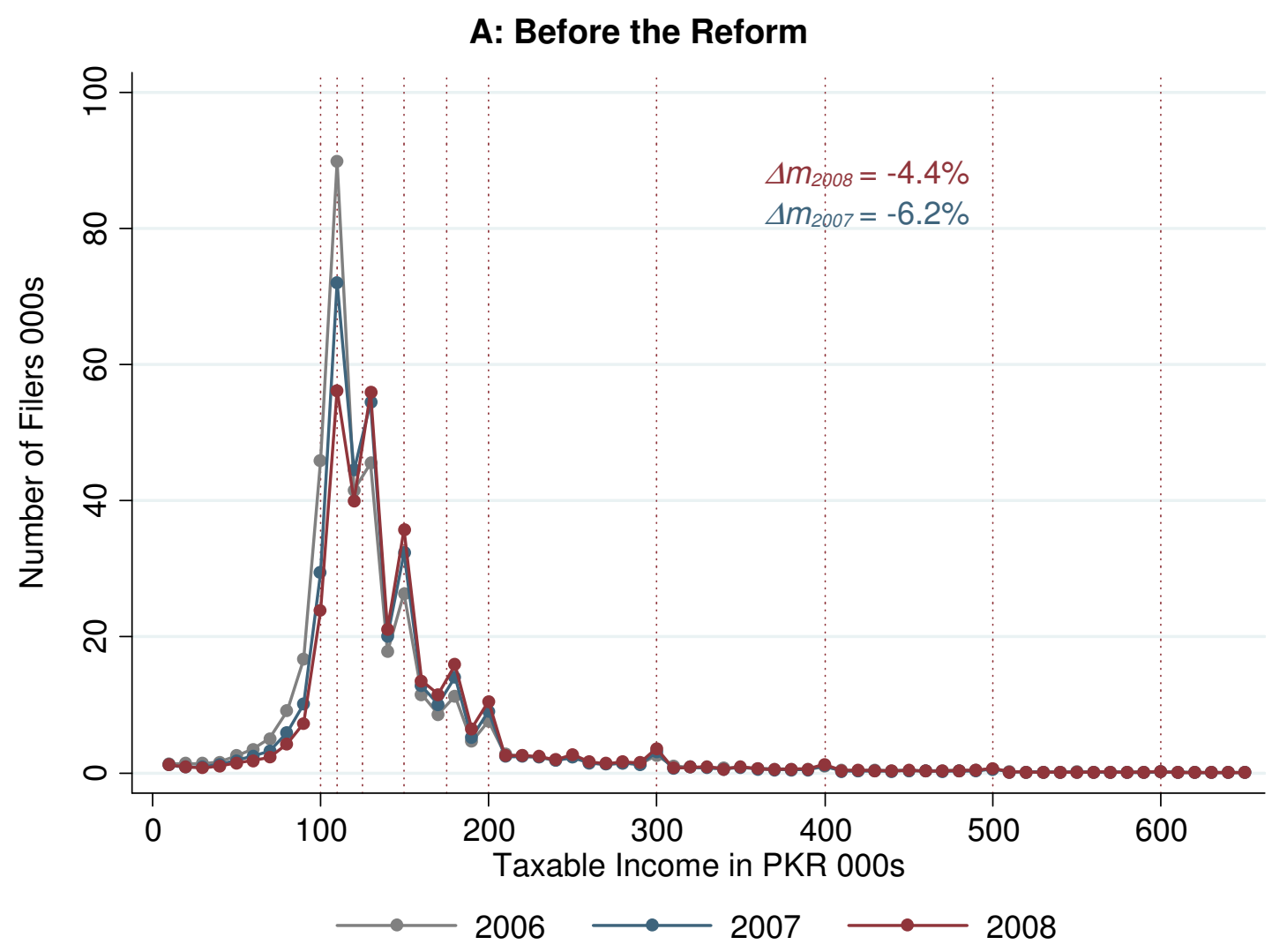

\section{B: After the Reform}

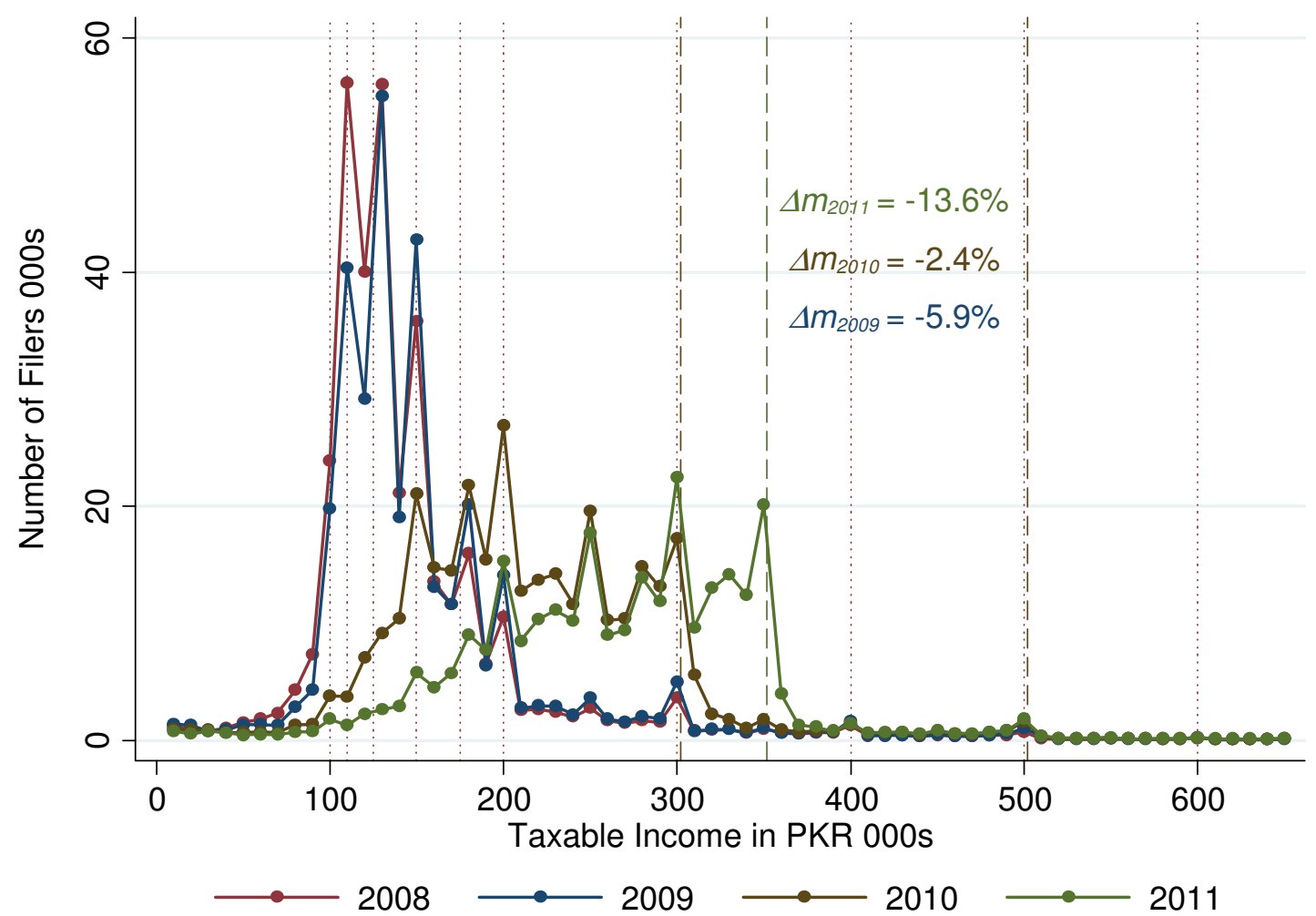

Notes: the figure illustrates the empirical taxable income distributions of sole proprietorship firms in 2006-11. Each dot in the figure represents the upper bound of a PKR 10,000 bin and denotes the number of tax filers reporting earnings within that bin. The notches in the 2006-08 schedule are shown by the vertical dotted red lines. The longdashed vertical lines in Panel B demarcate at PKR 300,000 and 350,000 the exemption threshold in 2010 and 2011 and at Rs. 500,000 the notch in the post-reform schedule in 2010-11. In Panel B, the 2008 distribution is plotted again for comparison purposes. Yearly changes in tax filing are shown by $\Delta m_{t}$, which is calculated as the change in the number of filers between years $t$ and $t+1$ as a percentage of filers in year $t$. 


\section{Effects of the Tax Reform on Partnership Firms - Intensive Margin}
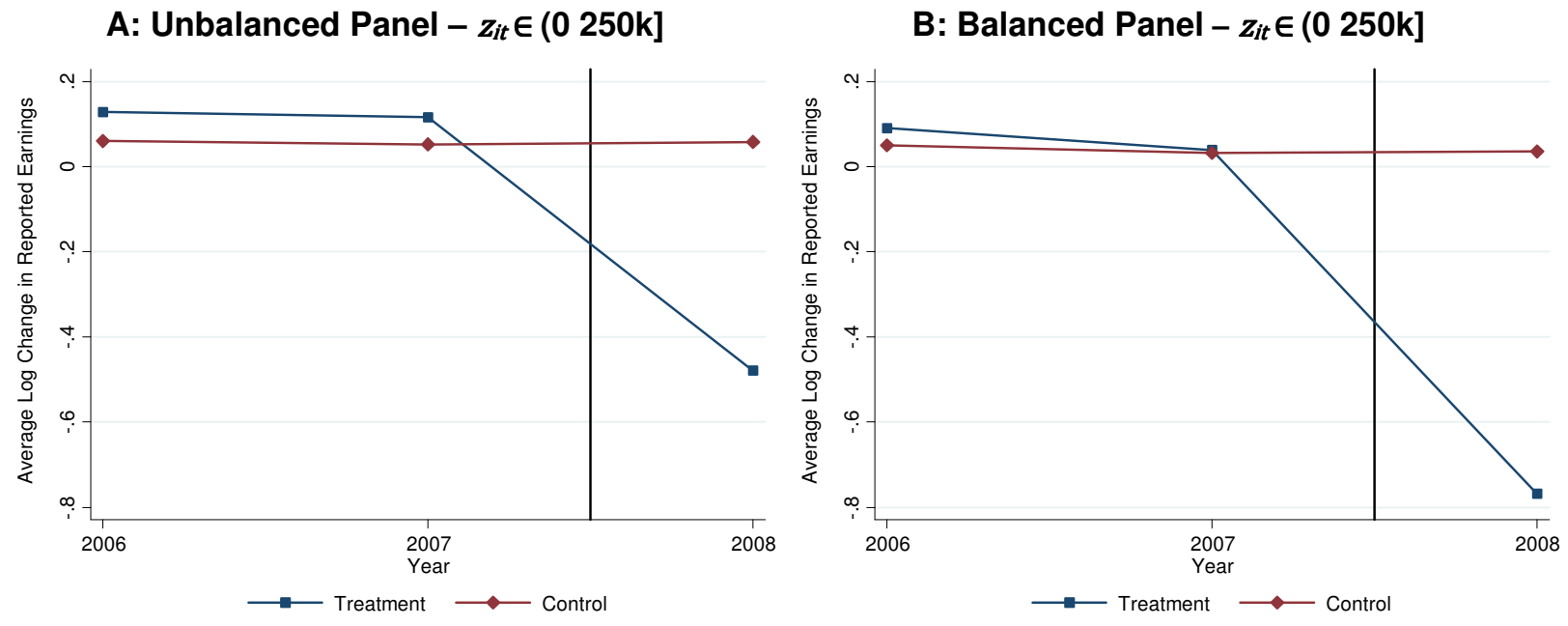

\section{C: Unbalanced Panel $-z_{i t} \in(0$ 450k]}
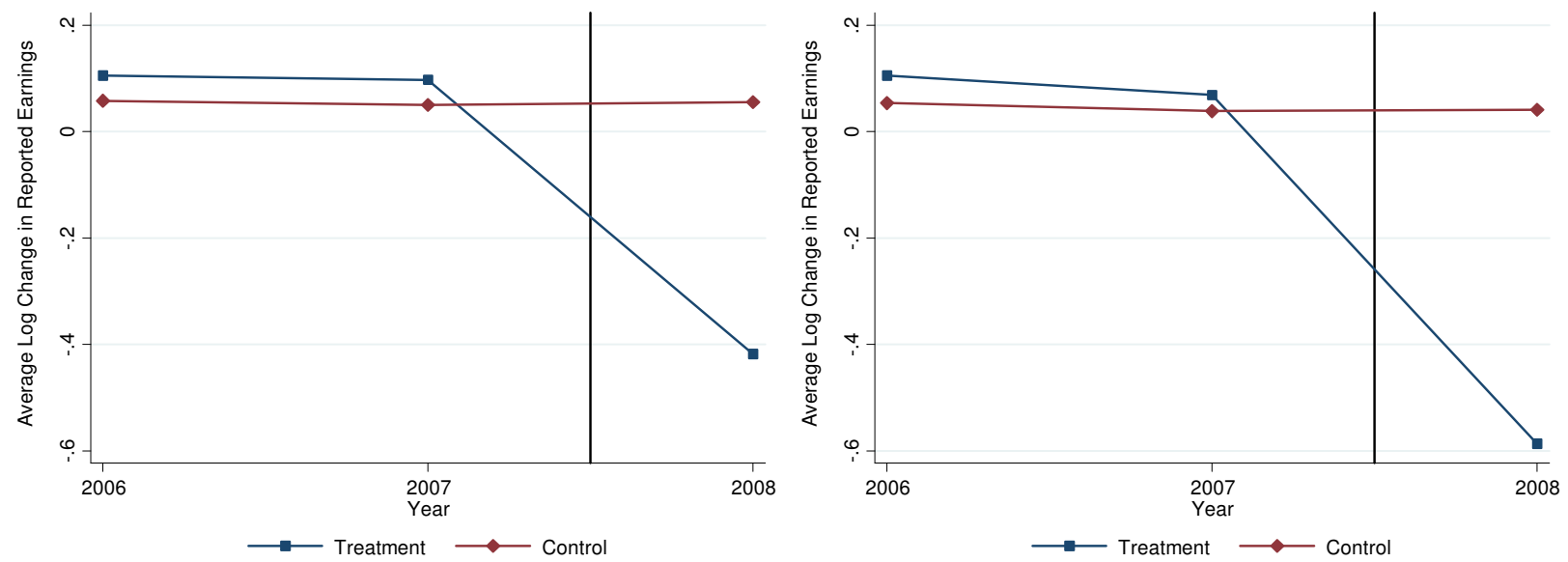

E: Unbalanced Panel $-z_{i t} \in(0650 \mathrm{k}]$
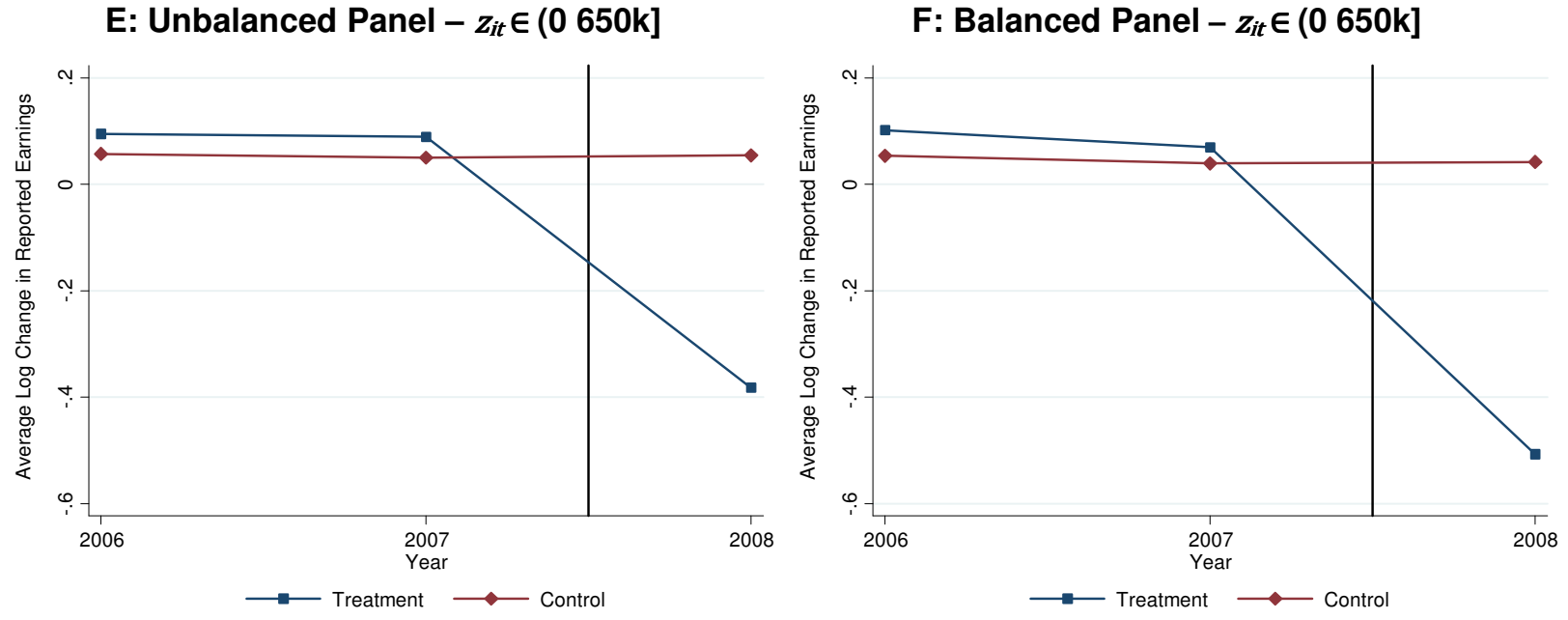

Notes: the figure illustrates the intensive margin response of partnership firms to the tax reform. The intensivemargin is defined to cover the responses of firms that do not exit the formal sector but may report lower earnings after the reform. The treatment and control groups comprise partnership and sole proprietorship firms respectively. As the control group itself experiences tax rate changes in 2010-11, the analysis is restricted to the period 2006-09. Each point in the plots denotes the log change in reported earnings between year $t$ and $t+1$ for firm $i$, averaged across all firms in year $t$. The sample for the left panels includes for year $t$ all the firms that report in years $t$ and $t+1$, while the right panels include the firms that report positive taxable income in all the four years (2006-09). The black vertical line in each panel indicates the time from which the tax changes affect the reporting behavior of the treated firms. 
A: Number of Firms

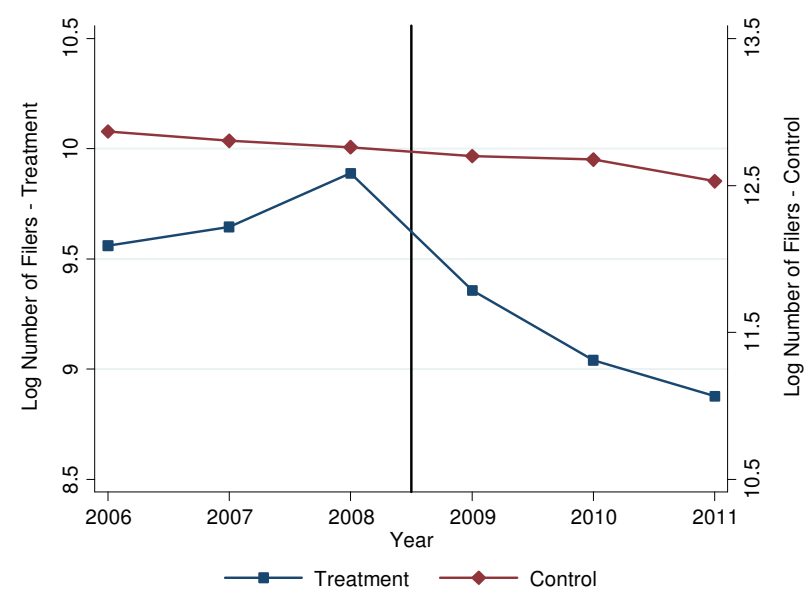

C: Number of Firms (Control)

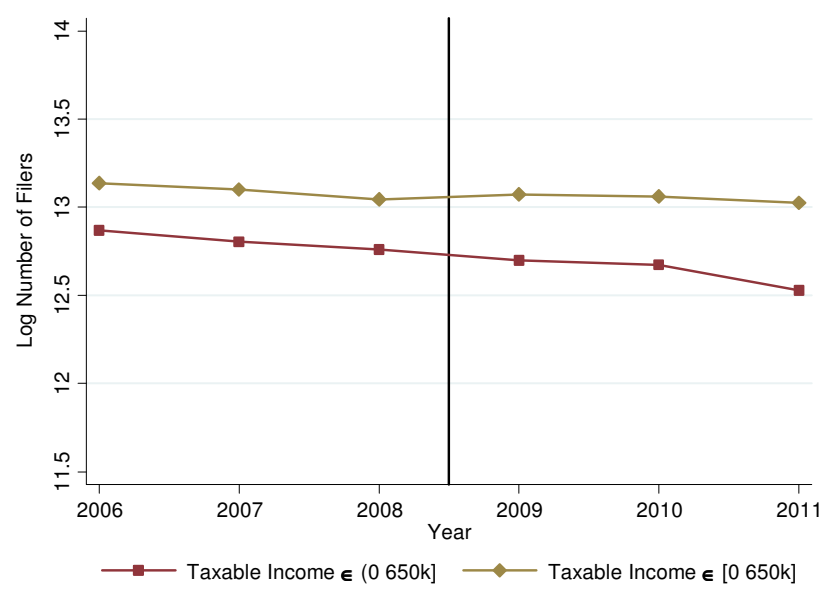

E: Counterfactual Number of Firms (Linear Trend)

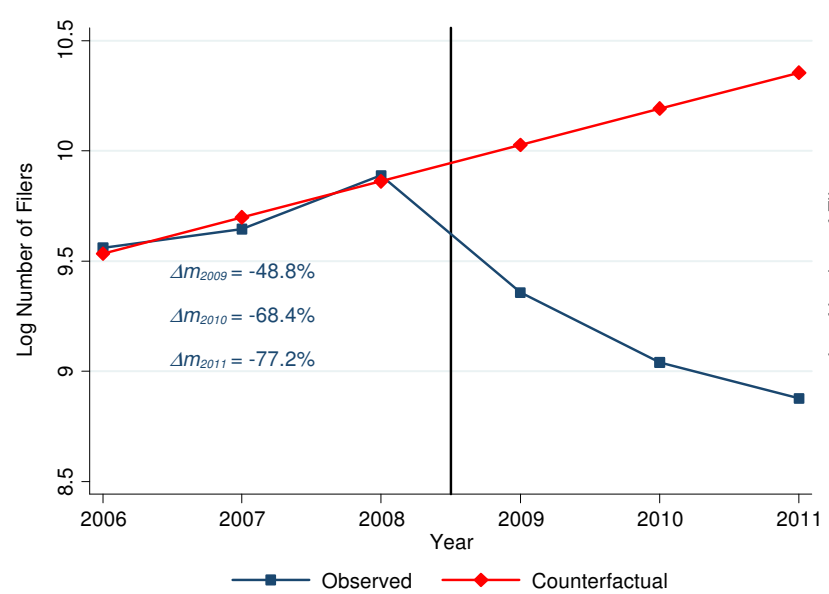

B: Number of Firms (Treatment)

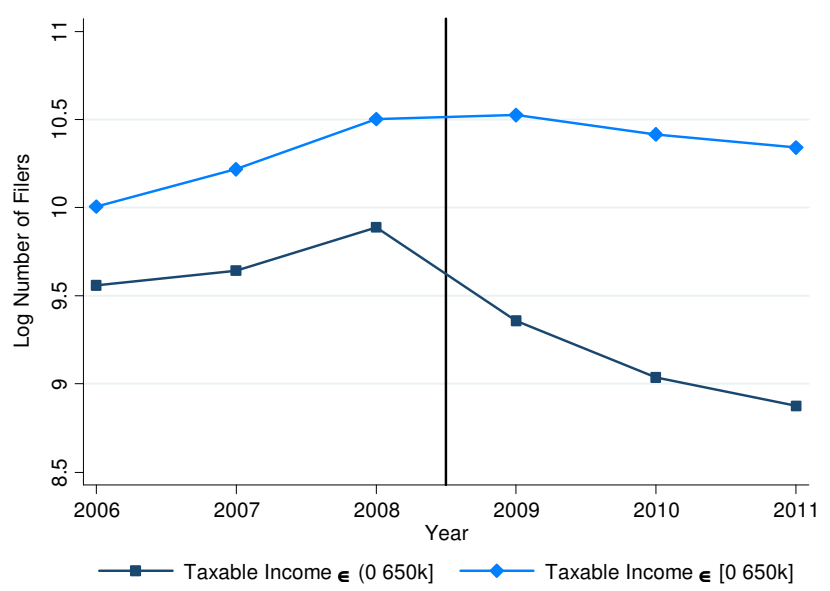

D: Entry of Firms (Treatment)

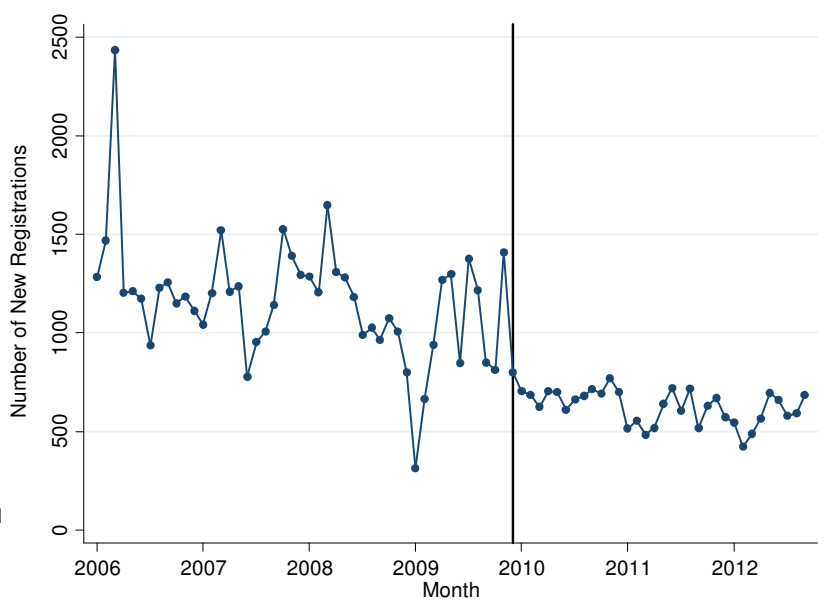

F: Counterfactual Number of Firms (Lower Bound)

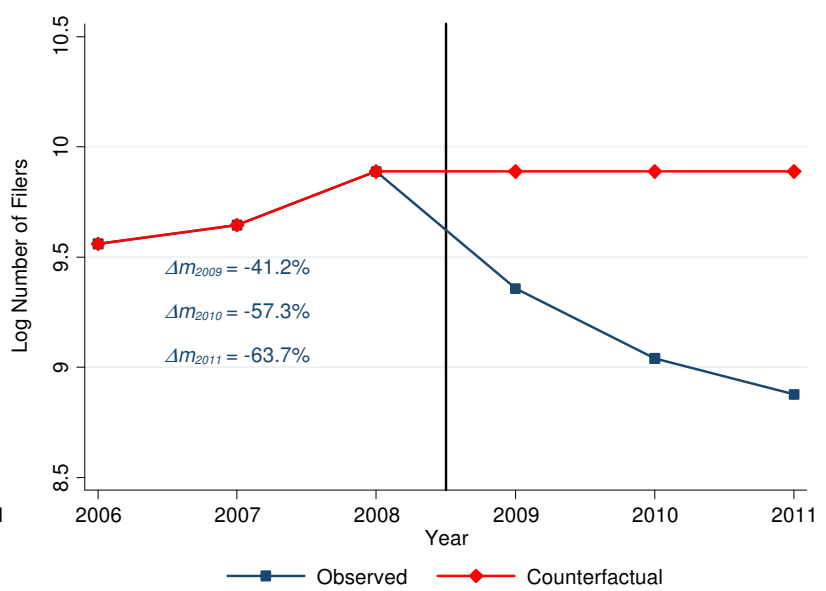

Notes: the figure displays the strategy for estimating the extensive margin responses of partnership firms. The treatment and control groups comprise partnership and sole proprietorship firms respectively. The control group itself experiences tax rate changes in 2010-11, though they are of a considerably smaller magnitude. Panel A illustrates the log number of firms in the treatment and control groups that report taxable earnings $\in(0650 \mathrm{k}]$ (positive filers); Panel $B$, along with the treated positive filers, shows the number of treated firms with taxable earnings $\in[0650 \mathrm{k}]$. Panel $C$ plots the corresponding two series for the control group. Panel $D$ reports the month-wise registrations of new partnership firms. Panel $\mathrm{E}$ and $\mathrm{F}$ compare the treated positive filers series and the counterfactuals obtained from the two alternative approaches: for Panel E, the counterfactual is obtained by running a DD regression on the two series in Panel A with separate linear time trends for the treatment and control groups; for Panel F, the number of filers in 2008 is assumed to be the counterfactual for the post-reform periods. The difference between the counterfactual and observed number of filers for year $t$ as a percentage of counterfactual filers for the corresponding year are denoted by $\Delta m_{t}$. 


\section{G: Observed and Counterfactual Taxable Income Distribution (2009)}

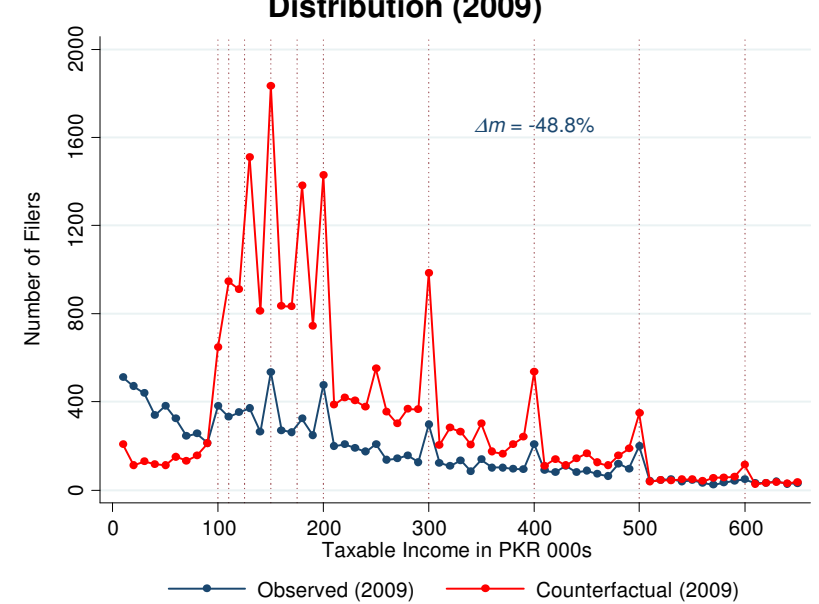

I: Observed and Counterfactual Taxable Income Distribution (2010)

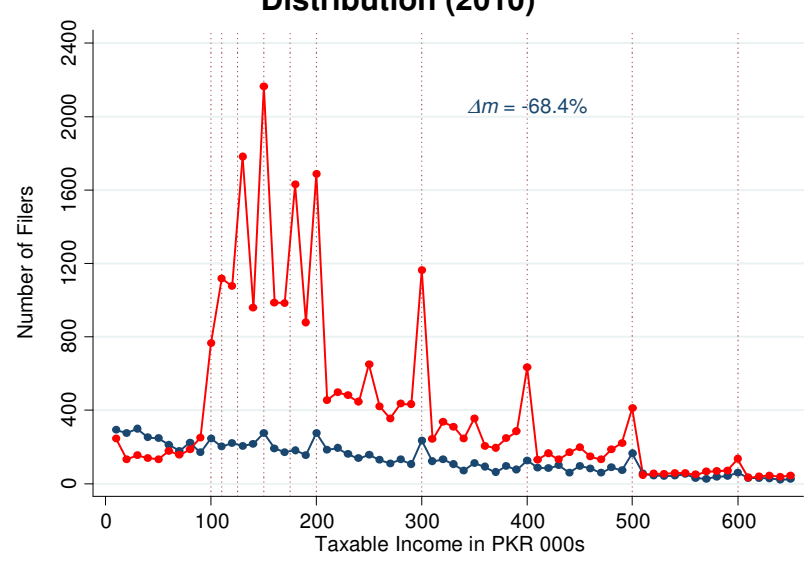

K: Observed and Counterfactual Taxable Income Distribution (2011)

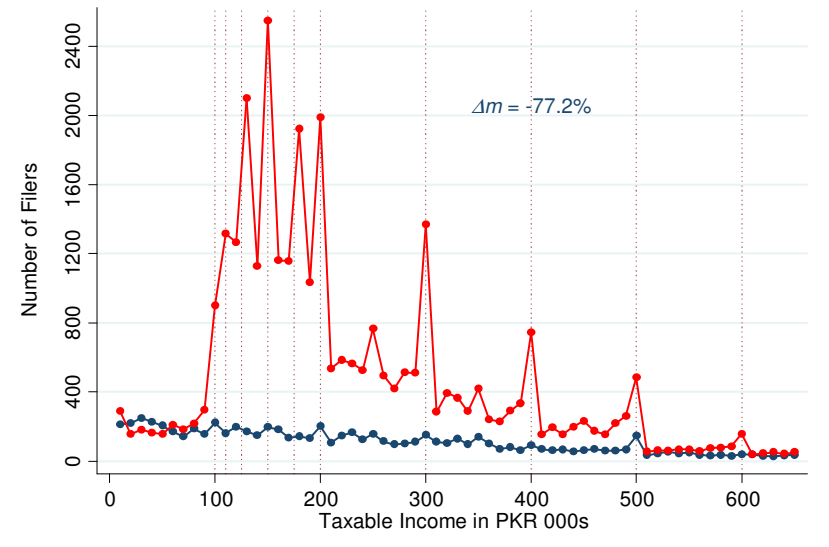

— Observed (2011) — Counterfactual (2011)
H: Observed (stripped of intensive response) and
Counterfactual Taxable Income Distribution (2009)

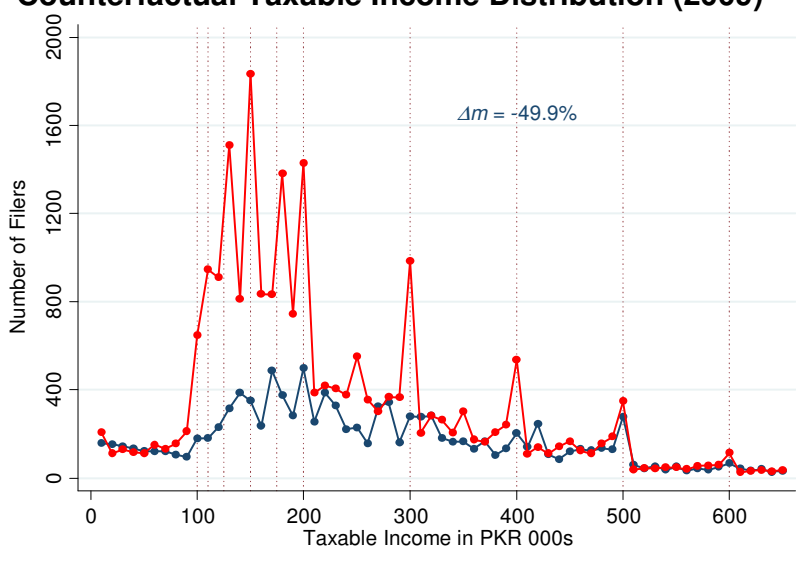

$\longrightarrow$ Observed w/o int. response (2009) —— Counterfactual (2009)

$\mathrm{J}$ : Observed (stripped of intensive response) and Counterfactual Taxable Income Distribution (2010)

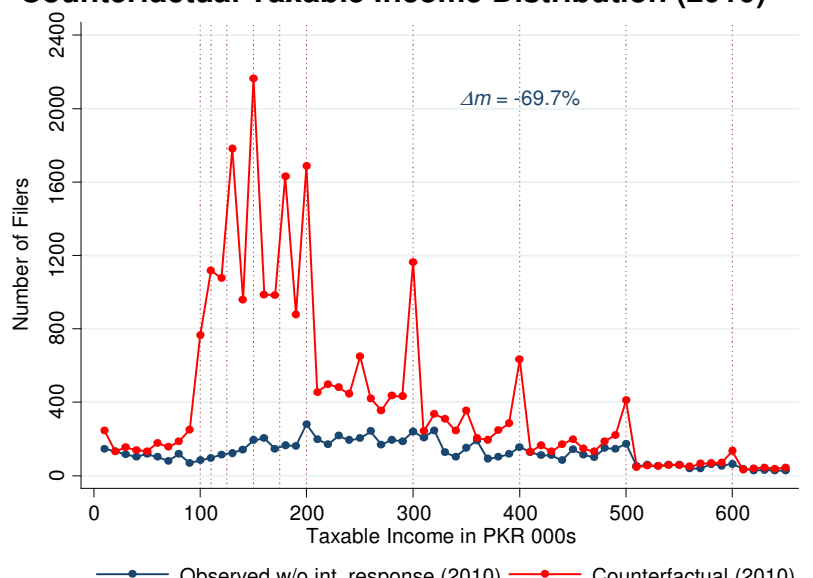

L: Observed (stripped of intensive response) and Counterfactual Taxable Income Distribution (2011)

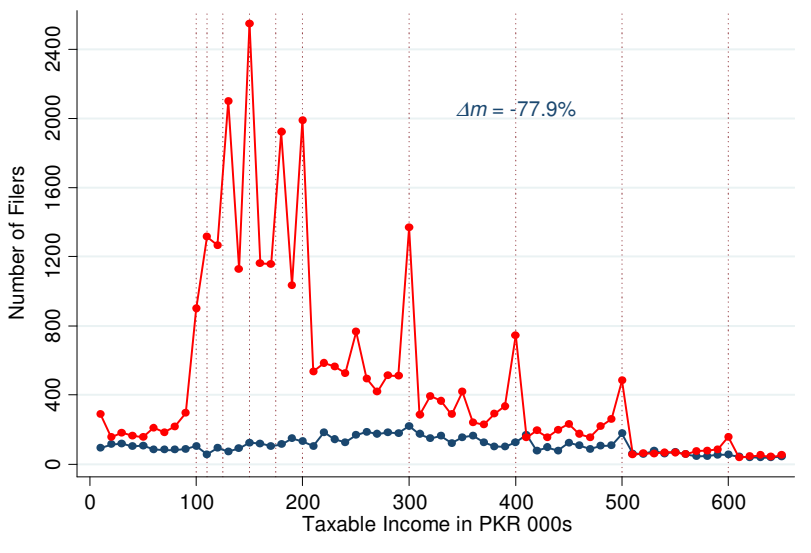

Notes: the figure displays the strategy for estimating the extensive margin response of partnership firms. Left panels illustrate the observed and counterfactual taxable income distributions of partnership firms in the post-reform periods 2009-11. The counterfactual distributions are obtained by shifting the 2008 distribution upwards proportionally to have the same mass as predicted by the DD counterfactual in Panel E of the figure. Right panels of the figure also compare the observed and counterfactual distributions of treated firms, but here the observed distributions have been stripped of intensive responses. The difference in filing between the two distributions as a percentage of the number of counterfactual filers is denoted by $\Delta m$. 


\section{Effects of the Tax Reform on Partners - Overall Response}

A: Partnership Income - Before the Reform

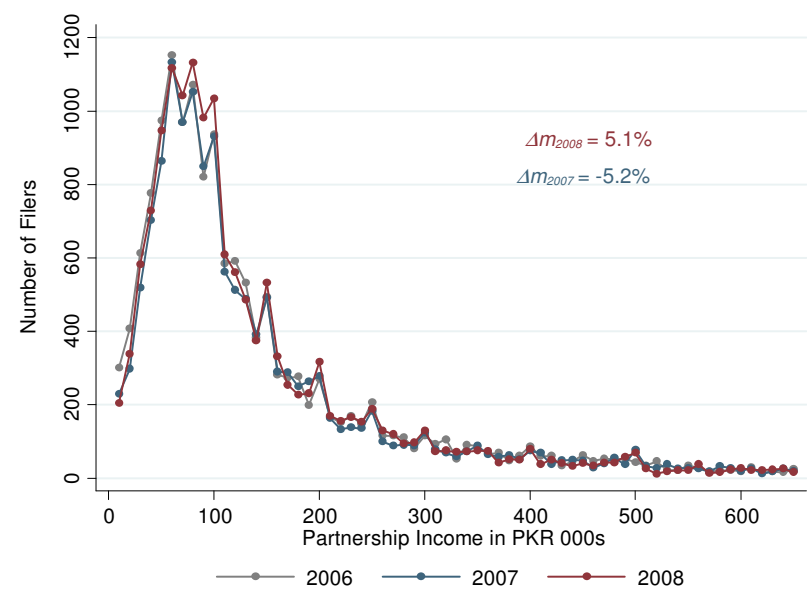

C: Sole Proprietorship Income - Before the Reform

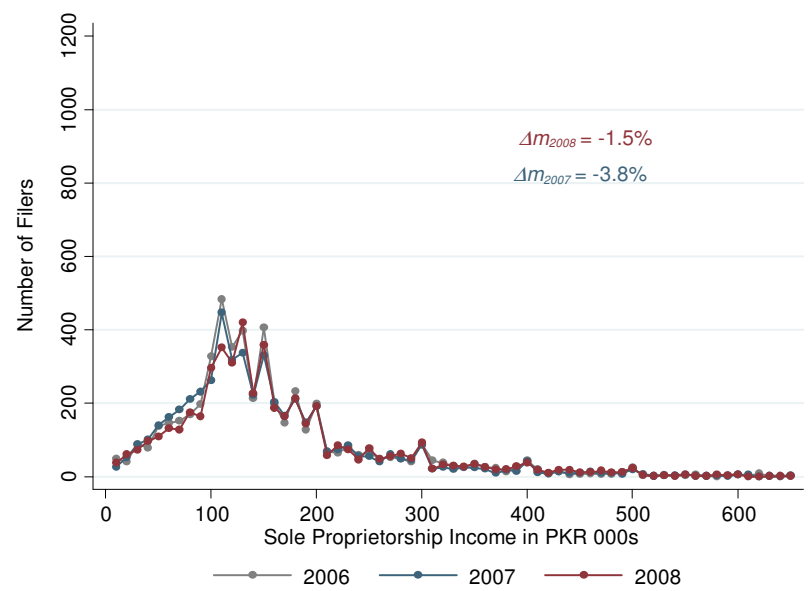

E: Taxable Income - Before the Reform

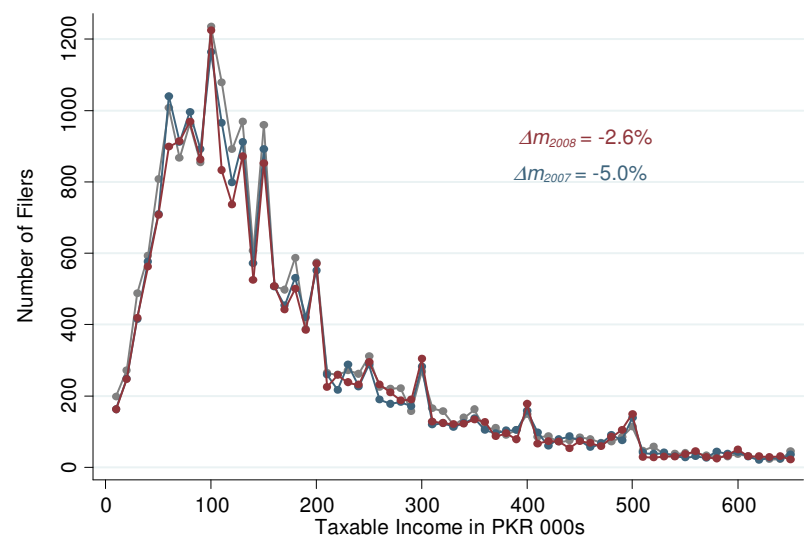

B: Partnership Income - After the Reform (Own Price Effect)

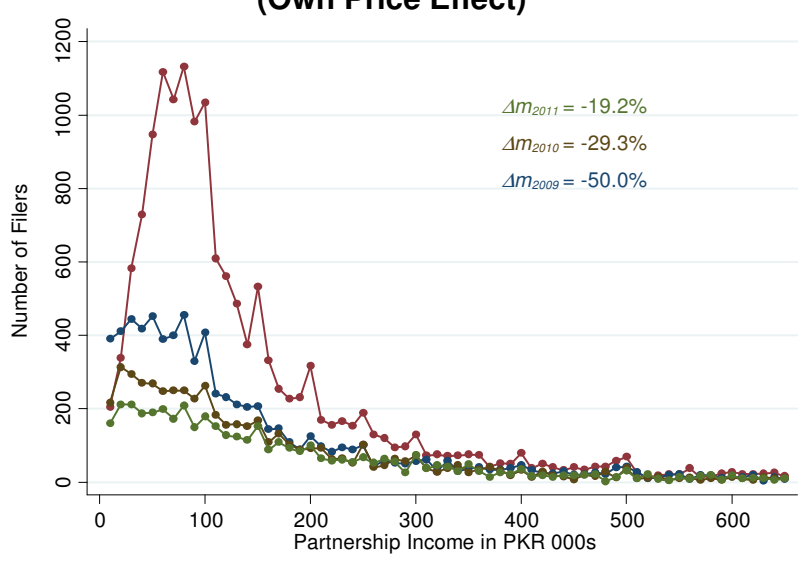

D: Sole Proprietorship Income - After the Reform

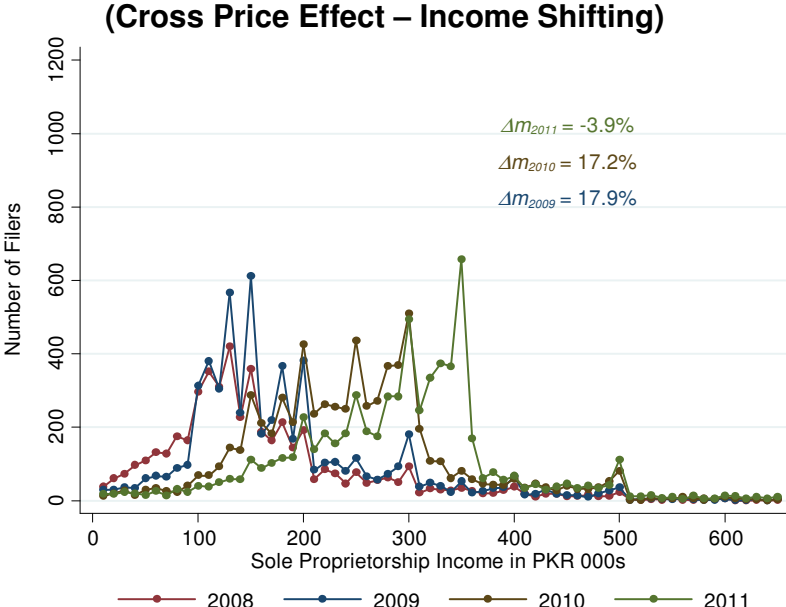

F: Taxable Income - After the Reform (Overall Effect Net of Income Shifting)

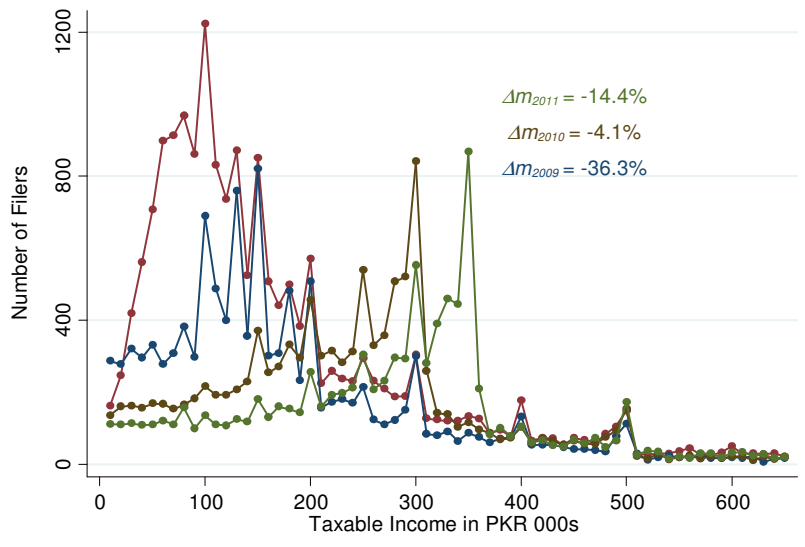

Notes: the figure shows the density distribution of taxable income and its constituent components - partnership earnings and sole proprietorship earnings - reported by owners of partnership firms. Left panels illustrate the prereform empirical densities, while the right panels plot the corresponding post-reform densities. Panels $A$ and $B$ reflect the own-price effect produced by the tax rate rise on partnership earnings. Panels $C$ and $D$ show the crossprice effect or income shifting to tax-favored sole proprietorship base. Panel $E$ and $F$ display the aggregate earnings effect produced by the tax changes. Each dot in the figure represents the upper bound of a PKR 10,000 bin and denotes the number of tax filers located within that bin. Yearly changes in tax filing are shown by $\Delta m_{t}$, which is calculated as the change in the number of filers between years $t$ and $t+1$ as a percentage of filers in year 
A: Partnership Income Response (Own Price Effect)

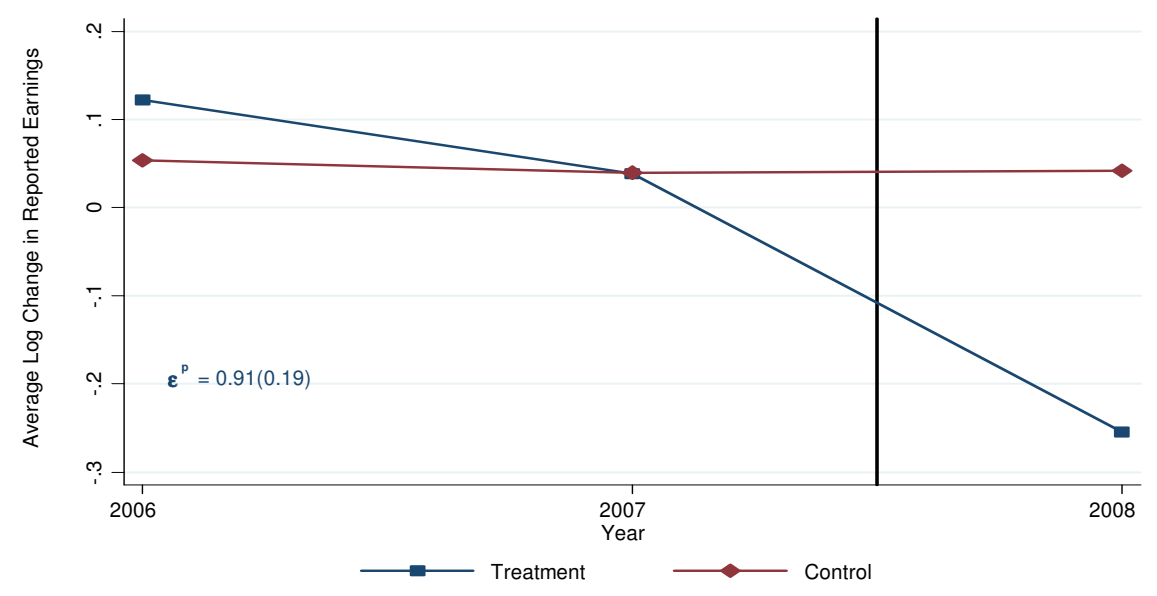

B: Sole Proprietorship Income Response (Cross Price Effect - Income Shifting)

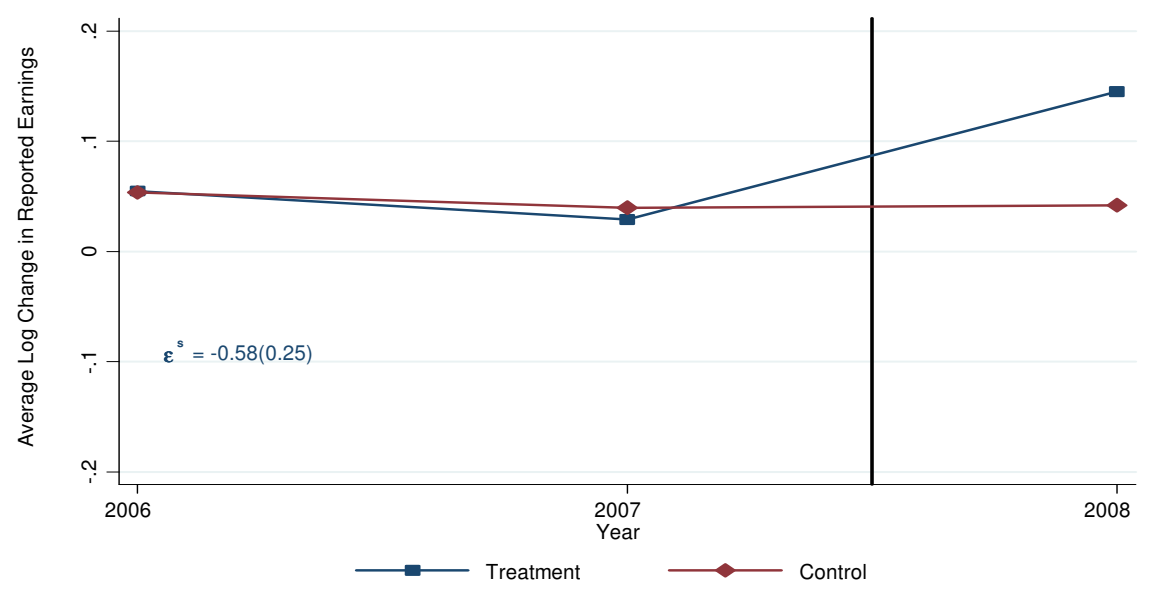

C: Taxable Income Response (Under-reporting Net of Income Shifting)

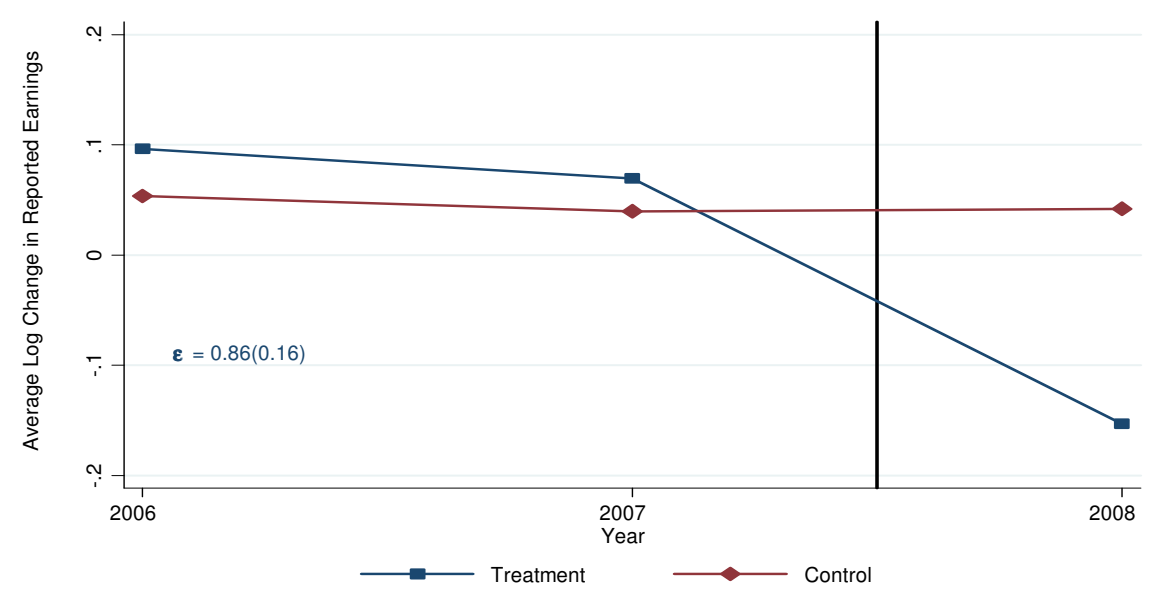

Notes: the figure examines the intensive margin response of the owners of partnership firms. Panels $A, B$ and $C$ illustrate the evolution of partnership income, sole proprietorship income and aggregate taxable income reported by the owners in their personal income tax returns. The treatment group comprises the individuals who report positive partnership income in all the three years prior to the reform, while the control group constitutes the individuals who report zero partnership income in all the years. As the control group itself experiences tax changes in 2010, the sample is restricted to a balanced panel of taxpayers who file in all the four years 2006-09. Each point in the plots represents log change in reported income of the respective type from year $t$ to $t+1$ for individual $i$ averaged over all such individuals in year $t$. The black vertical line in each panel indicates the time from which the tax changes affect reporting behavior of the treated taxpayers. The elasticities reported in the figure are from 2SLS DD regressions where log change in net-of-tax rate has been instrumented with the dummy for belonging to the postreform, treatment group. Standard errors are in parenthesis, which are clustered at the individual level. 


\section{Effects of the Tax Reform on Partners - Extensive Margin}

\section{A: Informality Response Net of Income Shifting}

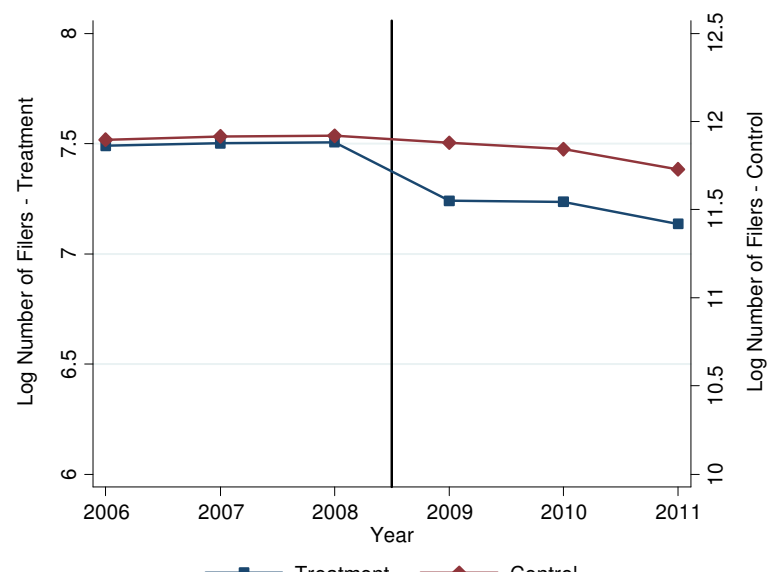

C: Aggregate Response

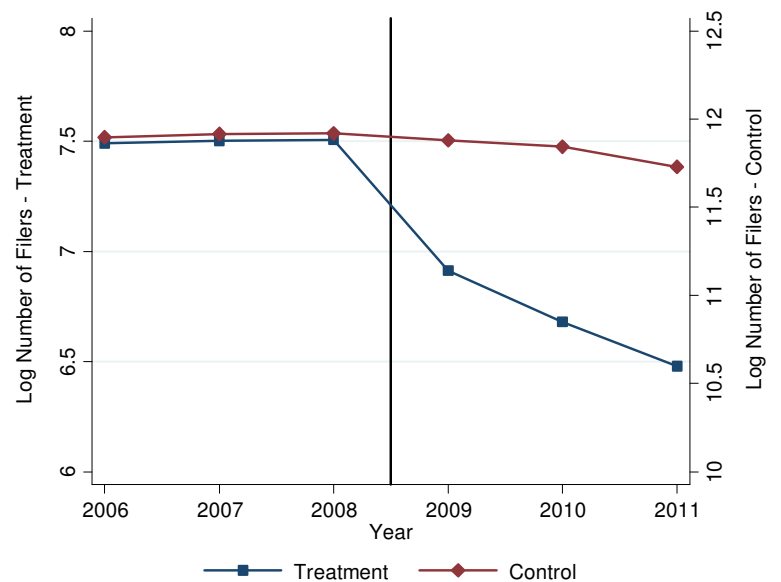

B: Informality Response Net of Income Shifting

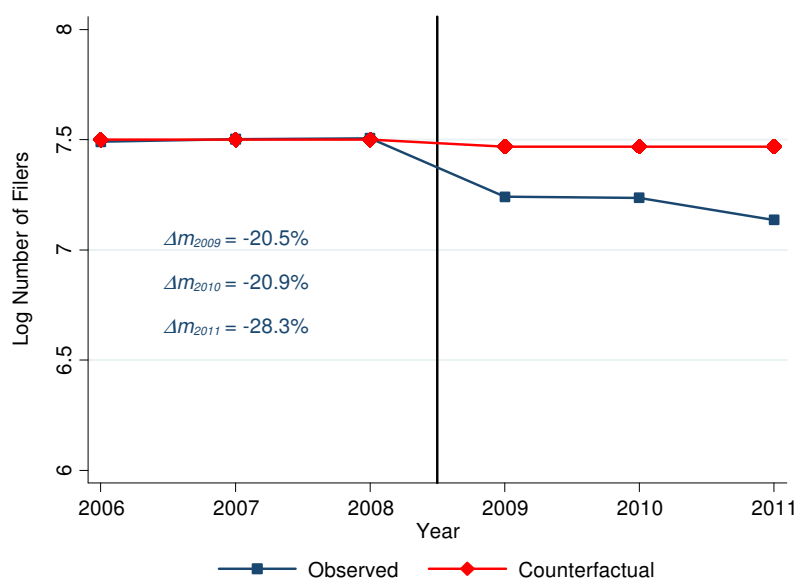

D: Aggregate Response

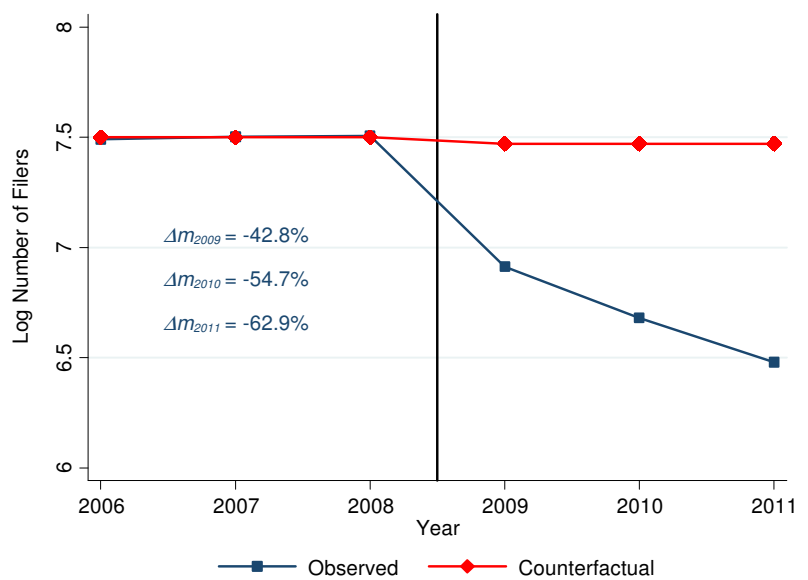

Notes: the figure illustrates the extensive margin responses of the owners of partnership firms. To track the same taxpayers over time, the sample is restricted to a balanced panel of individuals who file in all the six years 2006-11 and report earning $\in[0650 \mathrm{k}]$. The treatment group comprises the individuals who report positive partnership earnings in all the three pre-reform periods (2006-08), while the control group constitutes the individuals who report zero partnership earnings in all the years. Panel A depicts the log number of tax filers in the treatment and control groups who report positive taxable earnings in years 2006-11. Panel B shows such filers in the treatment group along with a counterfactual obtained from a DD regression on the two series in Panel A. The differences between the counterfactual and observed number of filers in year $t$ as a percentage of the counterfactual filers for the corresponding year are indicated with $\Delta m_{t}$. To explore switching of business organization from partnership to sole proprietorship form, Panels $C$ and $D$ repeat the analysis but regard the treated individuals as filers only if they report positive partnership income in year $t$. The difference between the observed number of filers shown in Panel D and Panel B are the owners of partnership firms which switched their business organization to tax-favored sole proprietorships. 


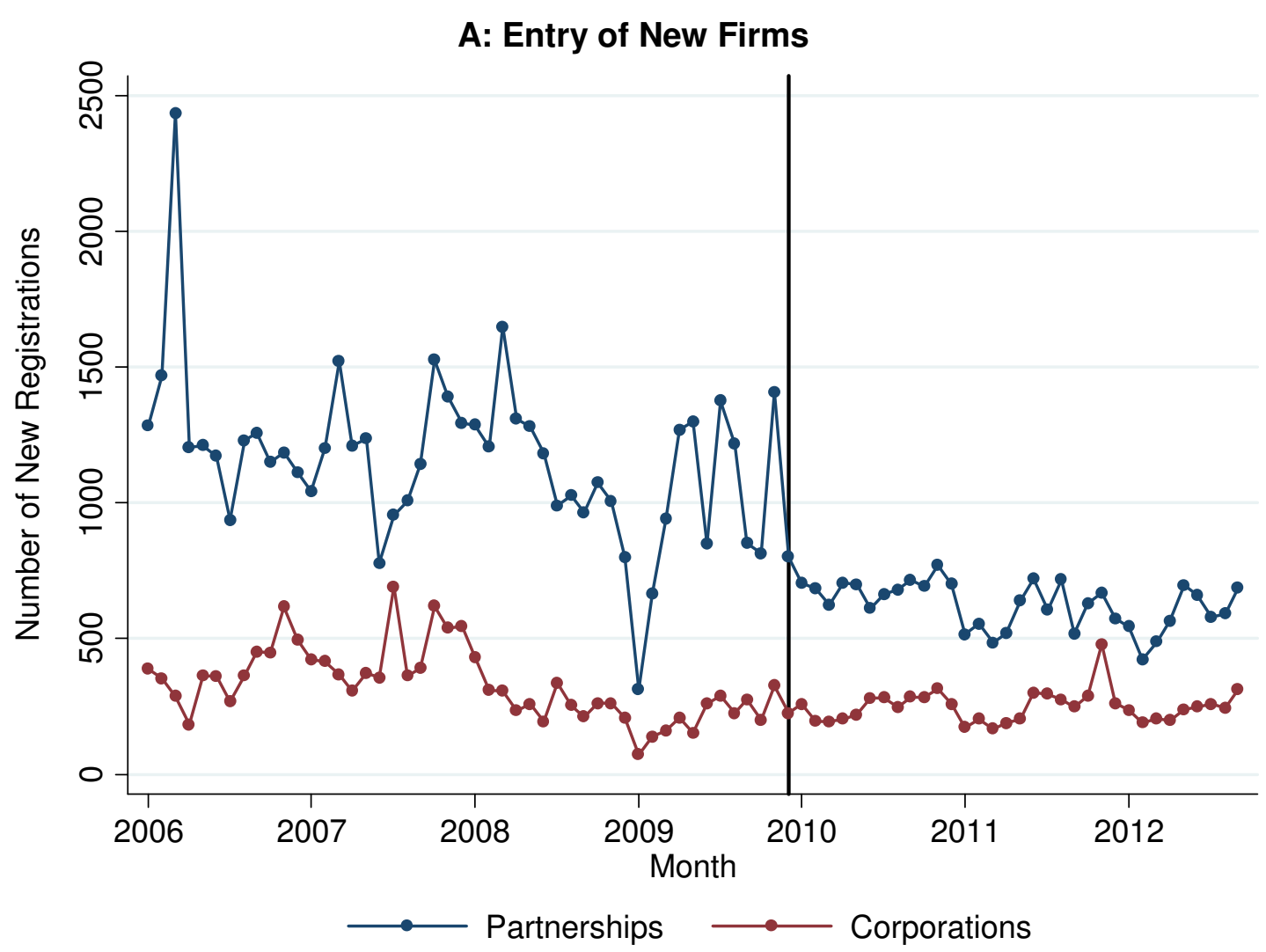

B: Taxable Income Distribution of Corporate Firms

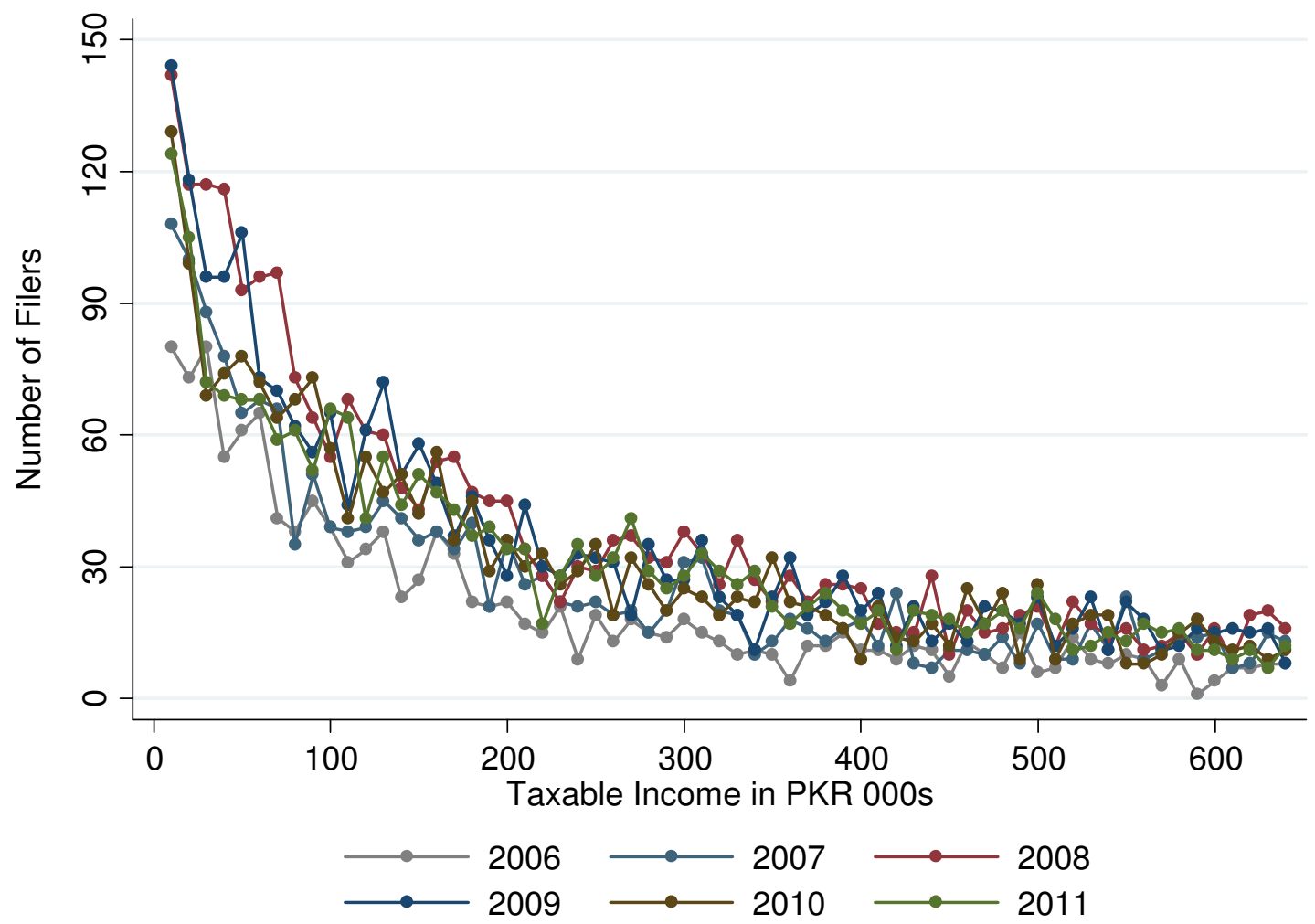

Notes: the figure explores income shifting to corporate tax base. Panel A compares the entry of new partnership and corporate firms: each dot in the plot denotes the number of new firms that register with the tax department in a given calendar month. Year $t$ on the $\mathrm{x}$-axis represents the first month of the tax year $t$ (July), and the solid vertical line indicates the month from which the tax changes take effect. To examine the changes in the stock of corporate firms, Panel B of the figure plots the empirical density distributions of taxable income reported by such firms in 2006-11. Each dot in the plots denotes the upper bound of a PKR 10,000 bin, and shows the number of firms that report taxable earnings within that bin. 
A: Partnership Firms Registered for VAT

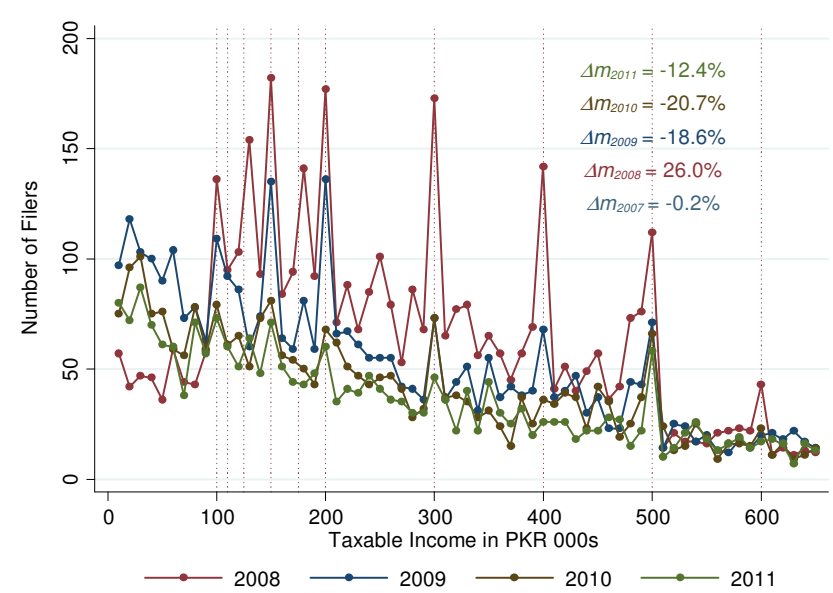

B: Partnership Firms Not Registered for VAT

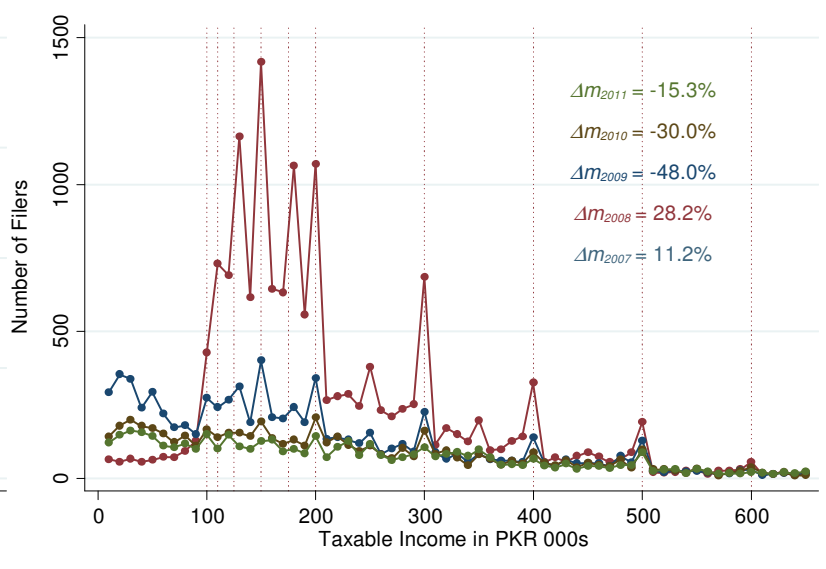

D: Sole Proprietorship Firms Not Registered for VAT

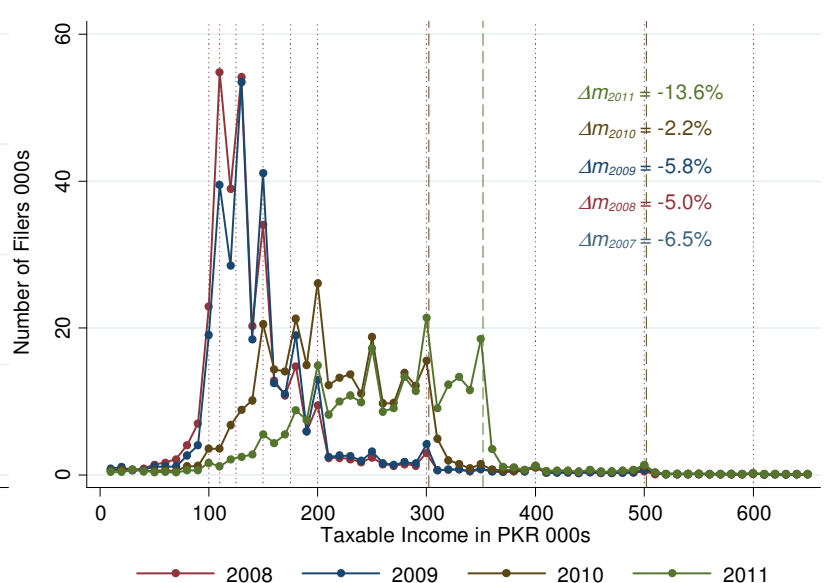

Notes: the figure illustrates the spillover effects created by the reform on VAT base. Panels $A$ and $C$ depict taxable income distributions of VAT-registered firms, while Panels $B$ and D demonstrate the corresponding distributions of firms not registered for VAT. Each dot in the plots represents the upper bound of a PKR 10,000 bin, and shows the number of firms that report taxable earnings within that bin. The notches in the 2006-08 schedule are denoted by the vertical dotted red lines. The dashed vertical lines demarcate at PKR 300,000 and 350,000 the exemption threshold in 2010 and 2011 and at PKR 500,000 the notch in post-reform schedule in 2010-11. Yearly changes in tax filing are shown by $\Delta m_{t}$, which is calculated as the change in the number of filers between years $t$ and $t+1$ as a percentage of filers in year $t$. The empirical distributions for the years 2006-07 are not shown, but yearly changes in filing for these years are included. 


\section{A: Partnership Firms Registered for VAT}

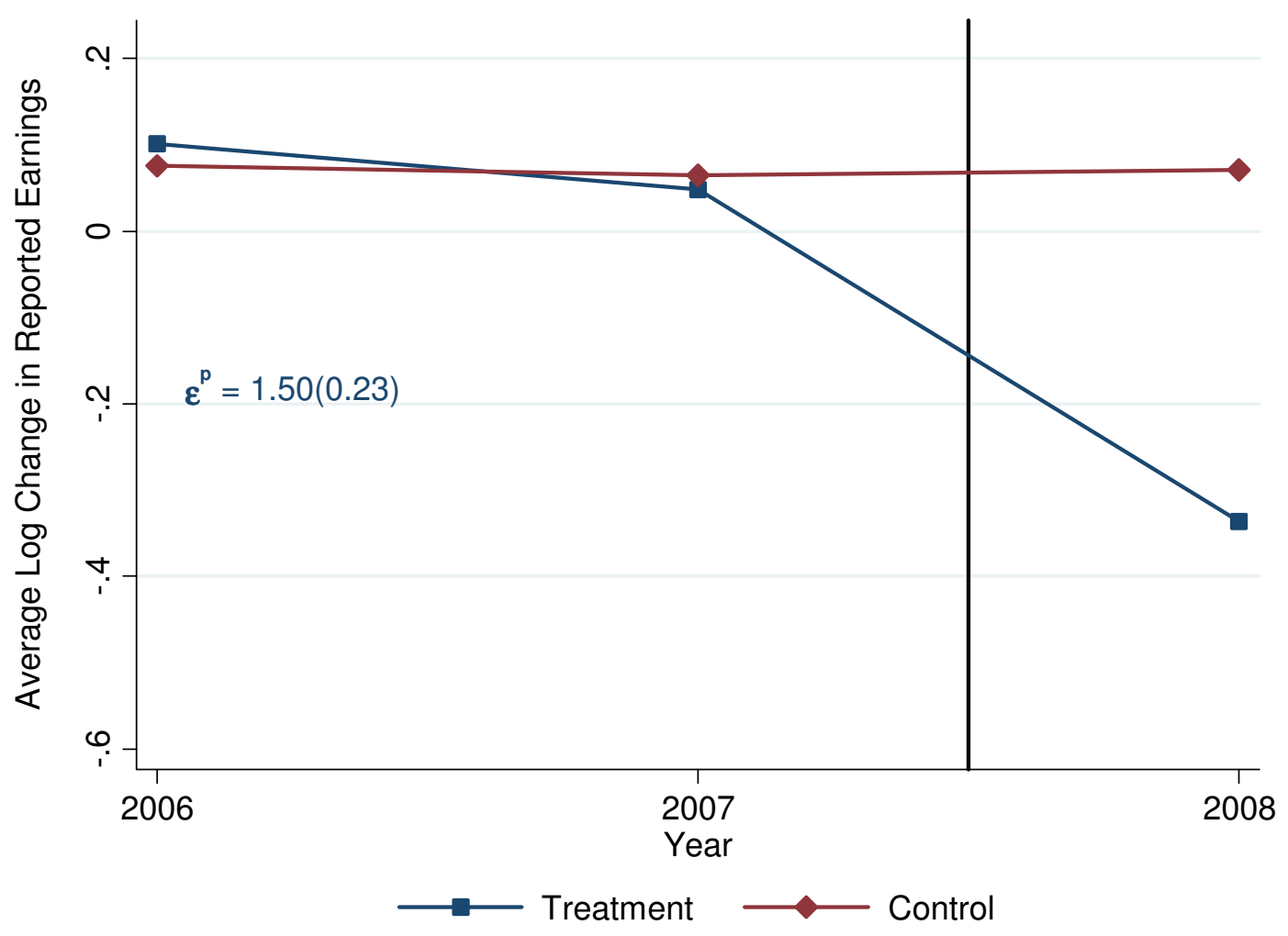

\section{B: Partnership Firms Not Registered for VAT}

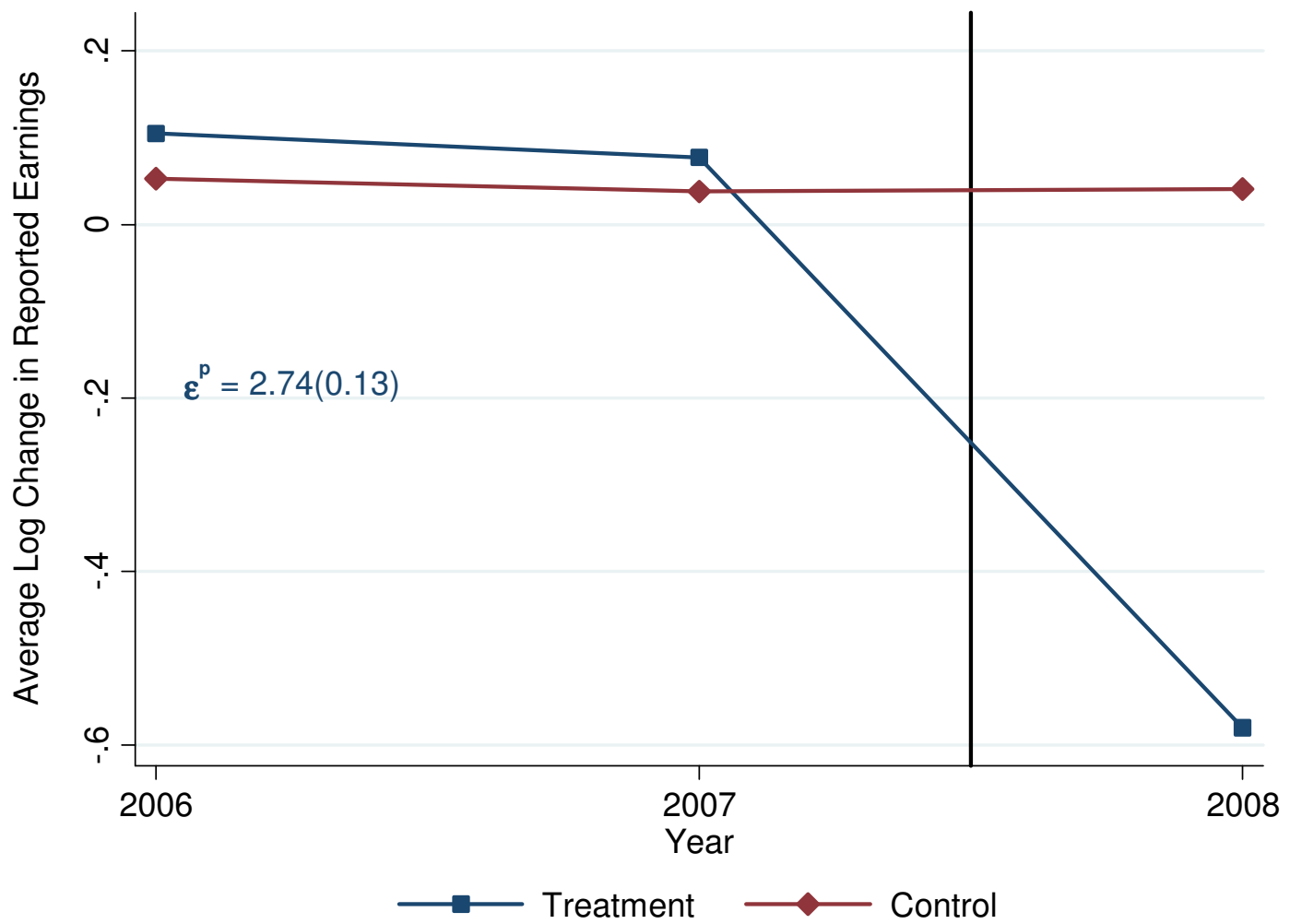

Notes: the figure illustrates the breakdown of partnership firms' intensive margin responses by their VAT registration status. The sample for the analysis is restricted to a balanced panel of firms that file in all four years (2006-09). The treatment group in Panels A and B consist respectively of VAT-registered and VAT-unregistered partnership firms, while control group comprises the corresponding sole proprietorship firms. Each point in the plots represents the log change in reported earnings from year $t$ to $t+1$ for firm $i$ averaged over all firms in year $t$. Black vertical line in each panel indicates the time from which the tax changes affect reporting behavior of the treated firms. 


\section{A: Partnership Firms Registered for VAT}

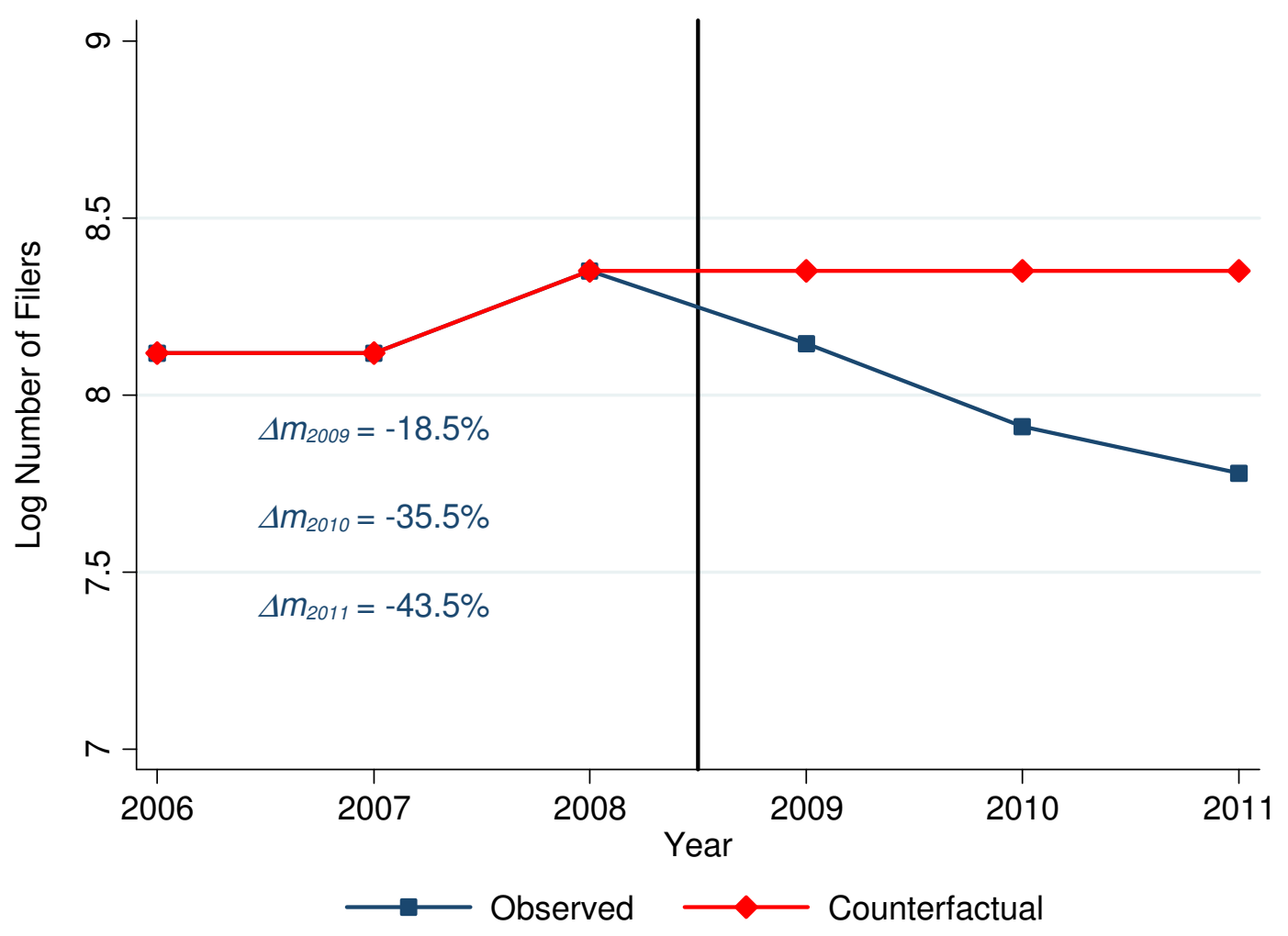

\section{B: Partnership Firms Not Registered for VAT}

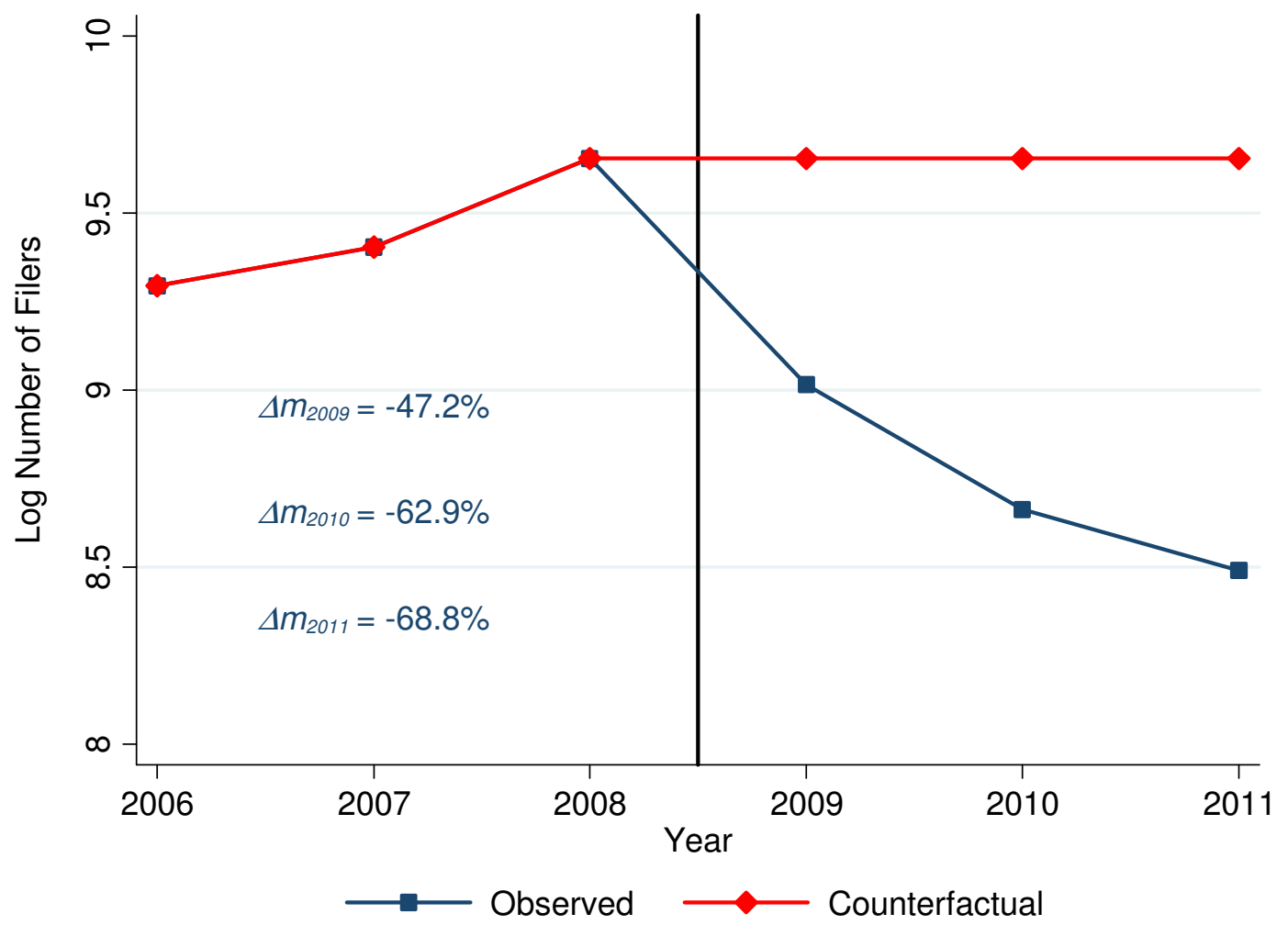

Notes: the figure demonstrates the breakdown of partnership firms' extensive margin responses by their VAT registration status. Panel A shows the log number of partnership firms registered for VATs that report positive taxable earnings in 2006-11 along with a counterfactual which assumes that the number of such firms would have stayed at the pre-reform level had there been no tax change. The difference between the counterfactual and observed number of filers for year $t$ as a percentage of the counterfactual number of filers for the corresponding year are denoted with $\Delta m_{t}$. Panels $\mathrm{B}$ repeats the analysis for partnership firms not registered for VAT. 
Table I

Size and Dynamics of Partnership Tax Penalty

\begin{tabular}{|c|c|c|}
\hline Year & $\begin{array}{l}\text { Partnership Tax Penalty } \\
\text { (PKR) }\end{array}$ & $\begin{array}{c}\text { Partnership Tax Penalty } \\
\text { (Percentage of Taxable Income) }\end{array}$ \\
\hline (1) & (2) & (3) \\
\hline 2006 & $\begin{array}{c}7,886 \\
(15,118)\end{array}$ & $\begin{array}{c}4.1 \\
(4.7)\end{array}$ \\
\hline 2007 & $\begin{array}{c}6,747 \\
(13,149)\end{array}$ & $\begin{array}{l}3.7 \\
(4.1)\end{array}$ \\
\hline 2008 & $\begin{array}{c}6,074 \\
(12,228)\end{array}$ & $\begin{array}{c}3.7 \\
(4.0)\end{array}$ \\
\hline 2009 & $\begin{array}{c}22,246 \\
(18,030)\end{array}$ & $\begin{array}{l}16.5 \\
(9.3)\end{array}$ \\
\hline 2010 & $\begin{array}{c}28,495 \\
(24,457)\end{array}$ & $\begin{array}{l}15.4 \\
(9.8)\end{array}$ \\
\hline 2011 & $\begin{array}{c}31,467 \\
(26,675)\end{array}$ & $\begin{array}{c}14.8 \\
(10.1)\end{array}$ \\
\hline
\end{tabular}

Notes: the table presents the estimates of the size and dynamics of the partnership tax penalty. For a taxpayer $i$ who reports a sum $x$ as partnership earnings, the penalty represents the additional tax liability that $i$ experiences in reporting $x$ as partnership earnings rather than sole proprietorship earnings. Column (2) presents the yearly average value of the penalty experienced by individuals who report positive partnership earnings in 2006-11. Column (3) shows the average penalty weighted by taxable income. Standard errors are in parenthesis. 


\section{Table II}

Intensive Margin Elasticities for Partnership Firms

\begin{tabular}{|c|c|c|c|c|c|c|}
\hline \multirow{3}{*}{$\begin{array}{l}\text { Taxable income } \\
\text { ( } \leq)\end{array}$} & \multicolumn{3}{|c|}{ Unbalanced Panel } & \multicolumn{3}{|c|}{ Balanced Panel } \\
\hline & \multicolumn{2}{|c|}{ \# Obs } & \multirow{2}{*}{$\varepsilon^{p}$} & \multicolumn{2}{|c|}{ \# Obs } & \multirow{2}{*}{$\varepsilon^{p}$} \\
\hline & Control & Treatment & & Control & Treatment & \\
\hline (1) & $(2)$ & (3) & (4) & (5) & (6) & (7) \\
\hline 250,000 & 779,124 & 19,438 & $\begin{array}{l}2.306 \\
(0.089)\end{array}$ & 484,374 & 3,915 & $\begin{array}{r}2.939 \\
(0.157)\end{array}$ \\
\hline 350,000 & 806,825 & 24,260 & $\begin{array}{l}2.246 \\
(0.077)\end{array}$ & 514,740 & 6,054 & $\begin{array}{r}2.671 \\
(0.129)\end{array}$ \\
\hline 450,000 & 816,231 & 27,068 & $\begin{array}{l}2.169 \\
(0.073)\end{array}$ & 525,264 & 7,503 & $\begin{array}{c}2.604 \\
(0.121)\end{array}$ \\
\hline 550,000 & 820,477 & 28,798 & $\begin{array}{l}2.115 \\
(0.073)\end{array}$ & 530,631 & 8,670 & $\begin{array}{r}2.495 \\
(0.119)\end{array}$ \\
\hline 650,000 & 821,916 & 29,538 & $\begin{array}{c}2.073 \\
(0.073)\end{array}$ & 531,975 & 9,207 & $\begin{array}{c}2.402 \\
(0.121)\end{array}$ \\
\hline
\end{tabular}

Notes: the table presents intensive margin elasticity estimates from 2SLS regressions. The sample for the analysis includes the partnership (treatment) and sole proprietorship firms (control) in Pakistan that report taxable earnings in the interval indicated in column (1). Column (4) and (7) illustrate the coefficients on log change in net-of-tax rate in differences-in-differences regressions, where log change in net-of-tax rate has been instrumented in the first stage with a dummy for belonging to the post-reform treatment group. The sample for columns (2) to (4) comprises the firms that report for two consecutive years $t$ and $t+1$ and for columns (5) to (7) the firms that report for all four years in the sample (2006-09). Standard errors are in parenthesis, which are clustered at the level of firm. All coefficients are significant at $1 \%$ level. 


\section{Table III}

Extensive Margin Elasticities for Partnership Firms

\begin{tabular}{|c|c|c|c|c|c|c|c|c|c|}
\hline \multirow[b]{2}{*}{$\begin{array}{c}\text { Taxable } \\
\text { Income } \\
(000 \mathrm{~s})\end{array}$} & \multicolumn{3}{|c|}{2009} & \multicolumn{3}{|c|}{2010} & \multicolumn{3}{|c|}{2011} \\
\hline & $\begin{array}{c}\text { Observed Distribution } \\
\text { Stripped of Intensive } \\
\text { Response } \\
\text { (\#Obs) }\end{array}$ & $\begin{array}{l}\text { Counterfactual } \\
\text { Distribution } \\
\text { (\#Obs) }\end{array}$ & $\eta^{p}$ & $\begin{array}{l}\text { Observed Distribution } \\
\text { Stripped of Intensive } \\
\text { Response } \\
\text { (\#Obs) }\end{array}$ & $\begin{array}{l}\text { Counterfactual } \\
\text { Distribution } \\
\text { (\#Obs) }\end{array}$ & $\eta^{p}$ & $\begin{array}{l}\text { Observed Distribution } \\
\text { Stripped of Intensive } \\
\text { Response } \\
\text { (\#Obs) }\end{array}$ & $\begin{array}{l}\text { Counterfactual } \\
\text { Distribution } \\
\text { (\#Obs) }\end{array}$ & $\eta^{p}$ \\
\hline (1) & (2) & (3) & $(4)$ & (5) & (6) & (7) & (8) & (9) & $(10)$ \\
\hline \multicolumn{10}{|c|}{ A: Linear Trend as Counterfactual } \\
\hline $0-200$ & 4,679 & 13,221 & $\begin{array}{c}\mathbf{2 . 4 3 8} \\
(0.222)\end{array}$ & 2,678 & 15,586 & $\begin{array}{c}3.125 \\
(0.260)\end{array}$ & 2,016 & 18,374 & $\begin{array}{c}3.360 \\
(0.314)\end{array}$ \\
\hline $200-300$ & 2,688 & 4,518 & $\begin{array}{c}1.716 \\
(0.279)\end{array}$ & 2,004 & 5,326 & $\begin{array}{c}2.643 \\
(0.238)\end{array}$ & 1,664 & 6,279 & $\begin{array}{c}3.114 \\
(0.263)\end{array}$ \\
\hline $300-400$ & 1,810 & 2,581 & $\begin{array}{c}1.486 \\
(0.341)\end{array}$ & 1,482 & 3,043 & $\begin{array}{c}2.552 \\
(0.299)\end{array}$ & 1,372 & 3,587 & $\begin{array}{c}3.072 \\
(0.289)\end{array}$ \\
\hline $400-500$ & 1,497 & 1,597 & $\begin{array}{c}0.407 \\
(0.300)\end{array}$ & 1,249 & 1,883 & $\begin{array}{c}2.186 \\
(0.330)\end{array}$ & 1,129 & 2,220 & $\begin{array}{c}3.191 \\
(0.360)\end{array}$ \\
\hline \multicolumn{10}{|c|}{ B: Pre-reform Level as Counterfactual (Lower Bound) } \\
\hline $0-200$ & 4,679 & 11,521 & $\begin{array}{c}\mathbf{2 . 2 4 1} \\
(0.220)\end{array}$ & 2,678 & 11,521 & $\begin{array}{c}2.896 \\
(0.258)\end{array}$ & 2,016 & 11,521 & $\begin{array}{c}3.113 \\
(0.310)\end{array}$ \\
\hline $200-300$ & 2,688 & 3,937 & $\begin{array}{c}1.344 \\
(0.279)\end{array}$ & 2,004 & 3,937 & $\begin{array}{c}2.080 \\
(0.238)\end{array}$ & 1,664 & 3,937 & $\begin{array}{c}2.446 \\
(0.263)\end{array}$ \\
\hline $300-400$ & 1,810 & 2,249 & $\begin{array}{c}\mathbf{0 . 9 7 1} \\
(0.322)\end{array}$ & 1,482 & 2,249 & $\begin{array}{c}1.697 \\
(0.299)\end{array}$ & 1,372 & 2,249 & $\begin{array}{c}1.940 \\
(0.289)\end{array}$ \\
\hline $400-500$ & 1,497 & 1,392 & $\begin{array}{c}-0.49 \\
(0.300)\end{array}$ & 1,249 & 1,392 & $\begin{array}{c}\mathbf{0 . 6 6 7} \\
(0.330)\end{array}$ & 1,129 & 1,392 & $\begin{array}{c}1.227 \\
(0.360)\end{array}$ \\
\hline
\end{tabular}

Notes: the table presents extensive margin elasticity estimates for partnership firms. Column (3), (6) and (9) of the table show the number of tax filers in the counterfactual distribution - the distribution that would have observed in the absence of the tax changes. Columns (2), (5) and (7) of the table report the number of filers in the observed distribution stripped of intensive responses - the distribution that would have been observed had there been no response to the tax rate changes along the intensive margin. Estimates in Panels $\mathrm{A}$ and $\mathrm{B}$ are based on the two alternative approaches to estimate the counterfactual. Standard errors are in parenthesis and are obtained from the regressions of log difference in number of filers in $1 \mathrm{k}$ bins of the two distributions against log changes in net-of-tax rate experienced by the tax filers in that bin. Coefficients significant at $5 \%$ level are shown in bold. 
Table IV

Intensive Margin Elasticities for Partnership Firms by VAT Registration

\begin{tabular}{|c|c|c|c|c|c|c|}
\hline \multirow{3}{*}{$\begin{array}{l}\text { Taxable income } \\
\text { ( } \leq)\end{array}$} & \multicolumn{3}{|c|}{ Firms Not Registered for VAT } & \multicolumn{3}{|c|}{ Firms Registered for VAT } \\
\hline & \multicolumn{2}{|c|}{ \# Obs } & \multirow{2}{*}{$\varepsilon^{p}$} & \multicolumn{2}{|c|}{ \# Obs } & \multirow{2}{*}{$\varepsilon^{p}$} \\
\hline & Control & Treatment & & Control & Treatment & \\
\hline (1) & (2) & (3) & (4) & (5) & (6) & (7) \\
\hline 250,000 & 468,144 & 3,168 & $\begin{array}{c}3.191 \\
(0.169)\end{array}$ & 16,821 & 771 & $\begin{array}{c}1.922 \\
(0.381)\end{array}$ \\
\hline 350,000 & 493,236 & 4,638 & $\begin{array}{c}2.945 \\
(0.144)\end{array}$ & 22,134 & 1,425 & $\begin{array}{r}1.756 \\
(0.274)\end{array}$ \\
\hline 450,000 & 501,009 & 5,490 & $\begin{array}{c}2.885 \\
(0.136)\end{array}$ & 24,945 & 2,019 & $\begin{array}{r}1.764 \\
(0.244)\end{array}$ \\
\hline 550,000 & 504,501 & 6,180 & $\begin{array}{c}\mathbf{2 . 7 7 1} \\
(0.132)\end{array}$ & 26,868 & 2,493 & $\begin{array}{r}1.723 \\
(0.225)\end{array}$ \\
\hline 650,000 & 505,317 & 6,414 & $\begin{array}{l}2.747 \\
(0.133)\end{array}$ & 27,393 & 2,799 & $\begin{array}{c}1.502 \\
(0.232)\end{array}$ \\
\hline
\end{tabular}

Notes: the table presents intensive margin elasticity estimates from 2SLS regressions. Sample has been stratified by VATregistration, and includes the partnership (treatment) and sole proprietorship (control) firms that file in all four years 2006-09 and report taxable earnings in the interval indicated in column (1). Column (4) and (7) report the coefficients on log change in net-of-tax rate in differences-in-differences regressions, where log change in net-of-tax rate has been instrumented in the first stage with a dummy for belonging to the post-reform treatment group. Standard errors are in parenthesis, which are clustered at the level of firm. All coefficients are significant at $1 \%$ level. 


\section{Table V}

Which Firms Respond to the Reform? Intensive Margin

\begin{tabular}{|c|c|c|c|c|c|c|c|c|}
\hline & \multicolumn{8}{|c|}{ Dependent Variable: Log Change in Reported Earnings } \\
\hline & (1) & (2) & (3) & (4) & (5) & (6) & (7) & (8) \\
\hline$\left.\Delta \ln \overline{(1-} \tau_{i t}\right)$ & $\begin{array}{c}2.404^{* * *} \\
(0.072)\end{array}$ & $\begin{array}{c}2.740^{* * *} \\
(0.090)\end{array}$ & $\begin{array}{c}2.121^{* * *} \\
(0.154)\end{array}$ & $\begin{array}{c}2.949^{* * *} \\
(0.085)\end{array}$ & $\begin{array}{c}2.568^{\star * *} \\
(0.078)\end{array}$ & $\begin{array}{c}2.808^{* * *} \\
(0.105)\end{array}$ & $\begin{array}{c}2.501^{* * *} \\
(0.085)\end{array}$ & $\begin{array}{c}2.924^{* * *} \\
(0.207)\end{array}$ \\
\hline$\left.\Delta \ln \overline{(1-} \tau_{i t}\right) \times$ Registered for VAT & & $\begin{array}{c}-1.097^{\star * *} \\
(0.142)\end{array}$ & & & & & & $\begin{array}{c}-0.659^{* * *} \\
(0.167)\end{array}$ \\
\hline$\left.\Delta \ln \overline{(1-} \tau_{i t}\right) \times$ Electronic Return Filer & & & $\begin{array}{l}0.348^{* *} \\
(0.171)\end{array}$ & & & & & $\begin{array}{c}0.744^{\star \star \star} \\
(0.218)\end{array}$ \\
\hline$\left.\Delta \ln \overline{(1-} \tau_{i t}\right) \times$ Tax Withholding & & & & $\begin{array}{c}-2.326^{\star \star *} \\
(0.130)\end{array}$ & & & & $\begin{array}{c}-2.031^{\star \star *} \\
(0.163)\end{array}$ \\
\hline$\left.\Delta \ln \overline{(1-} \tau_{i t}\right) \times$ Withholding Agent & & & & & $\begin{array}{c}-1.342^{* \star *} \\
(0.177)\end{array}$ & & & $\begin{array}{l}-0.077 \\
(0.247)\end{array}$ \\
\hline$\left.\Delta \ln \overline{(1-} \tau_{i t}\right) \times$ Large & & & & & & $\begin{array}{c}-1.591^{\text {** }} \\
(0.167)\end{array}$ & & $\begin{array}{c}-1.068^{\star \star \star} \\
(0.212)\end{array}$ \\
\hline$\Delta \ln \left(\overline{(1-} \tau_{i t}\right) \times$ Age & & & & & & & $\begin{array}{c}-0.385^{\star *} \\
(0.155)\end{array}$ & $\begin{array}{c}-0.419^{\star \star} \\
(0.182)\end{array}$ \\
\hline R-squared & 0.027 & 0.028 & 0.027 & 0.031 & 0.027 & 0.029 & 0.027 & 0.034 \\
\hline Observations & 540,705 & 540,705 & 540,705 & 540,705 & 540,705 & 418,716 & 522,126 & 410,247 \\
\hline
\end{tabular}

Notes: the table explores the heterogeneity in intensive margin response across firms. Columns (1) - (8) present the coefficients on log change in net-of-tax rate interacted with various firm characteristics in differences-in-differences regressions, where log change in net-of-tax rate has been instrumented in the first stage with a dummy for belonging to the post-reform treatment group. The regressions are based on a balanced panel sample that comprises the partnerships (treatment) and sole proprietorships (control) that report taxable earnings in the interval (0 650k] in 200609. The coefficent reported in the first row captures the responsiveness of tax evasion to marginal tax rates. The estimates in subsequent rows reflect how the responsiveness varies with firm observables. Details of the firm characteristics variables are given in Appendix A. Standard errors are in parenthesis, which are clustered at the level of firm. ${ }^{*},{ }^{* *},{ }^{* * *}$ represent statistical significance at the $10 \%, 5 \%$, and $1 \%$ percent levels respectively. 
Table VI

Which Firms Respond to the Reform? Extensive Margin

\begin{tabular}{|c|c|c|c|c|}
\hline & \multicolumn{4}{|c|}{ Dependent Variable: $1\left(z_{t}=0 \mid z_{2008}>0\right)$} \\
\hline & 2009 & 2010 & 2011 & All \\
\hline & $(1)$ & (2) & (3) & (4) \\
\hline Registered for VAT & $\begin{array}{c}-0.0969^{* * *} \\
(0.0125)\end{array}$ & $\begin{array}{c}-0.1350^{* \star *} \\
(0.0126)\end{array}$ & $\begin{array}{c}-0.0863^{* * *} \\
(0.0127)\end{array}$ & $\begin{array}{c}-0.0712^{\star * *} \\
(0.0119)\end{array}$ \\
\hline Electronic Return Filer & $\begin{array}{c}-0.3349^{\star * \star} \\
(0.0121)\end{array}$ & $\begin{array}{c}-0.2861^{\star \star \star} \\
(0.0095)\end{array}$ & $\begin{array}{c}-0.2521^{\star * *} \\
(0.0087)\end{array}$ & $\begin{array}{c}-0.2042^{\star \star \star} \\
(0.0074)\end{array}$ \\
\hline Withholding Tax Quartile 2 & $\begin{array}{c}0.0376^{* * *} \\
(0.0140)\end{array}$ & $\begin{array}{l}0.0239^{*} \\
(0.0127)\end{array}$ & $\begin{array}{l}0.0279^{* *} \\
(0.0123)\end{array}$ & $\begin{array}{c}0.0153 \\
(0.0112)\end{array}$ \\
\hline Withholding Tax Quartile 3 & $\begin{array}{c}-0.0693^{\star * \star} \\
(0.0142)\end{array}$ & $\begin{array}{c}-0.0658^{\star \star \star} \\
(0.0136)\end{array}$ & $\begin{array}{c}-0.0545^{\star \star *} \\
(0.0135)\end{array}$ & $\begin{array}{c}-0.0492^{\star \star *} \\
(0.0125)\end{array}$ \\
\hline Withholding Tax Quartile 4 & $\begin{array}{c}-0.1404^{* * *} \\
(0.0145)\end{array}$ & $\begin{array}{c}-0.1245^{\star \star *} \\
(0.0146)\end{array}$ & $\begin{array}{c}-0.0980^{* * *} \\
(0.0148)\end{array}$ & $\begin{array}{c}-0.0853^{\star * *} \\
(0.0139)\end{array}$ \\
\hline Withholding Agent & $\begin{array}{c}-0.0861^{* * *} \\
(0.0141)\end{array}$ & $\begin{array}{c}-0.0585^{\star * *} \\
(0.0155)\end{array}$ & $\begin{array}{c}-0.0867^{* * *} \\
(0.0161)\end{array}$ & $\begin{array}{c}-0.0597^{\star * *} \\
(0.0156)\end{array}$ \\
\hline Size Quartile 2 & $\begin{array}{l}-0.0157 \\
(0.0135)\end{array}$ & $\begin{array}{l}-0.0096 \\
(0.0119)\end{array}$ & $\begin{array}{l}-0.0067 \\
(0.0115)\end{array}$ & $\begin{array}{l}-0.0066 \\
(0.0102)\end{array}$ \\
\hline Size Quartile 3 & $\begin{array}{c}-0.1227^{\star * *} \\
(0.0142)\end{array}$ & $\begin{array}{c}-0.1166^{\star * *} \\
(0.0134)\end{array}$ & $\begin{array}{c}-0.0935^{\star * *} \\
(0.0133)\end{array}$ & $\begin{array}{c}-0.0878^{\star * *} \\
(0.0121)\end{array}$ \\
\hline Size Quartile 4 & $\begin{array}{c}-0.1569^{\star \star *} \\
(0.0156)\end{array}$ & $\begin{array}{c}-0.1440^{\star \star \star} \\
(0.0155)\end{array}$ & $\begin{array}{c}-0.1380^{\star * *} \\
(0.0158)\end{array}$ & $\begin{array}{c}-0.1268^{\star \star *} \\
(0.0146)\end{array}$ \\
\hline Controls & YES & YES & YES & YES \\
\hline Exit Probability & 45.3 & 62.5 & 67.6 & 75.1 \\
\hline R-squared & 0.2777 & 0.2764 & 0.2165 & 0.2020 \\
\hline Observations & 9,539 & 9,539 & 9,539 & 9,539 \\
\hline
\end{tabular}

Notes: the table explores the determinants of extensive response to the reform. Columns (1) - (4) report the coefficients from OLS regressions of an indicator that a firm reports positive taxable earnings in 2008 but does not in year $t$ on dummy covariates and a rich set of controls comprising (i) tax office fixed effects (fifteen categories) (ii) industry fixed effects (six-digit industry code the firm belongs to) and (iii) age fixed effects (10 categories). All variables are introduced non-parametrically. The details of the dummy covariates are in Appendix A. The sample for the regressions is restricted to partnership firms that report positive taxable income in 2008 and for which information on all the included variables (339 dummies) are available. Exit probability is defined as the ratio of the number of firms that do not file or file but report zero taxable earnings in year $t$ to the number of firms that report positive earnings in 2008 . Standard errors are shown in parentheses. ${ }^{*},{ }^{* *}$, ${ }^{* * *}$ represent statistical significance at the $10 \%, 5 \%$, and $1 \%$ percent levels respectively. 


\section{A Appendix}

\section{A.1 Details of the Firms Characteristics Used in Section 5}

( $i$ ) Large. The dummy variable takes the value 1 for firms with sales above the $75^{\text {th }}$ percentile of the size distribution, ${ }^{39}$ where firm size is defined as the average annual sales in the pre-reform periods.

(ii) Electronic Return Filer. All partnership firms were required to file returns electronically in the years 2008-11. Some of the firms did not comply with this mandatory provision, while a few were filing electronically even before the provision came into effect. I categorize a firm electronic filer if any of the four returns for tax years 2006-09 was filed electronically (about $80 \%$ of the firms).

(iii) Registered for VAT. The variable indicates if the firm was registered with the FBR to remit VAT on its sales (about $30 \%$ of the firms in the balanced panel sample).

(iv) Age. The dummy variable takes the value 1 if age of the firm - measured in the number of years since registering with the FBR - was more than the $75^{\text {th }}$ percentile (6 years).

(v) Tax Withholding. Pakistani tax code stipulates a comprehensive tax withholding scheme. In addition to wages, tax is withheld on a number of other transactions including the payment for goods and services, utility bills, cash withdrawal from banks, and imports from other countries. The withheld tax can be adjusted against the tax liability at the time of filing of returns. The firms that withhold tax are required to file a statement with the FBR indicating the transactions and the tax withheld thereon. The scheme has some elements of third party reporting, though it does not provide information on the total tax base as is the case with tax withholding on wages. The dummy variable takes the value 1 if the withheld tax of a firm weighted by its taxable income was more than the $75^{\text {th }}$ percentile in the pre-reform periods.

(vi) Withholding Agent. The variable is an indicator if the firm acted as a withholding agent, deducting tax on transactions made with its buyers or sellers (about $22 \%$ of the firms).

\footnotetext{
${ }^{39}$ The cutoff choice reflects the strongly skewed firm size distribution. The $75^{\text {th }}$ percentile corresponds to an annual turnover of Rs. 6.6 million (US $\$ 62,857$ ). Compared with this the $50^{\text {th }}$ percentile firm has a turnover of Rs. 1.9 million (US\$17,749) only.
} 
Effects of the Tax Reform on Partnership Firms - Intensive Margin

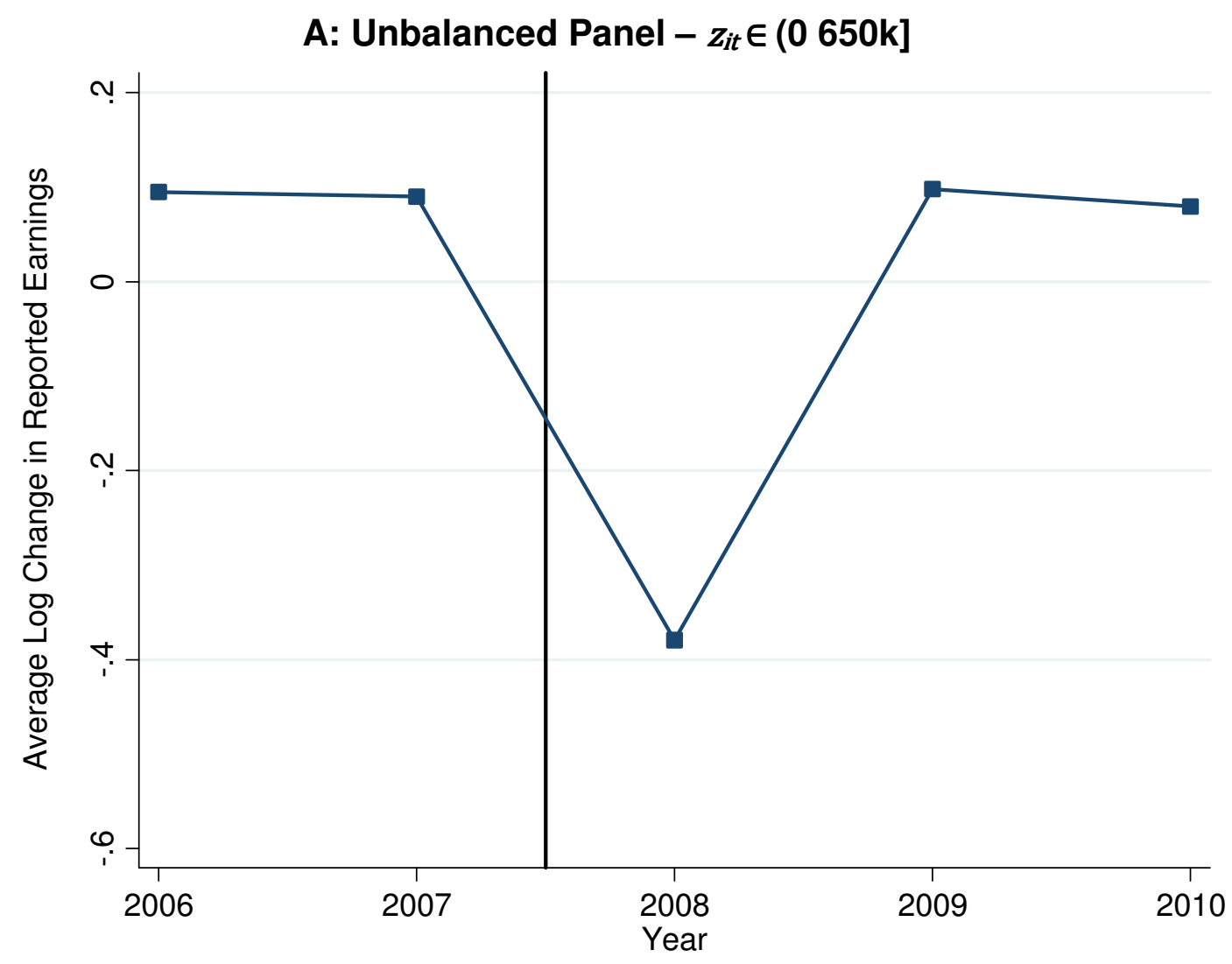

B: Balanced Panel $-z_{i t} \in(0650 \mathrm{k}]$

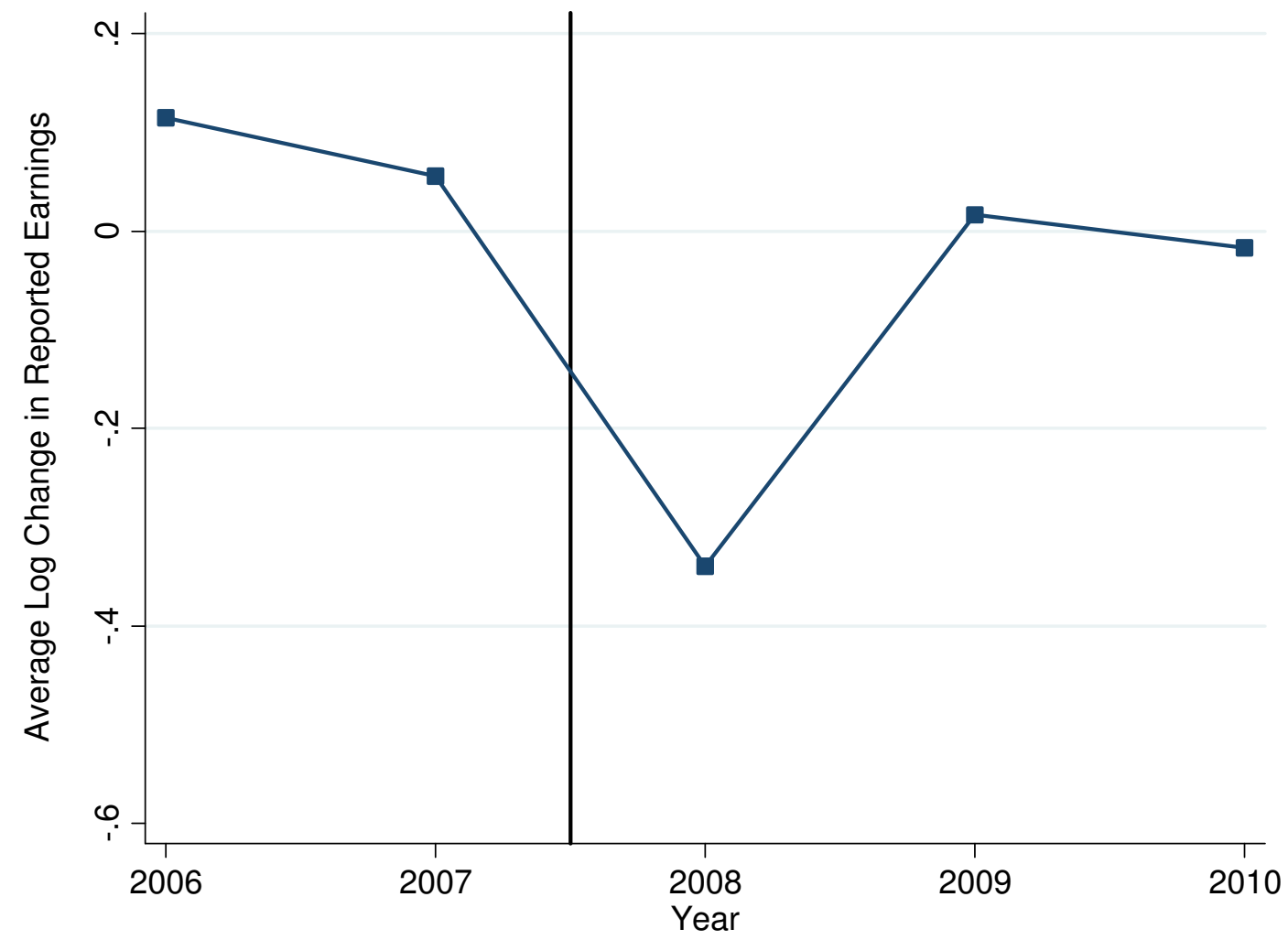

Notes: the figure explores the medium-term intensive margin response of partnership firms to the tax rate rise. Two panels of the figure show the earnings growth path of partnership firms in 2006-2011. Each point in the plots denotes the log change in reported earnings between year $t$ and $t+1$ for firm $i$, averaged across all firms in year $t$. The sample for Panel A includes for year $t$ all the firms that report in years $t$ and $t+1$, while Panel $\mathrm{B}$ includes the firms that report positive taxable income in all the six years (2006-11). The black vertical line in each panel indicates the time from which the tax changes affect the reporting behavior of firms. 